\title{
SCIENTIFIC POSTERS
}

\section{Carotid artery disease}

P1

\author{
MANAGEMENT OF RADIATION-INDUCED CAROTID \\ STENOSIS
}

$E S N R$

A. Afaq $^{1}$, G. Rajeswaran ${ }^{2}$;

${ }^{1}$ The Catherine Lewis Cancer Centre. The Hammersmith Hospitals NHS Trust, Imperial College L, London/GB,

${ }^{2}$ Chelsea \& Westminster Hospital, London/GB

\section{PURPOSE}

To review the imaging findings and management of patients with radiation-induced extracranial carotid artery stenosis (RICS). Symptomatic RICS was first described over three decades ago. It has a similar association with cerebral ischaemia and infarction as atherosclerotic carotid stenosis. Only case reports and small studies have been reported analysing the optimal management of this condition.

\section{MATERIAL AND METHODS}

A Medline search and analysis was carried out on all English language articles on the investigation and management of RICS.

\section{RESULTS}

It is difficult to distinguish between atherosclerotic and RICS on histologic and angiographic criteria. However, on ultrasound, noncalcified plaques and intraplaque hypoechoic foci may be more frequent in post-radiation plaques. Management options include carotid endarterectomy, carotid angioplasty and stenting. Endarterectomy can be difficult in RICS, due to adhesions, fibrosis of the arterial wall and tissue planes and the often extensive distribution of disease. Published reports over the past 10 years have shown with increasingly larger subject numbers that carotid angioplasty and stenting is a safe and feasible method to approach RICS.

\section{CONCLUSION}

In the rapidly evolving area of endovascular management of carotid stenosis, post-radiation stenoses deserve special consideration, in view of the challenge they pose to conventional surgery. The few, small sized studies are difficult to compare directly in view of differences in design and length of follow up but do show low rates of complications and restenosis where angioplasty and stenting is used.
P2

EVALUATION OF CAROTID ARTERY STENOSIS: SPIRAL CT ANGIOGRAPHY AND MAGNETIC-RESONANCE ANGIOGRAPHY IN COMPARISON WITH DIGITAL SUBTRACTION ANGIOGRAPHY.

ESNR

A.M. Turkin, I.V. Evgrafov, T.V. Mel'nikova-Pitskhelauri, V.N. Kornienko; Burdenko Neurosurgery Institute, Moscow/RU

PURPOSE

Duplex scanning is known to be the screening method in detection of carotid artery (CA) stenosis, but it is pure in quantitative stenosis evaluation. Digital subtraction angiography (DSA) is the gold standard both in detection and evaluation of CA stenosis, but it is invasive technique and don't provide the opportunity to study the structure of plaques. Advanced abilities of spiral CT angiography (CTA) and MR angiography (MRA) seems to be prospect in evaluation of stenotic processes of CA and also the structure of atherosclerotic plaques. The aim of this work is the comparative analysis of CTA, MRA and DSA in evaluation of stenotic processes of $\mathrm{CA}$, structure of atherosclerotic plaques. Additionally, conditions of cerebral hemodynamic functioning were evaluated using CT perfusion imaging in cases with severe stenosis $(>70 \%)$.

\section{MATERIAL AND METHODS}

42 patients with symptoms of CA stenosis were selected with duplex scanning as screening method. Stenosis was located in bifurcation area in 36 patients. All patients underwent CTA $(300 \mathrm{mAs}, 120 \mathrm{rV}$, collimation $6 \times 0.5$ ) and MRA (2DTOF, TR/TE=45/5,FA=50). 8 pts with severe stenosis (more, then $70 \%$ ), candidates for endarteriaectomia, were selected for DSA. Percents of stenosis were calculated on axial CT and MR projection with NASCET criteria. Perfusion CT ( $80 \mathrm{kV}, 200 \mathrm{~mA}, 50$ slices per 50 seconds) were completed before and after surgery. Cerebral Blood Volume (CBV), cerebral Blood Flow (CBF) and Mean Transit Time (MTT) were used for evaluation of tissue henodynamics.

RESULTS

In patients with stenosis of $70 \%$ and more CTA in comparison with and DSA showed sensitivity of $96 \%$ and specifty of $87 \%$. Sensitivity and specifity of MRA in patients with hemodynamically significant stenosis was $92 \%$ and $78 \%$, respectfully. In six cases stenosis was overestimated by MRA. CTA was used for evaluation of plaques density. Plaques with density less then $50 \mathrm{HU}$ were interpreted as "soft", with density, ranging between 50-130 HU - as "fibrotic", with the densities more than $130 \mathrm{HU}$ - as "calcified". Results of 
postoperative CT perfusion demonstrated some shortening of MTT and increasing in $\mathrm{CBF}$ in six cases.

\section{CONCLUSION}

High degree of correlation DSA results with both of CTA and MRA data was revealed. CTA was considered to be preferable method of stenosis evaluation. CTA was useful also in evaluation of plaques.structure. Duplex scanning data was gained by CTA, this techniques being used together are sufficient for the selection of the candidates for surgery and treatment planning.

\section{P3}

\section{CAROTID ARTERY STENTING WITH CEREBRAL PROTECTION}

\section{$E S N R$}

E. Akgul ${ }^{1}$, E. Aksungur ${ }^{2}$, N. Alatay $^{3}$, K. Aikimbaev ${ }^{3}$, K. Bicakci ${ }^{4}$, S. Bicakci ${ }^{5}$;

${ }^{1}$ Cukurova University Balcali Hospital, Adana/TR, ${ }^{2}$ Cukurova University, Adana/TR, ${ }^{3}$ CUKUROVA UNI. MEDICAL FACULTY, Adana/TR, ${ }^{4}$ Cukorova University Balcali Hospital, Adana/TR, ${ }^{5}$ Cukurova Univ. Balcali Hospital, Adana/TR

\section{PURPOSE}

Carotid artery disease is a major cause of ischemic stroke. The risk of stroke is directly related with degree of stenosis in patients with carotid artery disease. In this study, we evaluate safety and effectiveness of primary carotid artery stenting (CAS) under cerebral protection.

\section{MATERIAL AND METHODS}

Twenty-six patients admitted to hospital with clinical symptoms and diagnosis of carotid artery stenosis on carotid colour Doppler US, cervical MR angiography, CT angiography and DSA were included in this study. Stents were applied to 30 carotid artery stenosis, 4 of which were bilateral in 26 patients. Seven $(27 \%)$ of the patients were female and $19(73 \%)$ male; mean age was 63 (54-79) years. Cerebral CT and/or MRI were done before and after procedures. Follow-up was performed by Doppler US on 2nd day, at $1 \mathrm{st}$, 3rd, and 6th months and subsequently every six months. Rate of stenoses was over 50\%.

\section{RESULTS}

Procedure was successful in 28 lesions. Primary stent implantation was done after replacing protection filter distally. Carotid artery stenting (CAS) could not be applied in one (3.3\%) lesion because the stenosis couldn't be overcome. In another lesion, stent could not be opened because distal metal marking stayed on the stent while it was tried to be opened. The success of the procedure was 93.3\%. Embolic material in the filter after the procedure was seen in four patients (14.2\%). Procedure was complicated in $6(20.6 \%)$ patients. Early minor neurologic complication developed in one patient $(3.8 \%)$ and late minor neurologic complication developed in another one $(3.8 \%)$. Restenosis developed after 12 months in a patient (3.8\%) who had bilateral stent implantation. There was no fatality in early or late period.

CONCLUSION

CAS is less invasive than surgery and CAS under cerebral protection is a safe and effective method. Use of cerebral protective devices decreases the occurence of possible complications.

\section{P4}

SUCCESSFUL TRANSARTERIAL AND TRANSVENOUS EMBOLIZATION OF PERSISTENT PRIMITIVE TRIGEMINAL ARTERY-CAVERNOUS SINUS FISTULA WITH DETACHABLE COILS: CASE REPORT AND REVIEW OF LITERATURE

ESNR

S. Choi, S. Jeon, S. Yoon, Y. Lee, E. Kim, S. Juhng, B. Roh; Wonkwang University Hospital, Iksan/KR

\section{PURPOSE}

Trigeminal artery is a persistent, vascular anastomotic connection between the cavernous internal carotid artery and the basilar artery. It is associated with vascular steal, aneurysmal formation, vascular rupture, subarachnoid hemorrhage, and arteriovenous fistula. We report a case of a carotid-cavernous fistula through a persistent trigeminal artery with endovascular treatment.

MATERIAL AND METHODS

A 40-year-old woman presented with proptosis, conjunctival chemosis of the left eye, a left sixth cranial nerve palsy, and an audible bruit for 4 weeks. Cerebral angiography demonstrated a left carotid-cavernous sinus fistula associated with persistent primitive trigeminal artery. Endovascular treatment with Guglielmi detachable coil (GDC) via transarterial and transvenous routes was planned, because a suitable detachable balloon could not be obtained.

RESULTS

Postembolization angiography demonstrated nonfilling of the fistula and preservation of the internal carotid artery and persistent trigeminal artery. At 12 months follow-up, the patient had had no recurrence of audible bruit and diplopia.

CONCLUSION

The authors describe endovascular technique for coil embolization of a fistula and review literature concerning persistent primitive trigeminal artery-carotid sinus fistula.

\section{P5}

SPONTANEOUS GIANT ANEURYSM OF EXTRACRANIAL INTERNAL CAROTID ARTERY

ESNR

C.G. Ramos ${ }^{1}$, C. Pereira ${ }^{2}$, J. Xavier ${ }^{2}$, A. Stocker ${ }^{2}$;

${ }^{1}$ Porto/PT, ${ }^{2} \mathrm{HGSA}$, Porto/PT 


\section{PURPOSE}

Aneurysms of the extracranial internal carotid artery (ICA) are rare. They can be caused by a wide variety of conditions, the most common of all being atherosclerosis. Other causes include trauma, fibromuscular dysplasia, infection, auto-immune connective tissue disorder or arterial dissection. Clinically, they can be asymptomatic, present as cervical or oropharyngeal painless masses, cause compression of VII, IX, X or XII cranial nerves or may produce cerebral embolic events. Rupture is rare.

\section{MATERIAL AND METHODS}

A 77 year old patient, came to our hospital with a 3 month evolution dysphagia. She presented a large painless mass in the left lateral oropharyngeal wall. CT showed a large markedly enhancing lesion in the left parapharyngeal space, with peripheric calcification, which couldn't be individualized from the ICA. MR showed flow void within the mass. Based on these findings the possibility of a giant aneurysm of the ICA was advanced. Digital Subtraction Angiography showed a large aneurysm arising from the extracranial left ICA, with no opacification of the distal ICA suggestive of occlusion. The left ICA territory was adequately supplied by the contralateral ICA (through the anterior communicating artery), by the vertebro-basilar circulation and by external carotid artery collaterals. Occlusion of the left ICA with balloon was performed, without complications.

\section{RESULTS}

One month later, the patient was well, without neurological deficits or dysphagia.

\section{CONCLUSION}

In the study of a cervical or lateral oropharyngeal mass, imaging studies are crucial before obtaining a biopsy of the lesion, because giant aneurysm of the ICA is a possible diagnosis. Identification and treatment of this aneurysm is very important to prevent neurological complications.

\section{P6}

\section{SCIENTIFIC EXHIBIT: CT ANGIOGRAPHY AS A PLANNING TOOL FOR CAROTID ARTERY STENTING}

\section{ESNR}

S. Klein ${ }^{1}$, R. Huber ${ }^{1}$, A.J. Aschoff ${ }^{2}$, B.L. Schmitz ${ }^{1}$;

${ }^{1}$ University Hospitals Ulm, Ulm/DE, ${ }^{2}$ University Hospital Ulm, $\mathrm{Ulm} / \mathrm{DE}$

\section{PURPOSE}

There is an ongoing change of general strategies in neuroradiological interventions in that CT-angiography is increasingly used for preinterventional procedure planning. The purpose of this scientific exhibit is to present detailed informations on how to do CTA for planning of carotid artery stenting.

\section{MATERIAL AND METHODS}

CTA has been performed in 58 patients within a week prior and after carotid artery stenting for procedure planning and control of the interventional result. Scanning range covered the aortic arch, whole carotid artery as well as the intracranial circulation for planning of optimal projection angles for the intervention, primary catheter choice, measurements of stenosis degree and sizes of stent and protection system as well as assessment of additional intracranial stenosis and collateral circulation.On a 40 detector row CT (Philips Brilliance 40) CTA was acquired with an isotropic voxel size of $0.3 \mathrm{~mm}^{3}$, dose modulation, edge enhancing reconstruction algorithm and bolus tracking following injection of a highly concentrated contrast agent (Imeron 400).

RESULTS

CTA measurements were followed in $97 \%$ of procedures regarding stent sizing and and $100 \%$ of cases regarding size of the protection systen. In 2 cases stent sizes had to be changed because of substantial changes in anatomy due to vessel straightening by the wire of the emboli protection system.CTA measurements prooved to be highly accurate during the procedure as well as in the postinterventional CTA controls. Prior knowledge of detailed aortic arch anatomy, configuration of the carotid bifurcation, optimal projection angles for the intervention and intracranial collaterals was rated exceedingly valuable by the interventionalists.CTA measurements of carotid stenosis degree were in excellent agreement with angiographic results, with effective diameter having the best correlation to DSA measurements following NASCET criteria.

CONCLUSION

High resolution CTA as a quick and non-invasive modality is an extraordinary valuable planning tool for carotid artery stenting regarding all steps of the intervention.

\section{Cerebral aneurysms}

P7

SUCCESSFUL TREATMENT OF AN INTRACRANIAL ANEURYSM COMPLICATED BY NEUROGENIC PULMONARY EDEMA FOLLOWING SUBARACHNOID HEMORRHAGE

ESNR

Y. KÝROGLU ${ }^{1}$, I. Oran ${ }^{2}$, B. Cirak ${ }^{1}$, N. Karabulut ${ }^{3}$;

${ }^{1}$ Pamukkale University, Medical school, Denizli/TR, ${ }^{2}$ Ege University Hospital, Izmir/TR, ${ }^{3}$ Pamukkale University Hospital, DENIZLI/TR

\section{PURPOSE}

Medical complications after SAH include fever, anemia requiring transfusion, hyperglycemia, electrolyte abnormalities, pneumonia, hypertension, and neurogenic stunned myocardium and pulmonary 
edema. These complications have the greatest impact on mortality and functional outcome. Neurogenic pulmonary edema is an underdiagnosed clinical entity. Its pathophysiology is multifactorial but largely unknown. We present an acute pulmonary edema caused by an acute subarachnoid hemorrhage (SAH) and its successful treatment.

\section{MATERIAL AND METHODS}

38 years-old-male patient admitted with the complaint of sudden loss of conciousness during blowing a ball. Diagnostic radiologic evaluation included chest X-ray, CT, and cerebral angiography which ensued therapeutic intervention.

\section{RESULTS}

The patient underwent a cranial computerized tomography (CT) which disclosed diffuse SAH.On admission, it was also noted that the patient had respiratory dysfunction. Chest x-ray revealed bilateral pulmonary edema. Due to impaired blood oxigenisation, a percutaneous tracheostomy cannule was inserted. CT angiography demonstrated a saccular aneurysm on the supraclinoid portion of the internal carotid artery. His metabolic condition stabilised after 5 days and Hunt-Hess clinical grade improved to 3 . Aneurysm was treated by detachable coils one week after SAH. Posttreatment period was uneventful. His condition improved in the next 2 weeks. At one month, his neurologic examination revealed nearly normal findings.

CONCLUSION

Pulmonary edema is an important complication of SAH which increases morbidity and mortality. Meticulous control of hemodynamic parameters and monitorisation of the pulmonary functions are essential. Early tracheostomy helps improving pulmonary functions as well as helping suctioning of the pulmonary secretion to prevent pulmonary stasis. Embolisation of aneurysm appears to be more suitable than craniotomy in such patients with SAH complicated with neurogenic pulmonary edema.

\section{P8}

\section{SUDDEN DEATH BY RAPID FORMATION AND RUPTURE OF AN INFECTIOUS INTRACRANIAL ANEURYSM}

\section{ESNR}

M. Garcia Alzamora ${ }^{1}$, M. Schubert ${ }^{1}$, J. Spreer ${ }^{2}$, J. Kromeier ${ }^{3}$; ${ }^{1}$ Albert-Ludwigs-University Hospital Freiburg, Freiburg/DE, ${ }^{2}$ Albert-Ludwigs-University Freiburg, Freiburg/DE, ${ }^{3}$ Albert.-Ludwigs-University Hospital Freiburg, Freiburg/DE

\section{PURPOSE}

Infectious aneurysms are rare lesions associated with a high mortality rate. Appropriate clinical management of these lesions can be very difficult. Here we describe a case of sudden formation and rupture of an infectious intracranial aneurysm caused by Streptococcus pneumoniae and discuss the diagnostic and therapeutic difficulties that accompany these potentially fatal lesions.

\section{MATERIAL AND METHODS}

A 47-year-old female presented with lower back pain and urine retention. Laboratory analysis militated in favour of an inflammatory constellation. Magnetic resonance imaging of the lumbar spine excluded an abscess and/or a spinal inflammatory process. As the patient became slightly drowsy a cranial computer tomography (CCT) was performed that was unremarkable. An abdominal CT performed the following day showed an acute retroperitoneal haematoma. Conventional angiography revealed a $2.0 \mathrm{~cm}$ aneurysm of the superior mesenteric artery, which was successfully coiled. Two days later, the patient developed meningeal signs. Streptococcus pneumoniae was isolated from the spinal fluid and blood. Antibiotics were commenced.

RESULTS

24 hours later the patient became more and more drowsy. An emergency CCT showed dilated ventricles and a malresorptive hydrocephalus. Despite the placement of an external ventricular drainage, the patientât ${ }^{\mathrm{TM}_{\mathrm{S}}}$ clinical condition continued to deteriorate. A follow-up CCT 4 hours later demonstrated a $1.5 \times 0.8 \mathrm{~cm}$ hyperdense prepontine mass suspicious of a basilar artery (BA) aneurysm that was not apparent on the previous CCT. Immediately afterwards the patient fell into a deep coma and emergency intubation was required. A repeat CCT scan 1 hour later disclosed an extensive subarachnoidal haemorrhage with blood in the basal cisterns and the ventricles. The patient died shortly before the intended endovascular therapy.

CONCLUSION

Our case shows that lower back pain can be the first symptom of an abdominal infectious aneurysm. To our knowledge, this is the first report about the successive formation of both an abdominal and a cerebral infectious aneurysm. In our patient development of the infectious intracranial aneurysm occurred within five hours. Our case demonstrates the potentially hyperacute and devastating course of formation and rupture of a BA aneurysm even under antibiotic therapy and emphasizes the importance of close clinical and radiological follow-up in patients with infectious aneurysms.

\section{P9}

RUPTURED DISTAL LENTICULOSTRIATE ARTERY ANEURYSM ASSOCIATED WITH IPSILATERAL MIDDLE CEREBRAL ARTERY OCCLUSION

\section{ESNR}

I.B. $\mathrm{HAN}^{1}$, J.Y. $\mathrm{Ahn}^{2}$;

${ }^{1}$ Bundang CHA hospital, Pochon CHA university, Sungnam/KR,

${ }^{2}$ Yonsei university, Seoul/KR

\section{PURPOSE}

Ruptured lenticulostriate artery (LSA) anruysms are relatively rare and charaterized by deep location, uncertain natural history, and uncertain etiology. A case of basal ganglia and intraven- 
tricular hemorrhage due to a ruptured LSA aneurysm associated with ipsilateral middle cerebral artery (MCA) occlusion is presented.

\section{MATERIAL AND METHODS}

A 49-year-old man presented with sudden onset of severe headahe. The patient had no history of hypertension, infectious disease, heart disease, and head njury. The patient was alert and had no neurological deficit.

\section{RESULTS}

Brain computed tomography (CT) revealed right basal ganglia hemorrhage with extension to whole ventricle. Cerebral angiography disclosed an occlusion of M1 segment of right MCA and ipsilateral moyamoya-type vessels. The circulation to the distal middle cerebral artery territory on the right was collateralized from leptomeningeal vessels from the right anterior and posterior cerebral arteries. A small aneurysm was detected arising from the distal portion of lenticulostriate branch of the right MCA. There was no angiographic evidence of arteriosclerosis. Conservative treatment was initially selected because this aneurysm was considered to be pseudoaneurysm and deeply located in the basal ganglia. On the 14th day of admission, the patient suddenly became drowsy with profound left hemiparesis. Emergent CT showed recurrent hemorrhage due to rerupture of the aneurysm. The patient underwent urgent operation via right frontotemporal craniotomy. Severe stenotic proximal MCA and small aneurysm arising from the distal LSA were identified. Excision of the aneurysm was successfully achieved and microscopic examination of the aneurysm wall demonstrated true aneurysm.

\section{CONCLUSION}

Spontaneous basal ganglia hemorrhage is commonly associated with preexisting hypertension in the elderly. However, vascular lesions are frequently identified in young patients without a history of hypertension. They should be fully evaluated with magnetic resonance image and cerebral angiography. Furthermore, we should pay attention to detect aneurysms in patients with hemorrhage associated with moyamoya phenomenon like our case. While conservative treatment and careful follow-up angiography seem appropriate for lesions consistence with pseudoaneurysm, surgical intervention is recommended for prevention of rebleeding in selected cases.

\section{P11}

THE VALUE OF CT ANGIOGRAPHY IN ACUTE SPONTANEOUS INTRACRANIAL HAEMORRHAGE

\section{$E S N R$}

Z. Merhemic, K. Dizdarevic, Z. Kadenic, M. Niksic, E. Avdagic, I. Omerhodzic, H. El-Qoud, E. Hajdarpasic; Clinical Centre University Sarajevo, Sarajevo/BA

\section{PURPOSE}

The aim of this study is to compare the findings of CT angiography and intraoperative neurosurgical records in patient with acute spontaneous intracranial haemorrage.

\section{MATERIAL AND METHODS}

In time span of 6 months, 36 patients underwent CT angiography on 4-slice spiral CT system. Twenty three of these patients were operated on by single neurosurgeon (KD). Twenty one female and fifteen male patients, aged 26 to 72 years, mean age 51,7, with acute spontaneous intracranial haemorrhage were enrolled in this study.

\section{RESULTS}

Twenty-seven aneurysms in 20 patients and two brain AVM in 2 patients were detected by CT angiography. Intraoperatively, thirty two aneurysms in twenty one patients and two brain AVM in 2 patients were found. The CTA and surgical findings did not correlate in four patients, giving sensitivity of $85 \%$.

CONCLUSION

$\mathrm{CT}$ angiography as non-invasive and rapid diagnostic method is of great value in demonstrating vascular anatomy and the correct size of aneurysms, as well as in presenting the nidus, arterial supply and venous outflow of AVM. IA DSA is still needed for diagnosis of aneurysms smaller then $5 \mathrm{~mm}$, especially those located near bone structures. Also, DSA has some advantages in planning the surgical treatment of brain AVM.

\section{P12}

ENDOVASCULAR TREATMENT OF INTRACRANIAL ANEURYSMS: RELATION BETWEEN ANEURYSM LOCATION AND RECANALIZATION

\section{ESNR}

R. Díaz Aguilera ${ }^{1}$, F. Bravo Rodriguez ${ }^{2}$, M. Ramos Gómez ${ }^{2}$, A. Cano Sanchez 2 , F. Delgado Acosta ${ }^{2}$, M. Martinez Paredes ${ }^{1}$; ${ }^{1}$ Hospital Reina Sofia, Cordoba/ES, ${ }^{2}$ HOSPITAL UNIVERSITARIO REINA SOFIA, Cordoba/ES

\section{PURPOSE}

Coiling of intracranial aneurysms, ruptured and unruptured, has proved to be a safe and effective treatment. Nevertheless, followup of these patients is mandatory as recanalization or regrowth of the aneurysm may occur. Digital subtraction angiography (DSA) has been considered as the reference standard for the follow-up. However, Magnetic Resonance Angiography (MRA), a noninvasive and reliable technique, is currently replacing DSA. The aim of our study was to assess the hypothetical correlation between aneurysm location and recurrence depicted on MRA follow-up. MATERIAL AND METHODS

A total of 91 patients harboring 98 aneurysms were treated with coil placement between June 2001 and March 2006 at our institution. According to location, we divided aneurysms into four 
groups: 1) anterior communicating artery, 2) middle cerebral arteries, 3) posterior communicating arteries and 4) "other locations". We performed 140 MRA as follow-up method for these coiled aneurysms (some of them were examined twice). MRA were reviewed by an experienced neuroradiologist and findings were classified into one of two groups: "complete occlusion" and "recanalization". The correlation between location and recurrence was analyzed using Chi-square test.

RESULTS

According to location, there were 29 (29.6\%) anterior communicating artery aneurysms, $17(17.3 \%)$ middle cerebral arteries aneurysms, $23(23.5 \%)$ posterior communicating arteries aneurysms and 29 (29.6\%) "other locations" aneurysms. The median follow-up period was 11.8 months (range $2-60$ months). None of the patients suffered late rebleeding. Ten out of 140 MRA performed provided no reliable information, 62 were considered as "complete occlusion" and 68 were classified as "recanalization" of the aneurysm. We found correlation between middle cerebral arteries location and recurrence depicted on MRA (Chi-square: 17.369; $\mathrm{p}=0.008)$.

\section{CONCLUSION}

In our series, we found correlation between coiled intracranial aneurysms located at middle cerebral arteries and recurrences depicted on MRA (Chi-square: 17.369; p=0.008). Therefore, aneurysms of this location must be specially reviewed before deciding the most appropriate treatment option, surgery or endovascular therapy.

\section{P13}

MR ANGIOGRAPHY FOLLOW-UP OF COILED INTRACRANIAL ANEURYSMS: AGREEMENT BETWEEN OBSERVERS

\section{ESNR}

R. Díaz Aguilera ${ }^{1}$, F. Bravo Rodriguez ${ }^{2}$, M. Ramos Gómez ${ }^{2}$, A. Cano Sanchez 2 , J.M.M. Martos Becerra ${ }^{2}$, M. Martines Paredes ${ }^{3}$; ${ }^{1}$ Hospital Reina Sofia, Cordoba/ES, ${ }^{2}$ HOSPITAL UNIVERSITARIO REINA SOFIA, Cordoba/ES, ${ }^{3}$ Hospital Reina Sofía, Córdoba/ES

\section{PURPOSE}

MR Angiography (MRA) has emerged as a noninvasive, feasible and useful technique in the follow-up of patients with coiled intracranial aneurysms. Indeed, MRA has demontrated a good correlation with Digital Subtraction Angiography (DSA) in several studies. The aim of our study was to evaluate the level of interobserver agreement for 3D time-of-flight MR Angiography (3D TOF MRA) and contrast-enhanced MRA (CE-MRA) in the follow-up of intracranial aneurysms treated with coil placement.

\section{MATERIAL AND METHODS}

140 MRA, seventy 3D TOF MRA and 70 CE-MRA, were performed in 39 patients at 6,12 and 24 months after endovascular therapy of intracranial aneurysms. MR Angiographs were analyzed independently by two experienced neuroradiologist. The findings were classified into one of two categories: "complete occlusion" and "residual/recurrent aneurysm". The level of interobserver agreement for each study, 3D TOF MRA and CE MRA, and for MRA globally were evaluated by the means of the $\mathrm{k}$ statistic. Agreement was rated as follows: $\mathrm{k}<0.2$ poor; $\mathrm{k}=0.21-0.40$ fair; $\mathrm{k}=0.41-0.60$ moderate; $\mathrm{k}=0.61-0.80$ good; $\mathrm{k}>0.81$ excellent.

\section{RESULTS}

Three 3D TOF MRA and six CE-MRA provided no reliable information. Agreement between observers was judged as moderate for 3D TOF MRA $(\mathrm{k}=0.579 ; 95 \% \mathrm{CI}: 0.406-0.752)$ and good for CE-MRA ( $\mathrm{k}=0.657$; 95\% CI:0.492-0.822). Considering MRA globally, interobserver agreement was good $(\mathrm{K}=0.620 ; 95 \% \mathrm{CI}$ : $0.500-0.739)$.

\section{CONCLUSION}

Interobserver agreement for MRA performed in the follow-up of coiled intracranial aneurysms was good $(k=0.62)$. Considering 3D TOF MRA and CE MRA separately, interobserver agreement was superior for Contrast-enhanced studies $(k=0.65$ versus $k=0.57)$; therefore, the use of contrast material improves the agreement between observers.

\section{P14}

ENDOVASCULAR RECONSTRUCTIVE TREATMENT OF INTRACRANIAL VERTEBRAL ARTERY DISSECTING ANEURYSMS WITH STENTING OR STENT-ASSISTED COILING

ESNR

B. Lee ${ }^{1}$, I.K. YU ${ }^{2}$, H.J. Kim ${ }^{3}$;

${ }^{1}$ Eulji University Hospital, Daejeon/KR, ${ }^{2}$ Eulji university hospital, Daejeon/KR, ${ }^{3}$ Eulji University, Daejeon/KR

\section{PURPOSE}

To report the efficacy and limitations of stenting or stent-assisted coiling for intracranial vertebral artery dissecting aneurysms.

\section{MATERIAL AND METHODS}

Ten patients(5males,mean age:48.7 years ranging from 37 to 55 ) with intracranial vertebral artery dissecting aneurysm were treated with stent placement $(9$ patients $)$ or stent-assisted coiling( 1 patient $)$. Double stents placement was performed in seven of nine patients with stent placement alone At presentation,four patients had SAH, one patient had ischemic event,and five patients had headache. Angiographic follow-up(ranging from 1 week to 27 months) was available in eight patients. 


\section{RESULTS}

Two patients which were treated with single stent placement did not show complete occlusion of aneurysm on posttreatment or follow-up angiogram. Double stents placement was performed in seven patients. Immediate angiogram demonstrated complete occlusion(1 patient), near complete(1 patient), and incomplete(5 patients). Follow-up angiogram was obtained in 6 of 7 patients which showed complete occlusion(1 patient) and incomplete(5 patients: all stable). One patient which was treated with stentassisted coiling showed near complete occlusion on immediate angiogram and complete occlusion on 1 week follow-up angiogram. There were no periprocedural complications, rebleeding, and regrowth of the aneurysm.

\section{CONCLUSION}

Endovascular reconstructive treatment may be an alternative to preserve the patency of the parent vessel in treating intracranial dissecting aneurysm.However,the efficiency of single or double stent placement for intracranial vertebral artery dissecting aneurysm was limited.Further study should be necessary.

\section{P15}

THE POSSIBILITIES OF CT ANGIOGRAPHY IN THE DETECTION OF SMALL INTRACRANIAL ANEURYSMS

$E S N R$

V.N. Vuckovic-Vasiljevic ${ }^{1}$, B.D. Milakovic ${ }^{1}$, S. Milosevic Medenica ${ }^{2}$ ${ }^{1}$ Clinical Center of Serbia, BELGRADE/YU, ${ }^{2}$ Institute of Radiology, Belgrade/YU

\section{PURPOSE}

Saccular aneurysms represent $98 \%$ of all intracranial aneurysms (Suzuki 1979). According to their size, aneurysms are divided in three, five or six groups. The classification of Jasargil contains five groups as follows: 1 . baby aneurysms $<2 \mathrm{~mm}, 2$. small $2-6 \mathrm{~mm}$, 3. medium $6-15 \mathrm{~mm}, 4$. large $15-25 \mathrm{~mm}$, 5. giant $>25 \mathrm{~mm}$. The diagnosis of small aneurysms is more difficult by CT angiography, as well as by DSA.

MATERIAL AND METHODS

In the period from February 2004 to February 2006 we had 20 patients with small aneurysms (up to $6 \mathrm{~mm}$ ) diagnosed by CT angiography. There were 10 men and 10 women ranging in age from 45 to 76 years. All patients had clinical signs of subarachnoidall hemorrhage that was proved by CT. CT angiography was done on the CT scanner Somatom +4 according to following protocol: $-1 \mathrm{~mm}$ slice thickness, - $\mathrm{i} \mathrm{v}$ application of non-ionic contrast medium with $20 \mathrm{sec}$ of delay and speed of $2,5 \mathrm{ml} / \mathrm{sec}$. DSA was realised on the Angiotron equipement (Siemens) by standard 4 vessels catheterisation study.

\section{RESULTS}

In 20 patients evaluated by CT angiography we have found 22 aneurysms as follows: 13 on the anterior communicating artery, 6 on middle cerebral artery, 2 on posterior communicating artery and 1 on the pericallosal artery. Two patients had two aneurysms. Nine patients were operated acoording to $\mathrm{CT}$ angiography findings. Operative finding confirmed $\mathrm{CT}$ angiography diagnosis. In 8 patients DSA was done. In 6 of them CT angiography diagnosis was confirmed, while in 2 there was a discrepance in diagnosis. Five patients on CT angiography had aneurysms of diameter less than $2 \mathrm{~mm}$. Three of them were operated and the diagnosis was confirmed. Two of them were dismissed without surgery because of very small size of the aneurysm.

CONCLUSION

On the basis of our results we can conclude that the CT angiography is a valid method in diagnosis of small intracranial aneurysms, especially because Jasargil citates in his studies that such small - baby aneurysms can be seen only during the surgery.

\section{Cerebrovascular diseases}

\section{P16}

STRAIGHT SINUS DURAL AVF AND OCCLUSION OF GALENIC VEIN MIMICING THE TUMOR OF THE BILATERAL THALAMI

ESNR

I. Anno ${ }^{1}$, T. Isobe ${ }^{2}$, M. Hiratsuka ${ }^{3}$, A. Kunimatsu ${ }^{3}$, M. Minami ${ }^{1}$; ${ }^{1}$ Graduate School of Comprehensive Human Sciences, Tsukuba/ JP, ${ }^{2}$ Kitasato University, Sagamihara/JP, ${ }^{3}$ University of Tsukuba, Tsukuba/JP

\section{PURPOSE}

The vein of Galen occlusion sometimes reveals swelling of the bilateral thalami and which mimicks a tumor of the thalamus. The purpose of this presentation is a case report of an unusual dural arteriovenous fistula of the straight sinus and Galenic vein which cuases thlamic mass.

\section{MATERIAL AND METHODS}

Sixty nine years old male was admitted to the hospital due to consciousness disturbance and mental retardation for a month. The patient was referred to MRI examination from neurosurgery. MRI revealed swelling of bilateral thalami and there existed the marginal enhancement surrounding the mass. The neurosurgeon scheduled the biopsy of the mass in order to plan the radiation therapy. The MRI examination showed the mixed high and low intensity mass on the T2 weighted images in the bilateral thalami and also showed the marked dilatation of the subependymal vein around the lateral ventricles. DSA was also performed to rule out deep vein occlusion. There found the occlusion of the vein of Galen and straight sinus with abnormal tortuous feeding artery into the vein of Galen. 


\section{RESULTS}

DSA revealed the occlusion of not only the Galenic vein but also straight sinus with abnormal tortuous feeding artery into the vein of Galen. Then super selective cerebral angiography was performed. There found the dural arteriovenous fistula from superior cerebellar artery into the obstructed straight sinus and small pouch of the residual Ganenic vein was visualized.

CONCLUSION

Deep vein occlusion such as Galenic vein occlusion sometimes causes bilateral thalamic masses and misinterpreted as a thalamic glioma. We report an unusual dural arteriovenous fistulas and occlusion of straight sinus and which caused the enhanced mass of bilateral thalami. The etiology of the dural arteriovenous fistula is still unclear, however venous congestion and straight sinus occlusion may causes bilateral thalamic enhanced mass and mimics thalamic glioma.

\section{P17}

RETROGRADE FLOW IN THE DURAL SINUSES DETECTED BY THREE-DIMENSIONAL TIME-OF-FLIGHT MR ANGIOGRAPHY

ESNR

A. Uchino, K. Nomiyama, Y. Takase, T. Nakazono,

Y. Tominaga, S. Kudo;

Saga Medical School, Saga/JP

\section{PURPOSE}

Retrograde flow in the left dural sinuses is sometimes detected by three-dimensional time-of-flight (3D-TOF) magnetic resonance (MR) angiography. The purpose of this study was to evaluate the incidence of this phenomenon and its characteristic features on 3D-TOF MR angiograms.

\section{MATERIAL AND METHODS}

We reviewed cranial MR angiography images of 891 patients examined at our institution. All images were obtained by the 3DTOF technique with one of two 1.5-T scanners. Maximumintensity-projection (MIP) images in the horizontal rotation view were displayed stereoscopically. We reviewed source images, inferosuperior MIP images, and horizontal MIP images and identified retrograde flow in the dural sinuses.

\section{RESULTS}

We found retrograde flow in the dural sinuses of 56 patients on source images from 3D-TOF MR angiography; the incidence was $6.3 \%$. In 41 of the 56 patients, retrograde flow was identified in the left inferior petrosal sinus. In 12, it was seen in the left sigmoid sinus, and in 2, it was seen in the left inferior petrosal and left sigmoid sinuses. The remaining patient had retrograde flow in the left inferior petrosal and left and right sigmoid sinuses. The retrograde flow was faint on MIP images.

\section{CONCLUSION}

Retrograde flow in the dural sinuses is frequently detected on the left side during 3D-TOF MR angiography performed with the patient in the supine position.

\section{P18}

ISOLATED POSTERIOR CEREBRAL ARTERY DISSECTION

ESNR

I.B. HAN ${ }^{1}$, J.Y. Ahn ${ }^{2}$;

${ }^{1}$ Bundang CHA hospital, Pochon CHA university, Sungnam/KR, ${ }^{2}$ Yonsei university, Seoul/KR

\section{PURPOSE}

Intracranial dissections are rare, but generally considered to be an important cause of stroke in young patients and most often involve the vertebrobasilar system. Dissections that involve the only posterior cerebral artery (PCA) are extremely rare and and the natural history is not well-known. Isolated PCA dissection presenting with subarachnoid hemorrhage (SAH), misdiagnosed as giant saccular aneurysm at first, is presented.

MATERIAL AND METHODS

A 27-year-old man presented with decreased level of consciousness following sudden onset of severe headache. The patient was stuporous. His medical history was not significant for hypertension, infectious disease, heart disease, head injury, or intravenous drug use.

RESULTS

Brain computed tomography (CT) revealed diffuse SAH with focal clot in the left ambient cistern. Cerebral angiography disclosed a giant aneurysm with wide neck at P1-P2 junction. There was no evidence of arterial dissection including focal stenosis or dilatation. Endovascular placement of Guglielmi detachable coils (GDC) was performed and the aneurysm was occluded with 14 GDCs. The final angiography demonstrated some remnant of aneurysmal neck portion, but the procedure was terminated due to the high risk of parent lumen obstruction. Subsequently, the patient underwent external ventricular drainage of cerebrospinal fluid via Kocher's point. The patient was slightly confused but was able to follow commands after the procedure. However, the patient was suddenly semicomatous on postoperative 8 days. His left sided pupil was fully dilated and non-reactive. Emergent CT scan showed massive SAH with intraventricular hemorrhage on the whole ventricle. Repeat cerebral angiography revealed dilated P1 segment with aneurysmal change of P2 segment. Parent artery occlusion was planned, but the patient was died on the day due to brain herniation.

CONCLUSION

Isolated dissection of the PCA is extremely rare. Isolated PCA dissection presenting with ischemic symptoms have been de- 
scribed to have more benign clinical course and prognosis, and conservative treatment or anticoagulation may help. In a dissection presenting with $\mathrm{SAH}$, however, active treatment should be mandatory and proximal occlusion with surgical or endovascular treatment should be considered.

P19

TRANSVENOUS COIL EMBOLIZATION OF TRAUMATIC CAROTID-CAVERNOUS FISTULA ASSOCIATED WITH A PERSISTENT PRIMITIVE TRIGEMINAL ARTERY

\section{$E S N R$}

I.B. $\mathrm{HAN}^{1}$, J.Y. $\mathrm{Ahn}^{2}$;

${ }^{1}$ Bundang CHA hospital, Pochon CHA university, Sungnam/KR,

${ }^{2}$ Yonsei university, Seoul/KR

\section{PURPOSE}

Treatment options of trigeminal-cavernous fistula have evolved from direct surgery to endovascular treatment. A case of tranvenous coil embolization of traumatic carotid-cavernous sinus fistula (CCF) associated with a primitive trigeminal artery (PTA) is presented.

\section{MATERIAL AND METHODS}

A 45-year-old man presented with left pulsatile tinnitus soon after blunt head trauma. On clinical examination he was noted to have congestion in the left eye with neurological examination without any deficits.

\section{RESULTS}

Left carotid angiography demonstrated a left CCF, with major venous drainage through the ipsilateral superior opthalmic vein and the ipsilateral inferior petrosal sinus. Right vertebral angiography revealed a persistent PTA connecting to fistula. The patient exhibited Saltzman type 2 anatomy. Using the right transfemoral venous approach, a two-tip microcatheter was directed through the left inferior petrosal sinus, into the left cavernous sinus, and finally into the left superior opthalmic vein. Two complex-shaped platinum coils were detached initially in the posterior part of the affected cavernous sinus. Subsequently, six more platinum microcoils were positioned at the distal portion of the left inferior petrosal sinus. Final control angiography showed complete obliteration of the fistula and preservation of the left internal carotid artery and PTA. The patient's symptoms resolved immediately after this procedure.

\section{CONCLUSION}

Although the first-line treatment option for trigeminal-cavernous fistula have been described to be transarterial balloon embolization, transvenous coil emboilzation can be an effective treatment with minimal morbidity. This is especially important when transarterial embolization is not successful or unavailable.

\section{P20}

ENDOVASCULAR TREATMENT OF INTRACRANIAL VERTEBRAL ARTERY DISSECTIONS WITH STENT PLACEMENT OR STENT-ASSISTED COILING

ESNR

I.B. HAN $^{1}$, J.Y. Ahn ${ }^{2}$, J.Y. Joo ${ }^{3}$, C.K. Hong ${ }^{4}$;

${ }^{1}$ Bundang CHA hospital, Pochon CHA university, Sungnam/KR,

${ }^{2}$ Yonsei university, Seoul/KR, ${ }^{3}$ Severance Hospital, Seoul/KR, ${ }^{4}$ severance hospital, Seoul/KR

\section{PURPOSE}

Endovascular treatment with stent placement or stent-assisted coiling is recently introduced as an alternative to parent artery occlusion in intracranial vertebral artery dissections. We describe the efficacy and limitations of this method.

MATERIAL AND METHODS

Fourteen patients with intracranial vertebral artery dissection were treated with stent placement (10 patients) or stent-assiated coiling (4 patients). Double overlapping stents were deployed in 4 among 10 patients with stent placement alone. Angiographic follow-up at 6 to 12 months was available in 13 patients.

RESULTS

In 13 patients with dissecting aneurysm, immediate angiographic outcomes were complete occlusion (1 patient), near complete ( 2 patients), and incomplete (10 patients). Follow-up angiograms of 12 of these patients showed complete occlusion (6 patients) and incomplete (6 patients; 1 unstable and 5 stable). Complete occlusion rates in follow-up angiograms were superior in double stents placement $(75 \%)$ or stent-assisted GDCs emoblization than in stent placement alone $(0 \%)$. There were no instances of postprocedural ischemic attacks, new neurologic deficits, and no new minor or major strokes prior to patient discharge. On the modified Rankin scale applied in follow-up, all patients were assessed as functionally improved or of stable clinical status.

CONCLUSION

Intracranial vertebral artery dissections were acceptably treated with stent placement or stent-assisted coiling, and the patency could be preserved at follow-up. However, the efficiency of stent placement alone for intracranial vertebral artery dissecting aneurysm was limited. Stent-assisted coils embolization or double stents placements are a viable alternative for complete occlusion of dissecting aneurysms. 


\section{P21}

\section{A RARE CAUSE OF INTRAVENTRICULAR HAEMOR- RHAGE: DURAL AV FISTULA OF THE TRANSVERSE SINUS}

ESNR

R. Padmanabhan ${ }^{1}$, R. Stacey ${ }^{1}$, S. Wilamaratna ${ }^{1}$, W. Kuker ${ }^{2}$;

${ }^{1}$ Radcliffe Infirmary, Oxford/GB, ${ }^{2}$ The Radcliffe Infirmary, Oxford/GB

\section{PURPOSE}

To present a rare but clinically important cause of spontaneous intracranial haemorrhage and begnine intracranial hypertension.

\section{MATERIAL AND METHODS}

We describe the case of a 52 year old woman with a past history of begnine intracranial hypertension, who presented with sudden onset severe headache. The CT scan on admission showed primary intraventricular haemorrhage with no associated haemorrhage in the brain parenchyma or the extra-axial compartment. No sign of increased intracranial pressure or cerebral oedema was present. The cerebral angiogram demonstrated a dural arteriovenous fistula involving the left sigmoid and transverse sinuses with massive reflux into cortical veins. The straight sinus and the internal cerebral veins were also affected. Endovascular treatment was performed by transvenous occlusion of the transverse and partially the sigmoid sinus using detachable and pusher coils.

\section{RESULTS}

This resulted in an occlulsion of the fistula and normalisation of the flow pattern of the cortical and deep cerebral vein. There was also a significant decrease of the intracrainal pressure.

\section{CONCLUSION}

In addition of being a recognised cause of chronically increased intracranial pressure (benigne intracranial hypertension), increased venous pressue due to an av fistual may also cause spontaneous intraventricular haemorrhage, probably due to a congestion of the thalamostriate vein. Endovascular treatment may reverse the cause of both conditions.

P22

MODULATION OF BOLD- AND ARTERIAL SPIN LABELLING (ASL-CBF) RESPONSE AFTER MINOR POSTERIOR CIRCULATION STROKE

\section{ESNR}

R. Wiest ${ }^{1}$, W. Z Graggen ${ }^{2}$, L. Remonda ${ }^{3}$, A. Humm ${ }^{2}$, A. Federspiel ${ }^{4}$;

${ }^{1}$ Institute for Diagnostic and Interventional Neuroradiology, Bern/ $\mathrm{CH},{ }^{2}$ Inselspital Bern, Bern/CH, ${ }^{3}$ University Hospital of Berne, Berne/CH, ${ }^{4} \mathrm{UPD}$ Waldau, Bern/CH
PURPOSE

Blood oxygenated level dependent (BOLD) signal and arterial spin labelling cerebral blood flow (ASL-CBF) changes, as detected by functional magnetic resonance imaging (fMRI) are closely related to neural activity. The aim of this case series study was to investigate modulations of the BOLD and ASL-CBF response in the primary visual cortex after posterior circulation stroke with transient visual impairment.

MATERIAL AND METHODS

BOLD activity and ASL-CBF response have been investigated 24-48 hours after onset of transient visual symptoms in 2 patients who were treated conservatively, two patients who received thrombolysis after posterior circulation stroke and five healthy controls with checkerboard stimulation and visual evoked potentials (VEP).

\section{RESULTS}

After normalisation of transient visual symptoms the BOLDresponse and VEP showed no hemispheric differences between patients and controls. The relative blood flow in the posterior cerebral arteries and the relative ASL-CBF response to checkerboard stimulation were reduced in three patients, compared to controls. In the patient who received intraarterial thrombolytic therapy, improvement of the relative CBF and ASL-CBF responses was observed, indicating early reperfusion.

CONCLUSION

In this case series of four patients, we observed different CBF responses to conservative and thrombolytic therapy, and detected early reperfusion after intraarterial thrombolysis. Functional imaging, which makes use of the ASL-CBF technique, is feasible to measure early poststroke vascular changes, which may be hardly detectable with BOLD fMRI.

P23

COMPLICATED DEVELOPMENTAL VENOUS ANOMALY: IMAGING OF FOUR CASES

ESNR

S. Kervancioglu ${ }^{1}$, A. Sirikci ${ }^{2}$, I. Oran ${ }^{3}$, A. Memis ${ }^{4}$;

${ }^{1}$ Gaziantep University, Faculty of Medicine, Gaziantep/TR, ${ }^{2}$ Gaziantep University Medical School, Gaziantep/TR, ${ }^{3}$ Ege University Hospital, Izmir/TR, ${ }^{4}$ Ege University Faculty of Medicine, Izmir/TR

\section{PURPOSE}

Widely accepted classification of cerebrovascular malformations includes arteriovenous malformation (AVM), developmental venous anomaly (DVA), cavernous angioma, and capillary telengiectasia. The association of DVA and other vascular malformation including association of the DVA and cavernous angioma, the DVA and AVM, the DVA and arteriovenous fistula (arterialized DVA) have been reported in the literature. The 
arterialized DVA, and association of DVA and true AVM draining into the DVA are rare entities. We described four complicated DVA, including three arterialized DVA, and one DVA that formed the venous drainage route of AVM adjacent to it.

MATERIAL AND METHODS

Four patients, three male and one female are included in this paper. Their mean age was 27 years (range 19 to 35 years). They were admitted with complaints including sudden motor weakness, aphasia, disturbed conscious, or headache. Patients underwent cranial computed tomography (CT) and/or magnetic resonance imaging (MRI), and cranial angiography.

RESULTS

Cranial CT/MRI revealed hematoma in three patients and vascular abnormality in all patients. Angiography showed only "caput medusae" appearance of a DVA that visible on the arterial phase in there patients, and enlarged feeding arteries and a small nidus of an AVM draining into adjacent DVA in one patient.

CONCLUSION

Arterialized DVA and DVA that formed the venous drainage route of AVM adjacent to it are rare entities. In arterialized DVA, there are usually multiple tiny slightly dilated arterial feeders drained directly into veins, with each vessel acting as a single arteriovenous fistula. Because of the arteriovenous shunting, DVA appears in the arterial phase, and unlike with an AVM, there is no nidus visible on the angiograms. In the reviewing of the literature concerning the arterialized DVA and the DVA-AVM complex, all lesions had same hemodynamic feature that is the DVA appeared on arterial phase and continued to the venous phase. One can readily speculate that these two mixed vascular malformations share common pathogenesis. Arterialized DVA can be pathogenetic precursor of the AVM draining into DVA. From a clinical point of view, such malformations present a diagnostic and therapeutic problem, since they may be similar to simple DVAs on sectional imaging. Therefore we also recommend an angiographic study when a symptomatic DVA is present.

\section{P24}

CEREBROVASCULAR IMAGING IN SICKLE CELL ANAEMIA, WHAT TO LOOK FOR WITH WHICH MODALITY

$E S N R$

$\underline{\text { P.O. Cowley }}{ }^{1}$, A. Siddique ${ }^{2}$;

${ }^{1}$ Royal Free Hospital, London/GB, ${ }^{2}$ King's College Hospital, London/GB

\section{PURPOSE}

The aim of this exhibit is to illustrate the diverse range of cerebrovascular pathologies that patients suffer as a consequence of sickle cell anaemia, and to demonstrate the best methods for imaging those pathologies that are currently available.

\section{MATERIAL AND METHODS}

The range of cerebrovascular pathologies seen in our population will be described and illustrated in detail. The incidence of each will be compared with published data.

RESULTS

The strengths and pitfalls of time of flight and contrast enhanced MRA, transcranial doppler, CTA, DSA and perfusion studies will all be described. In addition, the utility of diffusion tensor imaging of white matter tracts will be discussed, and finally, imaging of surgical and endovascular interventions will be demonstrated.

CONCLUSION

In our relatively large population of sickle cell patients we see a broad array of cerebrovascular pathologies: large vessel occlusions, moyamoya, watershed infarcts, aneurysms and small vessel disease. MRI/MRA is the imaging modality of choice but transcranial doppler has a screening role and DSA, CTA and perfusion studies are helpful to elucidate these devastating complications of this chronic high maintenance condition.

\section{P25}

EVALUATION OF THE VERTEBROBASILLAR SYSTEM BY MAGNETIC RESONANCE ANGIOGRAPHY AND DOPPLER ULTRASOUND IN THE DIAGNOSIS VERTEBROBASILLAR INSUFFICIENCY

ESNR

$\underline{\text { D. Emlik }}^{1}$, A. Erbay $^{2}$, D. Kiresi ${ }^{3}$, A. Karabacakoglu ${ }^{4}$, S. Karaköse ${ }^{5}$;

${ }^{1}$ Selcuk University Meram Medical Faculty, Konya/TR, ${ }^{2}$ Selcuk University Meram Medicine School, Konya/TR, ${ }^{3}$ Selcuk University Meram Medical Faculty, Konya/TR, ${ }^{4}$ Sel, Konya/TR, ${ }^{5}$ Selçuk University Meram Medical Faculty, Konya/TR

\section{PURPOSE}

Although vertebrobasillar $\ddot{A} \pm$ nsufficiency (VBI) is a common problem of elderly patients, diagnosis of VBI is generally difficult. The aim of this study was to determine the findings and efficiencies of MRA and CDUS in the diagnosis of VBI. MATERIAL AND METHODS

We examinated 40 patients who were referred for evaluation of VBI and 20 patients have no signs and symptomps of VBI who were same ages and sex as a control group by CDUS and MRA. By CDUS (General Electric Logiq,USA), it was examined diameters, peak systolic and end-diastolic velocities, flow spectrums and color Doppler flow characteristics of extracranial segments of vertebral arteries (VA). On MR imaging (Picker PQS, USA), diameters and abnormalities such as elongation, bending, narrowing and stenosis, oclusion, in all segments of VA's were evaluated by MRA (3D TOF). In patients with having doubt findings, $0,1 \mathrm{mmol} / \mathrm{kg}$ Gadolinium was administered intravenous- 
ly. Also posterior circulation was evaluated by cranial MRI in patients with VBI

\section{RESULTS}

By CDUS, 9 patients having oclusion, 5 patients having king or stenosis and 6 patients having only hypolasia and 2 patients having $\ddot{A} \pm$ nsufficient flow were diagnosed. By MRA, 14 patients having oclusion, 4 patients having stenosis, 6 patients having kink, 6 patients having only tortiosity and one patient having fenestration were diagnosed. MRA of the other 5 patients were normal. Cranial MRI of 7 of all patients with suffering from VBI was abnormal. On MRA, there was distal oclusion in 5 of 14 patients having oclusion. In these patients the waveform with low velocity and high resistance was determined the same side extracranial segments of VA's by CDUS.

CONCLUSION

If only the extracranial pathologies of vertebral artery were in concern CDUS specifity was $81,5 \%$ and sensitivity was $84,6 \%$ according to MRA. If all the vertebrobasillary system pathologies were in concern CDUS sensitivity and specifity according to MRA were $57,1 \%$ and $60 \%$ respectively. As a result, CDUS is rather accurate than MRA and is operator dependent. So, we think that MRA is the first choice imaging modality in patients with VBI. But CDUS may be prefered to examination the patients who can not be evaluated by MRA because of having metalic implants and claustrophobia.

\section{P26}

THE IMPORTANCE OF IMAGING IN THE DIAGNOSIS AND MANAGEMENT OF SUPERFICIAL SIDEROSIS OF THE CENTRAL NERVOUS SYSTEM

\section{$E S N R$}

G.K. Hughes The National Hospital for Neurology and Neurosurgery, London/GB

\section{PURPOSE}

Superficial siderosis (SS) is a rare condition of the central nervous system characterised by chronic haemorrhage into the cerebrospinal fluid spaces of the brain and spinal cord. This results in deposition of ferritin material onto the leptomeninges and damage to neighbouring neural tissues, typically resulting in slowly progressive sensorineural deafness, cerebellar ataxia, myelopathy and dementia. The leptomeningeal deposition is apparent as a characteristic hypo-intense rim on T2-weighted magnetic resonance (MR) imaging; this has revolutionised the diagnosis of the condition and increased its recognition as an important, albeit rare, clinical syndrome. It is therefore timely to review the literature on superficial siderosis, with particular reference to how imaging is critical for its early diagnosis and understanding its pathogenesis.

\section{MATERIAL AND METHODS}

All available articles and case reports published on superficial siderosis were reviewed, with particular reference to those that shed light on its pathogenesis and natural history as well as those describing early diagnosis by the latest MR imaging techniques. RESULTS

Widespread availability of MRI, in particular gradient echo sequences detecting chronic organised haemorrhage, has led to diagnosis of SS at a much earlier and potentially more therapeutically amenable stage. However, much still remains unclear about the nature of accumulation of the blood degradation products and their relationship with clinical manifestations, as well as the potential for reversibility of such changes. Since clinical presentation is late and non-specific, these important questions are likely to be answered only by longitudinal imaging studies. The rarity of the condition makes it appropriate to target populations with risk factors (e.g. dural lesions, previous neurosurgery and oral anticoagulation) to increase the yield of a screening study for presymptomatic cases.

\section{CONCLUSION}

The main difficulty in management of SS is delayed diagnosis due to the condition's rarity, chronicity and non-specific clinical presentation. Prospective imaging studies of at-risk populations may enable investigation of the condition during its long presymptomatic phase, perhaps with the aid of advanced imaging techniques, such as serial high resolution MRI, MR spectroscopy or functional imaging studies of the leptomeningeal deposits and neighbouring brain areas. The incidence found in these at risk populations may also prove to be such as to warrant selective screening programs.

P27

CAUSATIVE FACTORS OF THE WATERSHED INFARCTION USING DIFFUSION-WEIGHTED MR IMAGINGS

ESNR

W.M. Byun ${ }^{1}$, H.W. Jang ${ }^{2}$, S. Lee ${ }^{3}$;

${ }^{1}$ College of Medicine, Yeungnam University Hospital, Daegu/KR, ${ }^{2}$ College of Medicine, Yeungnam University, Daegu/KR, ${ }^{3}$ Soonchunhyang University Hospital, Gumi/KR

\section{PURPOSE}

Occlusion or stenosis of the intracranial or extracranial vessels is recognized causes of the watershed infarction. Stroke mechanisms of the watershed infarction such as hemodynamic or embolic infarction are controversy. The purpose of this study was to investigate causes and mechanisms of the watershed infarction using diffusion-weighted (DW) MR image.

MATERIAL AND METHODS

DW MR imaging was analyzed in 89 cases of the acute watershed infraction patients. Combined infarction patterns were evaluated: 
(A) territorial, (B) subcortical, (C) multiple small cortical, (D) No combined. Occlusion or stenosis of the intracranial and extracranial vessels was evaluated by MR angiography or conventional digital subtraction angiography. Pattern (A) represent a large ischemic lesion involving the cerebral cortex and subcortical structures in 1 or more major cerebral artery territory. Pattern (B) is defined as subcortical infarction in the territory of deep perforating branches originating from distal internal carotid artery (ICA) or the middle cerebral artery (MCA). Pattern (C) represents a fragmented embolus or multiple microemboli in the distal territory of MCA. RESULTS

Causes of watershed infarction were ICA stenosis (52 cases), MCA stenosis (26 cases), ACA stenosis (2 cases) and cardiac/ unknown ( 9 cases). Watershed infarction caused by ICA stenosis was common. Most common combined pattern of the watershed infarction was pattern C (64\%).

\section{CONCLUSION}

Most watershed infarction due to MCA and ICA stenosis associated with multiple small cortical embolic infarctions. We suggest mechanism of most watershed infarction was caused by embolic sources rather than hemodynamic mechanism.

\section{P28}

\section{LOCAL THROMBOLYSIS OF INTERNAL CEREBRAL VEIN AND STRAIGHT SINUS THROMBOSIS}

ESNR

B.L. Schmitz ${ }^{1}$, A.J. Aschoff ${ }^{2}$, S. Klein ${ }^{1}$, R. Huber ${ }^{1}$;

${ }^{1}$ University Hospitals Ulm, Ulm/DE, ${ }^{2}$ University Hospital Ulm, $\mathrm{Ulm} / \mathrm{DE}$

\section{PURPOSE}

Internal cerebral vein thrombosis has a poor outcome justifying invasive therapeutic strategies. We present a case with a succesful local thrombolysis and literature review of possible treatment strategies.

\section{MATERIAL AND METHODS}

Case Report: A 44 year old woman presented with somnolence after several days of an ongoing gastrointestinal infection with dehydration. MRI showed bilateral right predominant thalamic edema and internal cerebral vein as well as straigth and right transverse sinus thrombosis. Because of ongoing clinical deterioration interventional therapy was initiated. Via a transfemoral venous approach a microcatheter was placed into the straight sinus next to the vein of Galen. Angiographic control of catheter position during the intervention was improved by transarterial DSA series via a catheter placed into the left vertebral artery. Local thrombolysis with urokinase 30000 units/hour was initiated and maintained over 48 hours.

\section{RESULTS}

CTA and DSA controls after 24 showed beginning recanalisation of the straight sinus with further improvement in $48 \mathrm{~h}$ controls. Follow up MRI after two weeks showed the thalamic edema completely resolved. There was no hemorrhagic transformation. The patient recovered completely without any neurologic deficit. CONCLUSION

Local thrombolysis is an option for the treatment of selected cases of internal cerebral vein and straight sinus thrombosis.

P29

\section{OSTEODURAL ARTERIOVENOUS SHUNT PRESENTED WITH SYRINGOMYELIA}

ESNR

M.Q. Ribeiro, J. Rocha;

Hospital Sao Marcos, Braga/PT

\section{PURPOSE}

Dural arteriovenous fistulas (AVF) is an uncommon potentially life threatening disease. Osteodural AVFs is a unique subgroup that is usually supplied by dural arteries and located within the bone along the convexitie or skull base. We present a case of a complex parietal osteodural arteriovenous shunt supplied by pial-dural arteries from both internal and external carotid arteries and also from posterior circulation, which presented with a syringomyelia secondary to tonsillar herniation.

MATERIAL AND METHODS

A 60 year-old woman sought medical attention complaining of neck pain with irradiation to the right arm without a specific radicular route added to parestesia in both arms progressively worsening during the previous 2 years. Spine MR showed a large and loculated syringomyelic cavity from $\mathrm{C} 2$ to $\mathrm{T} 4$ associated to a crowded foramen magnum with caudal protrusion of cerebelar tonsils that were $10 \mathrm{~mm}$ below the occipital line. We also noted abnormal prominent flow voids around the cerebellum and posterior neck triangle. Cerebral MR which revealed multiple flow voids particularly in the parietal lobe and posterior fossa around mesencephalon and cerebellum compatible with dilated venous structures from superficial and profound venous system. The posterior portion of sagital sinus and the transverse sinus bilaterally were exceptionally dilated and the former was associated with a vascular mass in the parietal bone shown erosion of inner and outer tables with epicranial expression. DSA revealed multiple and complex pial-dural malformation, fed bilaterally by the internal lexternal carotid arteries and posterior cerebral arteries. Synchronous dural arteriovenous fistulas of the superior sagital sinus and torcula were noted, supplied by the anterior artery of the falx of cerebri bilaterally and right marginal tentorial artery, respectively. Cerebral venous flow was abnormal with prolonga- 
tion of both the parenchymal phase and venous outflow. Additional cortical, or transdiploic venous drainage was found.

\section{RESULTS}

see conclusions

CONCLUSION

Osteodural AVFs is a rare entity. However, the existence, in this case, of mixed pial-dural feeders from external and internal carotid arteries bilaterally, the presence of multiple fistula points and furthermore the presentation with syringohidromielia secondary to cerebelar tonsils ectopia makes this case unique.

\section{Head and neck imaging}

\section{P30}

\section{ACCURACY OF DELAYED POST-CONTRAST FLAIR MR IMAGING FOR THE DIAGNOSIS OF LEPTOMENINGEAL INFECTIOUS OR TUMORAL DISEASES}

ESNR

S. Kremer $^{1}$, M. Abu Eid ${ }^{1}$, G. Bierry ${ }^{2}$, A. Bogorin ${ }^{1}$, M. Koob ${ }^{1}$, J.L. Dietemann ${ }^{3}$;

${ }^{1} \mathrm{CHU}$ de Strasbourg, Strasbourg/FR, ${ }^{2}$ University Hospital of Strasbourg, Strasbourg/FR, ${ }^{3}$ Strasbourg/FR

\section{PURPOSE}

To compare unenhanced, gadolinium enhanced, delayed gadolinium enhanced FLAIR images, gadolinium enhanced and delayed gadolinium enhanced T1 images in different kind of leptomeningeal diseases, and to determine the most accurate MRI sequence for the diagnosis of leptomeningeal disease.

\section{MATERIAL AND METHODS}

Ten patients (6 men, 4 women, age: $52,7+/-16,4)$ clinically suspected of cerebral leptomeningeal infectious or tumoral disease benefited of brain MR examination: Axial FLAIR and T1 SE images were acquired before, immediately after administration of gadobenate dimeglumine ( $0.1 \mathrm{mmol}$ per kilogram of body weight) (early enhancement), and 20 minutes after injection of contrast media (delayed enhancement). Images were analysed to determine the more appropriate technique for the diagnosis of leptomeningeal disease.

\section{RESULTS}

Early enhanced FLAIR and delayed enhanced T1 were always more or equally accurate for the diagnosis of leptomeningeal diasease, as compared to, respectively, unenhanced FLAIR and early enhanced T1 images Delayed enhanced FLAIR was always more accurate for the diagnosis of leptomeningeal disease as compared to early enhanced FLAIR images. Delayed enhanced FLAIR was in most of the cases more accurate for the diagnosis of leptomeningeal disease as compared to delayed enhanced T1 images.

\section{CONCLUSION}

Delayed enhanced FLAIR MR sequence seems to improve the diagnosis of leptomeningeal infectious or tumoral diseases as compared to other MR sequences.

P31

COMPARISON OF DIFFUSION - WEIGHTED MRI AND CONVENTIONAL MRI IN DETECTION OF MULTIPLE SCLEROSIS LESIONS IN BRAIN

ESNR

R. Mohamadian, Z. Miabi;

Tabriz university, Tabriz/IR

\section{PURPOSE}

Multiple sclerosis is a chronic disease that begins most commonly in young adults and is characterized pathologically by multiple areas of CNS white matter inflammation, demyelination, and glial scarring. The most valuable laboratory aid for diagnosis is magnetic resonance imaging MRI. Advance type of MRI has been developed on the basis of molecular diffusion which frequently detects acute and active lesions. Early diagnosis and beginning of treatment will be possible to hinder progression of disease. The aim of this study was to compare the findings of conventional and diffusion _ weighted (DW) MRI in assessing the cerebral lesions of patients with MS

\section{MATERIAL AND METHODS}

Thirty patients with clinically definite MS and 30 healthy volunteers (as control group) enrolled in this study in a descriptive prospective survey over a twelve month period of time. Conventional and DW MRI were conducted in both groups. Total number, morphology, location and the mean size of the intra cerebral plaques Of MS were compared between two groups. The sensitivity and the specificity of both imaging methods in detecting these plaques were determined.

\section{RESULTS}

Thirty patients with MS with the mean age of $32.7+8.97$ years and 30 healthy persons with the mean age of $32.75+9.23$ years were enrolled. The number of the plaques within the brain was significantly higher by the conventional method ( $\mathrm{p}$ less 0.05 ). Ovoid lesions were greater in number in the conventional method group. More lesions were detected by the conventional method in the areas of periventricular, cenrum semioval and corpus callosum. Regarding the size of plaques, the minimum measurement was significantly lower in the conventional method group. The sensitivity of both methods was $100 \%$. The specificity of conventional and DW MRI was $86.6 \%$ and $96.6 \%$ respectively. CONCLUSION

In our study the sensitivity of both methods was the same but the specificity of DW MRI was found higher. Sometimes DW MRI may detected lesions which are not obvious by routine methods. 
P32

\section{FIBROUS DYSPLASIA MIMICKING SKULL BASE TUMOR}

$\underline{\text { ESNR }}$

W.H. Cho

Sanggye Paik Hospital, Inje University College of Medicine, Seoul/KR

\section{PURPOSE}

Fibrous dysplasia of the skull base, which rarely occurs, is commonly misdiagnosed as a tumor on MR imaging. We tried to investigate the MRI findings of fibrous dysplasia of the skull base with goal of heightening of awareness of this entity.

\section{MATERIAL AND METHODS}

We retrospectively reviewed the MRI findings in four patients with fibrous dysplasia of the skull base. The patients were 3 male and one female aged 43-50 years. Three patients were confirmed by follow-up CT imaging and one, by surgery. We evaluated the lesions according to the location, signal intensity and contrast enhancement pattern on MR imaging.

\section{RESULTS}

Of four fibrous dysplasia, two cases are located in clivus, one is located in sphenoidal sinus and one, in right greater wing and body of sphenoid bone. All cases are single and relatively well defined mass without destructive pattern. All cases showed low signal intensity (SI) on T1-weighted images. On T2-weighted images, three cases showed low SI and one showed high SI. On the subsequent post-contrast T1-weighted images, strong enhancement was seen in three patients, whereas peripheral rim enhancement was seen in one.

\section{CONCLUSION}

Fibrous dysplasia of the skull base is oftenly misdiagnosed as more aggressive neoplastic disease on MR imaging. An awareness of diagnostic pitfall and familiarity with the MR imaging features of fibrous dysplasia can avoid the unnecessary invasive procedure.

\section{P33}

PNEUMOSINUS DILATANS AND MULTIPLEX: REPORT OF THREE RARE CASES AND REVIEW OF THE LITERATURE

$E S N R$

Y. KİROGLU ${ }^{1}$, N. Karabulut ${ }^{2}$, N. Sabir ${ }^{3}$, B. Yagci ${ }^{2}$;

${ }^{1}$ Pamukkale University, Medical school, Denizli/TR, ${ }^{2}$ Pamukkale University Hospital, DENIZLI/TR, ${ }^{3}$ Pamukkale University, Denizli/TR

\section{PURPOSE}

Pneumosinus dilatans (PSD) is a term used to describe a localized abnormal dilatation of one or more paranasal sinuses without radiological evidence of localized bone destruction, hyperostosis or mucous-membrane thickening. The involvement of all paranasal sinuses and mastoid air cells has been named as pneumosinus dilatans multiplex (PSMD). Herein, we presented three unusual cases of pneumosinus dilatans; one is a second case of PSDM in English literature, another is the first reported case of a frontal PSD case associated with frontoethmoidal meningocele, mental retardation and facial asymmetry and the third one is PSD with a huge arachnoid cyst.

MATERIAL AND METHODS

$\mathrm{CT}$ and MR imaging was performed in three male patients (patient 1, 17 years; patient 2, 21 years; patient 3, 49 years respectively) presented with seizures.

\section{RESULTS}

In patient 1 , pneumosinus dilatans multiplex was detected with concomittant enlargement of all paranasal sinuses and mastoid air cells. Pneumosinus dilatans of right frontal sinus accompanied by left frontoethmoidal meningocele and pneumosinus dilatans of the left sphenoid clinoid process associated with huge ipsilateral middle cranial fossa arachnoid cyst were seen in patient 2 and 3 respectively.

CONCLUSION

Early recognition of the PSD and accompanying disorders is necessary to effectual treatment and to prevent the worse pathologies that may develop later. Besides the cranial deformity and cosmetic problems, early PSD formation may also represent an intracranial space-occupying lesion especially when multiple sinuses are involved so it may cause to different level of mental retardation. PSD may also be clue of some occult pathologies such as menengiomas. Furthermore because of the high association rates of PSD to some pathological process or syndromic conditions, it must not be considered a trivial radiologic finding, but instead the patients must be carefully evaluated clinically and radiologically.

\section{P34}

MRI AND MRA OF BILATERAL CAROTID BODY TUMORS ESNR

V.K. Katsaros ${ }^{1}$, P. Lampropoulou ${ }^{2}$, M. Mitropoulou ${ }^{2}$, A. Papadopoulou ${ }^{3}$, N. Marangos ${ }^{3}$, C. Drossos ${ }^{2}$;

${ }^{1}$ IKA Oncology Hospital, Holargos-Athens/GR, ${ }^{2}$ IKA Oncology Hospital, Athens/GR, ${ }^{3}$ Euroclinic of Athens, Athens/GR

\section{PURPOSE}

To determine the imaging features of magnetic resonance imaging (MRI) and MR angiography (MRA) and study the value in the differential diagnosis and surgical planning for bilateral carotid body tumors. Also to show their ability as follow-up methods of choice. 


\section{MATERIAL AND METHODS}

Two patients with bilateral suspected pulsatile carotid space mass were imaged by MRI and MRA. Its characteristic findings were analyzed for lesion shape, margin, signal intensity, angle of common carotid bifurcation, and the relationship between the great vessels and carotid space mass.

RESULTS

The first patient was operated in 1994 and the histology showed a right carotid body tumor. She also complained for a left carotid space mass. The follow up studies (CT, MRI and MRA) showed a relapse right and a left carotid body tumor (May 2005). The second patient demonstrated (January 2005) bilateral carotid body tumor in combination with a left sided glomus jugulare and also left sided facialis Schwannoma. The tumors of the left side were surgically removed after embolization of the chemodectomas. Combined MRI and MRA assessment of carotid body tumors yielded an accuracy of $100 \%$. It was also revealed that the anatomy shown on the MRI and axial MRA source images was consistent with that found by surgery.

\section{CONCLUSION}

MRI in combination with MRA is considered as non-invasive imaging technique for the evaluation of carotid space tumor showing superiority to other modalities in the differential diagnosis between vascular versus non-vascular tumours. This method may take the place of traumatic carotid angiography.

\section{P35}

\section{DEFORMITIES OF THE INNER EAR AND THE INTERNAL AUDITORY CANAL}

$E S N R$

N. Marangos ${ }^{1}$, V.K. Katsaros ${ }^{2}$;

${ }^{1}$ Euroclinic of Athens, Athens/GR, ${ }^{2}$ IKA Oncology Hospital, Holargos-Athens/GR

\section{PURPOSE}

A new classification of inner ear deformities is necessary, based on arrested or altered of inner ear embryogenesis.

\section{MATERIAL AND METHODS}

Since high resolution computed tomography of the temporal bones and occasionally magnetic resonance imaging are used in the evaluation of cochlear implant candidates with hereditary hearing loss, several inner ear and internal auditory canal malformations have been observed, that cannot be classified as Mondini dysplasias. This is based in over 1200 examined children as cochlear implant candidates.

\section{RESULTS}

88 cases of various temporal bone malformations not necessarily included in previous classifications, but with impact in cochlear implant surgery or outcome were found.

\section{CONCLUSION}

Cochlear implant is contraindicated on some of these deformities, on others electrode insertion might be a challenge and in some cases poorer auditory performance with the cochlear implant may occur.

P36

PREOPERATIVE BALLOON TEST OCCLUSION OF THE CAROTID SYSTEM USING PERFUSION MAGNETIC RESONANCE IMAGING IN PATIENTS WITH CAROTID BODY TUMORS

ESNR

${\mathrm{K} . \mathrm{BICAKCI}^{1}}^{1}$, F. Binokay ${ }^{2}$, E. Akgul $^{2}$, E. Aksungur ${ }^{3}$; ${ }^{1}$ CUKUROVA UNÝVERSITY BALCALI HOSPITAL, ADANA/ TR, ${ }^{2}$ Cukurova University Balcali Hospital, Adana/TR, ${ }^{3}$ Cukurova University, Adana/TR

\section{PURPOSE}

To evaluate the cerebral blood perfusion in patients with carotid body tumors before undergoing surgery.

MATERIAL AND METHODS

Eight patients with carotid body tumor underwent balloon test occlusion (BTO) by digital subtraction angiography (DSA) and perfusion magnetic resonance (MR) imaging before surgery. On DSA, a 5-F occlusion balloon catheter was used for temporary occlusion while the patients were examined by continuous neurologic testing, stump arterial pressure monitoring, and electrocardiographic monitoring for 30 minutes. Immediately after BTO, patients were transferred to MR unit for perfusion MR, with the occlusion balloon in place but deflated. The balloon was reinflated immediately before perfusion MR scanning and deflated at the end of perfusion sequence which lasted 76 seconds. Perfusion MR data of all patients were evaluated qualitatively and quantitatively on a seperate workstation using a commercial software.

\section{RESULTS}

Three of the patients showed asymmetric regional blood flow abnormalities. A perfusion deficit on the motor area in one patient was detected, whereas two other patients had perfusion abnormalities on frontal and occipital regions. One patient had a slight prolongation of mean transit time in the occipital area. No abnormalities were detected in the remaining four patients.

\section{CONCLUSION}

Perfusion magnetic resonance imaging has emerged as a powerful diagnostic tool in evaluating cerebral hemodynamics. It is also a practical imaging method for preoperative assessement of collateral cerebral blood flow. SPECT has been widely used for evaluation of cerebral perfusion in various pathologies, as well as, for balloon test occlusion of the carotid system. However, scan time is relatively long (10-20 min.) when compared to perfusion 
MR (2-3 min). Patient transfer is another problem particularly in hospitals with seperate radiology and nuclear medicine departments. We conclude that perfusion magnetic resonance is a valuable and powerful imaging modality for assessement of preoperative cerebral hemodynamics in patients with carotid body tumors.

P37

\section{CORNELIA DE LANGE SYNDROME: TEMPORAL BONE CT FINDINGS}

\section{ESNR}

E.Y.Y. Kim ${ }^{1}$, Y.K.H. Kim ${ }^{2}$, J.S.H. Kim ${ }^{3}$, J.K.J.M. Lee ${ }^{4}$;

${ }^{1}$ Samsung Medical Center, Sungkyunkwan University School of Medicine, Seoul/KR, ${ }^{2}$ Chung-Ang University Hospital, Seoul/KR, ${ }^{3}$ Korea University, Anam Hospital, Seoul/KR, ${ }^{4}$ Samsung Medical Center, Seoul/KR

\section{PURPOSE}

Cornelia de Lange syndrome is a relatively uncommon disorder characterized by combined congenital anomaly of multiple organs including ear anomalies and mental retardation of unknown etiology. The purpose of this study was to describe the findings of temporal bone CT in Cornelia de Lange syndrome.

\section{MATERIAL AND METHODS}

Enrolled were three boys and two girls, ranged from 8 months to 6 years, with Cornelia de Lange syndrome that were diagnosed with physical features. All patients had sensorineural hearing impairment on both sides that was confirmed with behavioral audiometry and/or auditory brainstem response. All patients underwent unenhanced helical temporal bone CT. Coronal images were reconstructed with $1-\mathrm{mm}$ thickness. Two neuroradiologists reviewed $\mathrm{CT}$ by consensus with regard to the presence of ear anomalies.

\section{RESULTS}

All patients showed soft tissue in the middle ear cavities and large lateral process of the malleus and enlarged incus on both sides. The height of the cochlea was diminished with approximately two turns and the vestibule was dilated on both sides in all patients. Dehiscence of the distal tympanic and mastoid segment of the facial nerve was suspected on both sides in two patients.

CONCLUSION

The dysmorphic ossicles in the soft-tissue filled middle ear cavity and inner ear anomalies may be characteristic findings of Cornelia de Lange syndrome on temporal bone CT.

\section{P38}

\section{SAFETY OF GADOBENATE DIMEGLUMINE AND GADO- PENTETATE DIMEGLUMINE IN PATIENTS WITH CNS DISEASE}

ESNR

G. Pirovano ${ }^{1}$, J.R. Parker ${ }^{2}$, C. Venetianer ${ }^{2}$, N. Shen ${ }^{2}$, M.A. Adams ${ }^{3}$, A. Spinazzi ${ }^{1}$;

${ }^{1}$ Bracco Diagnostics, Princeton/US, ${ }^{2}$ Bracco Diagnostics Inc., Princeton/US, ${ }^{3}$ Bracco Diagnostics, Inc., Princeton/US

\section{PURPOSE}

To evaluate the safety of gadobenate dimeglumine (Gd-BOPTA) and gadopentetate dimeglumine (Gd-DTPA) in adults and children with CNS disease.

\section{MATERIAL AND METHODS}

A total of 184 adult patients with CNS disease were enrolled in crossover, intra-individual comparisons of Gd-BOPTA (MultiHance, Bracco Imaging) and Gd-DTPA (Magnevist, Schering AG), while a further 296 patients with CNS disease (122 adults, 174 children) were evaluated in randomized, double-blind, parallel-group studies with the two agents. In all studies, the contrast agents were administered as a single bolus injection of $0.1 \mathrm{mmol} / \mathrm{kg}$ body weight. The safety of Gd-BOPTA and GdDTPA was evaluated by means of physical exams, recording of vital signs, clinical laboratory investigations, and 12-lead ECG at baseline and at at different time-points up to 24 hours postdose. Data from these comparative studies were pooled into an integrated safety database and adverse event (AE) rates were calculated. Chi-square analysis was used to test for significant differences in AE rate between Gd-BOPTA and Gd-DTPA.

\section{RESULTS}

No significant safety finding were noted for either agent in terms of vital signs, clinical laboratory investigations, and 12-lead ECGs. In intra-individual comparative studies, in which each patients acted as their own control, the AE rate was $7.9 \%$ (14/177) after Gd-BOPTA and 8.7\% (16/183) after Gd-DTPA ( $\mathrm{P}=0.77)$. In parallel-group studies in which patients received either of the agents, the AE rate was $10.9 \%(16 / 146)$ after Gd-BOPTA and $8.7 \%(13 / 150)$ after Gd-DTPA $(\mathrm{P}=0.51)$. In pediatric subjects with CNS disease enrolled in a parallel-group study, the AE rate was $12.9 \%(11 / 85)$ with Gd-BOPTA and $14.6 \%$ (13/89) with GdDTPA ( $\mathrm{P}=0.75)$. The type of AE recorded was similar between agents, including headache, injection site reactions, mild rash, and nausea. Most AE were minor, transient, and self-limiting after either Gd-BOPTA or Gd-DTPA in both pediatric and adult patients. No serious AE were observed with either agent. CONCLUSION

Gadobenate dimeglumine is a safe MR contrast agent for use in adults and children with CNS disease at a dose of $0.1 \mathrm{mmol} . \mathrm{kg}$ body weight. In a series of intra-individual and parallel group 
studies, the rate of adverse events after gadobenate dimeglumine was low $(8 \%-13 \%)$ and essentially equivalent to that of another widely used contrast agent, Gd-DTPA.

\section{P39}

POTENTIAL ROLE OF HIGHER RELAXIVITY CONTRAST AGENTS IN MRI OF THE CENTRAL NERVOUS SYSTEM

ESNR

M. Essig ${ }^{1}$, W.G. Bradley ${ }^{2}$;

${ }^{1}$ German Cancer Research Centre, Heidelberg/DE, ${ }^{2}$ University of California, San Diego, San Diego/US

\section{PURPOSE}

To review data from recent studies comparing a higher relaxivity MRI contrast agent (gadobenate dimeglumine, Gd-BOPTA; MultiHance) with other gadolinium agents in patients with suspected CNS disease.

\section{MATERIAL AND METHODS}

Principal results from studies in patients with CNS disease were reviewed. Published studies with Gd-BOPTA include a multicenter trial in patients with CNS metastases in which Gd-BOPTA was administered at cumulative doses up to $0.3 \mathrm{mmol} / \mathrm{kg}$, two multicenter controlled trials in which Gd-BOPTA at cumulative doses of 0.15 and $0.2 \mathrm{mmol} / \mathrm{kg}$ was compared with gadodiamide at a cumulative dose of $0.3 \mathrm{mmol} / \mathrm{kg}$, and several crossover studies in which Gd-BOPTA and another gadolinium chelate were given to the same patients at a dose of $0.1 \mathrm{mmol} / \mathrm{kg}$. The effect of $\mathrm{Gd}-$ BOPTA on signal intensity, lesion enhancement, and patient management was evaluated.

\section{RESULTS}

The study in patients with metastatic disease showed that $0.1 \mathrm{mmol} / \mathrm{kg}$ Gd-BOPTA is sufficient for most clinical situations, but that an increased dose of $0.2 \mathrm{mmol} / \mathrm{kg}$ provides additional information in certain cases (e.g., for the detection of additional metastases). In this trial a cumulative dose of $0.3 \mathrm{mmol} / \mathrm{kg} \mathrm{Gd}$ BOPTA did not provide information beyond that available with a cumulative dose of $0.2 \mathrm{mmol} / \mathrm{kg}$. Two controlled trials further showed that a cumulative dose of $0.2 \mathrm{mmol} / \mathrm{kg}$ bodyweight is diagnostically equivalent to a cumulative dose of $0.3 \mathrm{mmol} / \mathrm{kg}$ gadodiamide (Gd-DTPA-BMA). In these trials, $0.1 \mathrm{mmol} / \mathrm{kg} \mathrm{Gd}-$ BOPTA was shown to provide higher $\mathrm{S} / \mathrm{N}$ than an equivalent dose of Gd-DTPA-BMA in tumor patients. These findings were confirmed in several crossover studies in which enhancement after $0.1 \mathrm{mmol} / \mathrm{kg}$ Gd-BOPTA was shown to be superior to enhancement after the same dose of Gd-DTPA. In these studies, quantitative enhancement was significantly greater after GdBOPTA. Inter-reader agreement was good for all evaluations and a significant preference for Gd-BOPTA over Gd-DTPA was expressed by all readers for all qualitative comparisons.

\section{CONCLUSION}

Preliminary evidence suggests that a higher relaxivity agent may be of most benefit for the imaging of poorly enhancing lesion (gliomas, metastases, MS plaques) or for imaging specific vascular pathologies, such as AVMs. Available data support the application of higher relaxivity contrast agents in MR neuroimaging applications to increase enhancement and potentially improve patient management and surgical planning.

P40

A PATIENT WITH RARE STRABISMUS FIXUS: PRE- AND POSTOPERATIVE MRI FINDINGS.

ESNR

U. Lachmund $^{1}$, B. Schröder-Frei ${ }^{2}$, K. Chalupka ${ }^{3}$, N. Husain ${ }^{2}$, O. Bergamin $^{2}$, K. Landau ${ }^{2}$, S. Kollias ${ }^{1}$;

${ }^{1}$ University Hospital of Zurich, Zurich/CH, ${ }^{2}$ University of Zurich, Zurich/CH, ${ }^{3}$ Universitätsspital Zürich, Zurich/CH

PURPOSE

To report the pre- and postoperative MRI findings in patient with strabismus fixus.

MATERIAL AND METHODS

In a 38 year old patient with strabismus fixus in both eyes, preand postoperative MRI was performed. We examined the shape and morphology of the external eye muscles in the axial and coronal planes and their changes during eye movements (adduction and abduction) in the preoperative and postoperative status. RESULTS

The left eye was operated. We were able to demonstrate the malposition and partially herniation of the muscle cone, which led to the fixed eye position. After complex muscle operation the MRI could demonstrate the nearly normal muscle insertion.

CONCLUSION

We present the neuroimaging and ophthalmological findings in a case of advanced strabismus fixus. Orbital MRI offers preoperative information on muscle insertion for treatment planning and postoperatively, provides information on muscle changes and function for estimating the success of the operation.

P41

A NEW CLASSIFICATION OF ESTHESIONEUROBLASTOMA BASED ON IMAGING FINDINGS

ESNR

C. Ozdoba ${ }^{1}$, G. Schroth ${ }^{2}$, L. Remonda ${ }^{3}$, J. Kovacs ${ }^{4}$, A. Lukes ${ }^{4}$, K. Laedrach ${ }^{4}$, J. Raveh ${ }^{4}$; 
${ }^{1}$ Institute for Diagnostic and Interventional Neuroradiology, Bern/ $\mathrm{CH},{ }^{2}$ Inselspital, Bern/CH, ${ }^{3}$ University Hospital of Berne, Berne/ $\mathrm{CH},{ }^{4}$ Inselspital / Universität Bern, Bern/CH

\section{PURPOSE}

To improve current classification schemes of esthesioneuroblastoma by detailed analysis of imaging findings and to correlate tumor extent with recurrence and survival rates.

\section{MATERIAL AND METHODS}

Over a period of fifteen years (1989-2004), 15 patients (nine men, six women, 16-77 yrs, mean age 52.4 yrs) were operated for esthesioneuroblastoma. 12 patients had pre-operative MR imaging, in three cases, CT was performed. All imaging studies were retrospectively evaluated for exact delineation of tumor boundaries and assessment of structures infiltrated by the tumor. A grading scheme was developed that rated infiltration from one point (e.g., nasal cavity) to five points (e.g., dural infiltration) for 23 anatomic structures. A total of 76 points was possible.

\section{RESULTS}

The mean tumor infiltration rating was 45.5 points. Although all tumors were classified as Grade 4 in conventional classification schemes, our grading system provided a finer differentiation; the range was 25 to 68 points. Tumor recurrence was markedly earlier in cases with $>50$ points. (Please note: At the time of writing, the data analysis is not yet complete; detailed results will be available for the ESNR meeting.)

\section{CONCLUSION}

Current grading schemes for esthesioneuroblastoma are not sufficiently detailed. Infiltration of surrounding structures alone does not necessarily mean that a tumor is inoperable; only a large degree of infiltration into surrounding structures does markedly reduce the recurrence-free interval.

\section{P42}

\section{LESIONS AND PSEUDOLESIONS OF THE PETROUS APEX: AN IMAGING REVIEW.}

\section{ESNR}

N. Chaudhary ${ }^{1}$, S.E.J. Connor ${ }^{2}$;

${ }^{1}$ King's College Hospital, LONDON/GB, ${ }^{2}$ King's College Hospital, London/GB

\section{PURPOSE}

To review the CT and MRI appearances of lesions and pseudolesions of the petrous apex.

\section{MATERIAL AND METHODS}

There are a variety of pathologies which arise from the petrous apex. Such lesions may present with symptoms due to mass effect or cranial nerve palsies, or may also be detected during the investigation of unrelated disease. The CT and MRI findings of this is clearly laid out in this review.

\section{RESULTS}

Developmental (congenital cholesteotoma) and inflammatory (apical petrositis, chronic skull base osteomyelitis, cholesterol granuloma, acquired cholesteotoma, mucocele) lesions of the petrous apex will be discussed and illustrated. Whilst it is more frequent for neoplastic lesions to extend from adjacent structures, we will demonstrate a variety of tumours and tumour-like conditions (metastasis, rhabdomyosarcoma, Langerhans cell histiocytosis, endolymphatic sac tumour,osteosarcoma chondrosarcoma) which directly involve the petrous apex. There are a range of normal radiological appearances some of which may be mistaken for pathology (e.g. asymmetric marrow space development). Examples of such pseudolesions and other benign conditions affecting the petrous apex (e.g. benign effusions and meningoceles) will also be presented together with an imaging algorithm to aid their differentiation.

CONCLUSION

$\mathrm{CT}$ and MRI are complementary in providing an appropriate differential diagnosis and in aiding surgical planning of the lesions of the petrous apex. This pictorial review lends a clear understanding of the anatomy and contents of the petrous apex and the various pathological conditions thereof.

\section{P43}

UNUSUAL ORIGIN OF THE MARGINAL TENTORIAL ARTERY FORM THE MIDDLE MENINGEAL ARTERY, DETECTABLE ONLY BY ANGIOGRAPHIC COMPUTED ANGIOGRAPHY (ACT)

\section{ESNR}

G. Benndorf, C.M. Strother, R.P. Klucznik; The Methodist Hospital, Houston/US

PURPOSE

Description of an unusual origin and course of the marginal tentorial artery (MTA) from the middle meningeal artery (MMA) using angiographic computed tomography (ACT).

MATERIAL AND METHODS

A 43-year-old male, presenting with epistaxis was referred for diagnostic cerebral angiography and embolization. The diagnostic external carotid arteriogram didn't not reveal a particular bleeding source and was otherwise found to be normal. A small arterial branch, however, was noted possibly arising from the left MMA. Exact origin and course of the vessel was difficult to identify using standard DSA. ACT was performed using a flat detector (FD) biplane angiographic system (Axiom Artis dBA, Siemens Medical, Erlangen) and the following parameters: $20 \mathrm{sec}, 538$ projections, $0.4 \mathrm{i}$, ${ }^{\circ}$ increment, $512 \times 512$ matrix, 538 projections, $220 \mathrm{i},{ }^{\circ}$ total angle and manual contrast injection $(15 \mathrm{cc})$. Image post-processing was performed using a commercially available workstation and software (Leonardo, Dyna-CT). 


\section{RESULTS}

Maximum intensity projections (MIPs) revealed clearly the origin of the branch from the MMA, distal to the foramen spinosum. MIPs in axial view showed precisely the anatomical relationship of the branch to the foramina of the skull base as well as its entire course along the tentorial edge, not visualized on DSA, allowing for identification as an anatomical variant of the MTA. ACT further demonstrated its branching off within the tentorium cerebelli and showed opacification of minute distal network of the dura, not visualizable by any other imaging technique currently available.

\section{CONCLUSION}

Due to the superior spatial and contrast resolution of FD-technique, ACT provides highly accurate anatomical information on vascular and osseous structures, not obtainable with currently available standard DSA systems or other clinical imaging techniques. ACT represents a new dimension of vascular imaging and will not only improve knowledge and understanding of complex anatomical regions such as the skull base. It also has potential impact on future diagnostic imaging of small intracranial vessels, including brains stem perforators and vascular beds of brain tumors.

\section{P44}

ATYPICAL MR FINDINGS IN MULTICENTRIC GLIOBLASTOMA MULTIFORME

ESNR

T. Stosic-Opincal, S. Lavrnic, M. Gavrilov, S. Gavrilovic, V. Peric; Clinical Center of Serbia, Belgrade/YU

\section{PURPOSE}

Multicentric glioblastoma multiforme (GBM) is uncommon brain neoplasm, with incidence varying between 2.4 and $4.9 \%$ of all GBMs. True multicentric tumors are described as lesions widespread within different lobes or hemispheres, without evidence of spreading along the cerebrospinal fluid, blood pathways, or median commissures.

\section{MATERIAL AND METHODS}

We present a case of magnetic resonance imaging (MRI) and single-voxel proton-MR spectroscopy evaluation of multicentric GBM in previously well 53-year-old woman who presented with sudden onset of headaches, and progressive disorientation. Since MRI/MRS features were indefinite, biopsy was performed and the diagnosis of GBM was confirmed by histopathologic examination. RESULTS

T2-weighted and FLAIR images revealed hyperintense, illdefined, space-occupying lesions in the hipoccampal and parahipocampal regions of both hemispheres, as well as in left subcortical temporo-occipital region, with sparse perifocal edema. The lesion on the left demonstrated moderate mass effect on temporal horn of the left lateral ventricle. Lesions showed irregular postcontrast enhancement. On diffusion-weighted MRI lesions were hyperintense, indicating restricted diffusion. Single-voxel protonMR spectroscopy of all lesions demonstrated the reduction of all intracerebral metabolites with marked increase in lipids. Spectral analysis of peritumoral region revealed no increase in choline level, which is uncommon since it is well known that in GBM tumor cells infiltrate well beyond the margins of signal abnormality on MRI. The differential diagnosis of these multiple lesions included infectious diseases (tuberculmas) and metastasis. Since MRI/MRS features were indefinite, biopsy was performed and the diagnosis of GBM was confirmed by histopathologic examination.

\section{CONCLUSION}

MRI completed with DWI and MR spectroscopy help in determining the nature of cerebral lesions; however, since the findings can be atypical, the caution is needed when using these techniques in specific differential diagnosis.

\section{Intracranial stenting}

\section{P45}

TECHNICAL DIFFICULTIES AND STRATEGIES WITH THE USE OF LEO SELF-EXPANDING STENT FOR THE TREATMENT OF INTRACRANIAL ANEURYSMS.

\section{ICS}

J.M. Pumar $^{1}$, F. Vazquez ${ }^{2}$, M. Blanco ${ }^{2}$, J. Fernandez-Villa ${ }^{2}$, J.A. Castiñeira ${ }^{3}$;

${ }^{1}$ Hospital Clinico Universitario, SANTIAGO DE COMPOSTELA/ ES, ${ }^{2}$ Hospital Clinico Universitario, Santiago de Compostela/ES,

${ }^{3}$ Hospital Clinico Universitario, Santiago de Compostela/ES

\section{PURPOSE}

We report initial experience with the use of the Leo microstent in combination with detachable coils in treatment of patients with widenecked cerebral aneurysms, with an emphasis on technical difficulties and recommendations for a good placement and/o deployment MATERIAL AND METHODS

32 patients identified as harboring wide-necked aneurysm were selected for stent-assisted coiling. Aneurysms were located 10 at the paraophthalmic and 14 at the cavernous segment of the internal carotid artery and 8 at the posterior comunicanting posterior artery. After appropriate antiplatelet therapy, the Leo stent was delivered to the aneurysm site and positioned without difficulty. In 26 patients angiographic follow up was obtained in six-months, in 20 was obtained in one year and the other 6 patients is waiting for your control at 6 months

RESULTS

Stent placement in the desired position with complete o nearly complete occlusion of the aneurysm was feasible in all patients. In one patient, the stent was minimally displacement during microwire manipulation for aneurysm microcatheterization through the 
mess stent. Angiographic results at one year showed 26 complete occlusion and 6 residual necks

\section{CONCLUSION}

The Leo stent represent a significant advance in the vascular treatment of intracranial aneurysm in order to high radial force, the easy delivery system and its possibility to reposition. It is a feasible, secure and effective system

P46

LONG-TERM ANGIOGRAPHIC AND CLINICAL OUTCOME AFTER ELECTIVE STENT-ASSISTED INTRACRANIAL ANGIOPLASTY BASED ON ATHEROSCLEROTIC LESION CHARACTERISTICS

ICS

$\underline{\text { S. Yamamoto }}^{1}$, T. Mori ${ }^{2}$, H. Izumoto ${ }^{2}$, T. Kunieda ${ }^{2}$;

${ }^{1}$ Shonan Kamakura General Hospital, Kamakura City/JP, ${ }^{2}$ Shonan

Kamakura General Hospital, Kamakura City/JP

\section{PURPOSE}

Although previous studies suggest that elective stent-assisted intracranial angioplasty (SAIA) is safe and effective for treatment of atherosclerotic lesion, there have been few reports regarding its long-term outcome. The purpose of this study was to evaluate the long-term angiographic and clinical efficacy of elective SAIA for the treatment of symptomatic atherosclerotic occlusive disease.

MATERIAL AND METHODS

Since November 2000, 27 elective cases (26 stenoses and 1 total occlusion, 24 men and 3 women, mean age 72.2 years) were consecutively treated with balloon expandable coronary stent following balloon angioplasty, at least 7 days after the last ischemic attack. In all patients, medical therapy had failed and all lesions show $>70 \%$ luminal, long and tortuous stenosis or total occlusion (Mori type B 14 and type C 13), not suitable for the treatment with balloon angioplasty alone. Case records were retrospectively analyzed for location of the lesion, degree of stenosis, periprocedural complication, angiographic and clinical outcome.

RESULTS

Lesions were located at intracranial ICA in 12, M1 in 1, intracranial VA in 7 and BA in 7 patients. Successful SAIA was achieved in 25 patients $(92.6 \%)$, and average stenosis rate was reduced from $81.9 \%$ to $16.3 \%$. Periprocedural complications occurred in 3 lesions of Mori type C (11.1\%), (1 TIA, 1 stent migration and 1 hyperperfusion syndrome). Migrated stent was successfully removed without thromboembolic event, and hyperperfusion syndrome was over without permanent disability. There were no death, stent thrombosis, perforation, vessel rupture, and myocardial infarction. Periprocedural neurological morbidity and mortality was $0 \%$. Angiographic follow-up was available in all successful cases and significant restenosis was seen in 3 cases $(10.3 \%)$ during the follow-up period. There was no recurrent clinical ischemia after successful SAIA, including the 3 cases with restenosis (mean follow-up 19 months, range,3-65 months).

CONCLUSION

Even if in patients with long, tortuous stenosis or total occlusion of Mori type B or C, elective SAIA is technically feasible and safe with minimal risk, and effective for long-term stroke prevention.

P47

CONFORMABILITY OF SELF-EXPANDING INTRACRANIAL STENTS TO CURVED VASCULATURE USING ANGIOGRAPHIC COMPUTED TOMOGRAPHY (ACT) - AN IN VITRO STUDY

ESNR

N. Ebrahimi, B. Claus, C.Y. Lee, G. Benndorf;

The Methodist Hospital, Houston/US

\section{PURPOSE}

Radiographic visibility of self-expandable intracranial stent is poor due to their small size and low radiopacity. The purpose of this study was to evaluate the mechanical behavior of currently available self-expandable intracranial stents in a curved vessel model, using a novel imaging modality, Angiographic Computed Tomography (ACT).

MATERIAL AND METHODS

Neuroform2, Neuroform2-Treo (Boston Scientific), LEO (Balt Extrusion), Enterprise (Cordis) were used. The stents were bent in a polytetra-fluoroethylene (PTFE) tube with varying angles ranging from $30 \mathrm{o}$ to $150 \mathrm{o}$., Openings of 4,5 and $8 \mathrm{~mm}$ were created to simulate an aneurysm neck. ACTs were obtained using a flat detector system (Axiom Artis, Siemens, Medical Solution, Germany). Post-processing was performed on a commercially available workstation (Leonardo, Siemens).

RESULTS

ACT provided excellent visualization of stent mechanics and deployment characteristics of the stents and was superior to DSA or DR (non-subtracted DSA). It showed in detail the stent structure and its changes while conforming to a curved model, and provided in-stent views, not obtainable using other imaging techniques. Open cell design: it was evident at the 0o curvature the stents showed already a minor asymmetric deployment at the simulated aneurysm necks. In either case of the tube openings, with increasing diameter and angle, the cells demonstrated continuous increase in size, as well as an outward prolapse of the struts at the convexity of the model curve, starting at $110 \mathrm{o}$. With increasing angle an inwards prolapse of struts at the concavity of the model curve was observed. Closed cell design: the stents showed an increasing trend to flatten or even kink at the concavity of the model curve, starting at the $90 \mathrm{o}$ bending. The diameter of the midsection reduced considerably within each PTFE tube as the degree of the curvature increased. 


\section{CONCLUSION}

The conformability of open and closed cell design stents to curved vascular model may differ considerably. Open cell design stents may show an increased opening of cells at the convexity and inwards and outwards prolapse of struts. Closed cell design stents may flatten or, with more acute curvature, kink. Both phenomena may occur during stent placement in curved intracranial vessels harboring aneurysms, potentially complicating endovascular treatment. ACT is superior to DSA and DR in visualizing small intracranial stents and enables detecting adverse stent mechanics.

\section{Other}

\section{P48}

\section{FIBROUS AND INFLAMMATORY MESENTERIC MASS: AN ATYPICAL SIGN OF ERDHEIM-CHESTER DISEASE}

\section{ESNR}

C. Gehanne ${ }^{1}$, J. Alexiou ${ }^{1}$, C. Grosjean ${ }^{1}$, A. De Boeck ${ }^{1}$, N. Damry ${ }^{2}$, S. Kampouridis ${ }^{3}$, M. Lemort ${ }^{4}$; ${ }^{1}$ Institut Bordet, Bruxelles/BE, ${ }^{2}$ Brugman, Bruxelles/BE, ${ }^{3}$ Bordet, Bruxelles/BE, ${ }^{4}$ Institution Bordet, Bruxelles/BE

\section{PURPOSE}

Erdheim-Chester disease, a non familial disease of the adult, is a non Langerhans' cell disease which is characterized by a constant xanthogranulomatosis of long bones and with a potential to affect multiple organs.

\section{MATERIAL AND METHODS}

We report a 56 year-old female patient was admitted with loss of balance, walking difficulties, disturbed oral expression and night sweats persisting for several months. Her past history reveals mesenteric panniculitis, diagnosed by biopsy eight years ago. Clinical examination revealed bilateral solid masses at the level of the cheek bones and a large supraumbilical abdominal mass. Neurological evaluation shows ataxia, dysarthria and bilateral pyramidal syndrome. She has been followed up for the past seven years for pericardial effusion which has recently increased. Brain magnetic resonance imaging (MRI) revealed abnormal intensities in the pons (hyperintense on T2, hypointense on $\mathrm{T} 1$ and contrast enhancement after Gadolinium injection). There were also abnormal intensities in the cerebellar peduncles and the cerebellar hemispheres, but without any contrast uptake after injection. Ultrasonography and CT scan of the orbital region showed well defined and poorly vascularised solid masses in the subcutaneous fat layer, without bone involvement. Isotopic studies depicted hyperactivity in the distal part of long bones in the forearms and the legs. Conventional X-Ray of the appendicular skeleton showed diffuse symmetrical bone sclerosis at the distal end of the tibias, fibulas, radius and ulna. Bone MRI confirmed these regions of bone sclerosis (hypointense on T1 and T2) . Nevertheless, mild hyperntensities on $\mathrm{T} 2$ images were noted around the sclerotic margins and in the parosteal regions. At that stage, ErdheimChester disease was considered. Biopsy of the orbital lesions confirmed the diagnosis by revealing foamy histiocytes. Revision of the abdominal biopsy performed several years ago allowed depiction of foamy histiocytes within the nonspecific fibrous and inflammatory changes. Treatment consisting of steroids was started, but did not affect the course of the disease.

RESULTS

Results are explained in material and methods

CONCLUSION

Erdheim-Chester disease is characterized by infiltrations of non Langerhans' cell histiocytes, affecting diaphysis and metaphysis of long bones predominantly in the lower limbs. It can be confined to bone or associated with extraskeletal sites which in turn compromise the vital prognosis.

P49

NO EVIDENCE OF HEPATITIS C VIRUS - RELATED CEREBRAL DAMAGE IN PATIENTS WITH HIV/HCV COINFECTION: A QUANTITATIVE MRI STUDY

ESNR

M.M. Thurnher ${ }^{1}$, L. Kramer ${ }^{2}$, C. Armbruster ${ }^{3}$, A. Rieger ${ }^{4}$, R. Wechsberg ${ }^{2}$;

${ }^{1}$ Neuroradiology, Vienna/AT, ${ }^{2}$ Medical University of Vienna, Vienna/AT, ${ }^{3}$ Otto-Wagner-Spital Wien, Vienna/AT, ${ }^{4}$ Medical University Vienna, Vienna/AT

\section{PURPOSE}

The recent description of mild cognitive impairment and cerebral metabolic changed resembling human immunodeficiency virus (HIV) - related brain injury in patients with mild chronic hepatitis $\mathrm{C}$ infection have raised speculation on a previously unknown neuropathologic effect of the hepatitis $\mathrm{C}$ virus (HCV). Since HIV infection accelerates $\mathrm{HCV}$ - related liver disease and potentiates $\mathrm{HCV}$ viremia, we hypothesized that $\mathrm{HIV} / \mathrm{HCV}$ co-infected patients would develop more severe brain atrophy than comparable patients infected with HIV alone.

\section{MATERIAL AND METHODS}

A computer-assisted segmentation technique with thin section MR imaging (Sienax) was performed on brain MRIs from $39 \mathrm{HIV}$ infected patients without $\mathrm{HCV}$ infection, $25 \mathrm{HIV}+\mathrm{HCV}$ coinfected patients and 32 age-matched healthy controls. All patients were neurologically asymptomatic and free of focal MRI changes. The ratio of brain parenchymal volume to total intracranial volume (brain parenchymal fraction, an objective surrogate predictor of neuropsychological impairment) was calculated. Serum and 
plasma chemistry and haematology values, virologic and immunological analysis were extracted from patients' medical history if not older than three months of MRI examinations. Symptomatic HIV+ involvement was confirmed by a neurologist and a neuropsychologist. Clinical history (demographic data); neurological signs (including presence of HAD) and symptoms. CD4+ Tlymphocyte counts (cells/mm3) and HIV-1 RNA level (viral load, copies $/ \mathrm{mL}$ ) in plasma were obtained. In addition, antiretroviral treatment was assessed.

\section{RESULTS}

Both HIV infected and HIV/HCV co-infected patients had reduced brain parenchymal fractions (0.80) compared to healthy controls (0.83, $\mathrm{p}=0.001)$. However, there was no difference between patients infected with HIV alone (0.80) and co-infected patients (0.80, $\mathrm{p}=0.348)$. Multilinear regression identified that HIV infection $(\mathrm{p}<0,001)$ and age $(\mathrm{p}=0.002)$ but not HCV infection contributed to reductions in brain parenchymal fraction.

\section{CONCLUSION}

This quantitative MRI study demonstrates no difference in cortical and subcortical atrophy between neurologically asymptomatic patients infected with HIV alone and patients co-infected with HCV. Only age and HIV infection were significantly related to brain atrophy, challenging the hypothesis of a HCV-related brain damage.

\section{P50}

\section{ATLAS OF WHITE MATTER ANATOMY WITH FIBER TRACTOGRAPHY BY DIFFUSION TENSOR MRI}

\author{
$E S N R$ \\ J. Castedo, A. Duque, E. Roa, P. Rodrigo; \\ Hospital Montepríncipe, Madrid/ES
}

\section{PURPOSE}

Fiber tractography (FT) of the white matter using diffusion tensor imaging (DTI) is a recent magnetic resonance imaging (MRI) technique that allows visualizing the anatomy and the integrity of the white matter tracts. The purpose of this study is to represent bidimensionally and three-dimensionally the pathway of the main white fibers based on high-spatial-resolution DTI data and to expose our methodology.

\section{MATERIAL AND METHODS}

A 1.5-T MR unit (Intera; Philips Medical Systems, Best, The Netherlands) was used. DTI data were acquired by using a singleshot-planar imaging sequence with the sensitivity-encoding, or SENSE, parallel-imaging scheme (reduction factor, 2.0). The imaging matrix was $112 \times 112$, with a field of view of $224 \times 224 \mathrm{~mm}$. Transverse sections of $2.0 \mathrm{~mm}$ thickness were acquired parallel to the anterior commisure-posterior commisure line. A total of 60 sections covered the entire hemisphere and brainstem without gaps. Diffusion weighting was encoded along
32 independent orientations, and the $\mathrm{b}$ value was $800 \mathrm{~mm}^{2} / \mathrm{sec}$. The DTI datasets were transferred to a workstation and processing using PRIDE V4 (Philips, Best, The Netherlands) for anatomical realignment, determination of vóxel eigenvectors and calculation of fiber tracts orientation in a region of interest. On the DT imaging colour maps, red, green, and blue colours were assigned to right-left, anterior-posterior, and superior-inferior orientations, respectively. We study the main white matter tracts in four healthy volunteers, two men and two women, aged from 26 to 42 years, without history of neurologic abnormality. Informed consent was obtained from all subjects.

\section{RESULTS}

In all subjects, axonal directions underlying the main neuronal pathways could be delineated. We show bi-dimensionally and three-dimensionally the following tracts of white matter: radiatio optica, corpus callosum, associaton fibers, limbic system, corticospinal tract, commissura anterior, pedunculus cerebellaris medius, pedunculus cerebellaris superior and pedunculus cerebellaris inferior. Tracts were superimposed on coregistered anatomic MR images.

\section{CONCLUSION}

Fiber tracking by diffusion tensor imaging obtained additional or unique findings in the study of anatomy of white matter tracts using DTI-FT in comparison with those obtained by using conventional MR imaging. These images may prove useful for educational, teaching and clinical purposes. The depiction of the cerebral white matter architecture has become a routine procedure.

P51

EARLY CT IDENTIFICATION OF NON-HAEMORRHAGIC LESIONS OF CORPUS CALLOSUM IN DIFFUSE AXONAL INJURY

ESNR

D. Gadda, A.T.T. Neri, L. Vannucchi, F. Niccolai, L. Carmignani, P. Pacini; Ospedale del Ceppo, Pistoia/IT

\section{PURPOSE}

Computed tomography (CT) is considered to play a minimal role in the early identification of non-haemorrhagic traumatic lesions of corpus callosum, whose involvement has been demonstrated to be an indicator of worse prognosis in diffuse axonal injury (DAI). Aim of our study was to evaluate the possible increase in sensitivity of CT in the detection of non-haemorrhagic lesions of corpus callosum from baseline (within 6 hours of trauma) to early follow-up CT (24-72 hours) and when evaluating CT images with a narrow window width and approximating the window level to the mean density values of white matter. 


\section{MATERIAL AND METHODS}

Separate anonymous image series were retrospectively obtained from the baseline and early follow-up CT scans at the level of corpus callosum (CC), with our standard window settings for supratentorial structures (Window Width-WW 90 HU, Window Level-WL 35HU) and with non-conventional window settings (WW $30 \mathrm{HU}$, WL 25HU) in 5 consecutive patients with DAI and MRI diagnosis of purely or predominantly non-haemorrhagic CC lesions. The image sets were blindly and separately evaluated in a random sequence by two radiologists, who assigned a score for the presence of a CC lesion: 1- absent, 2-probably absent, 3-probably present, 4- present. Statistical analyses were carried out to evaluate interobserever agreement with weighted $\mathrm{k}$ test and to compare the scores with Wilcoxon test.

\section{RESULTS}

Interobserver agreement was excellent ( $\mathrm{k}$ 0.92). The scores on follow-up CT scans (Mean 3.55, 95\%CI 3.19-3.90) were found to be significantly higher $(\mathrm{p}<0.001)$ than on baseline CT (Mean 1.40, 95\% CI 1.04-1.75). On follow-up CT scans the scores when utilizing the non-conventional window settings (Mean 4, 95\%CI $3.43-4.56)$ were found to be significantly $(\mathrm{p}<0.05)$ higher than when reviewing the images with our standard window parameters (Mean 3.1, 95\%CI 2.53-3.66).

\section{CONCLUSION}

CT sensitivity for the detection of non-haemorrhagic lesions of corpus callosum increases after 24 hours from trauma and when for images analysis a narrow window width is utilized and the window level approximates to the mean density values of white matter

\section{P52}

\section{SIGN OF PROTON MRS IN GLIOMA BEFORE AND AFTER IRRADIATION}

\section{ESNR}

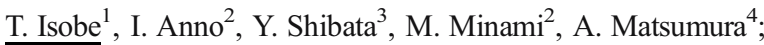
${ }^{1}$ Kitasato University, Sagamihara/JP, ${ }^{2}$ Graduate School of Comprehensive Human Sciences, Tsukuba/JP, ${ }^{3}$ University of Tsukuba, tsukuba/JP, ${ }^{4}$ University of Tsukuba, Tsukuba/JP

\section{PURPOSE}

In this study, we investigated the metabolite changes in glioma using proton MRS from before to after radiotherapy, to see whether or not early metabolic changes occur during therapy.

\section{MATERIAL AND METHODS}

Twelve patients with histological proven gliomas were examined by means of single-voxel proton MRS using a point-resolved spectroscopy (PRESS) sequence with a repetition time of $2000 \mathrm{~ms}$ and echo times of $68 \mathrm{~ms}, 136 \mathrm{~ms}$ and $272 \mathrm{~ms}$. The proton MRS was evaluated by both the spectrum pattern and the quantification of the metabolites. As to radiotherapy, each patient received a total dose of $64.8 \mathrm{~Gy}$ (1.8 Gy/fraction) with a $10 \mathrm{-MeV}$ linear accelerator. RESULTS

Both the N-acetylaspartate (NAA) peak and creatine/phosphocreatine (t-Cr) peak were lower after radiotherapy than before. The peaks of both the lipids (Lip) and lactate (Lac) were higher after radiotherapy than before. Moreover, the concentration of cholinecontaining compounds (Cho) was $4.60 \pm 1.18 \mathrm{mmol} / \mathrm{kg}$ wet weight before radiotherapy and was reduced to $3.07 \pm 0.10 \mathrm{mmol} / \mathrm{kg}$ wet weight $(\mathrm{p}<0.01)$ after radiotherapy.

CONCLUSION

Radiotherapy-induced changes in brain metabolism were well detected with proton MRS in the early phase. The effect of radiotherapy can be evaluated according to the value of Cho.

P53

\section{INTRACRANIAL SYNOVIAL SARCOMA}

ESNR

V.K. Katsaros ${ }^{1}$, A. Papadopoulou ${ }^{2}$, A. Katsarou ${ }^{3}$, D. Floros ${ }^{4}$, N. Marangos ${ }^{2}$;

${ }^{1}$ IKA Oncology Hospital, Holargos-Athens/GR, ${ }^{2}$ Euroclinic of Athens, Athens/GR, ${ }^{3}$ Red Cross Hospital Athens, Athens/GR, ${ }^{4}$ Micromedica, Athens/GR

\section{PURPOSE}

To present a very rare case of intracranial synovial sarcoma, observed spontaneously.

\section{MATERIAL AND METHODS}

A 15-year-old female was admitted to our institution, for a cervical spine MRI, reporting a gradual pain of the dorsal neck, initiated after an injury three months ago. After obtaining the first sequence we discovered a large skull base mass. We performed immediately a skull base MRI including T2-, proton density, STIR (fat suppression T2-W) images, T1-W images and T1-W fat saturation images, before and after i. v. Gd chelate administration. MR arteriography, MR venography, CT and DSA were also performed. RESULTS

A large space-occupying lesion was demonstrated, extending from the right petrous bone to the occipital bone at the level of the foramen magnum and the right atlantooccipital junction. The margins were normal and discrete, and the signal intensity behaviour was inhomogeneous in all sequences. After i. v. Gd chelate administration the lesion showed intense non-homogeneous enhancement and was described more precisely. CT revealed the presence of calcifications. The MR-venography demonstrated lower flow in the right transverse and sigmoid sinus, as well in the right internal jugular vein. Otorhinolaryngological evaluation revealed a slight ipsilateral conductive hearing loss. The whole mass was macroscopically removed via a retrosigmoid, transmastoid, infratemporal approach. Postoperative course was 
uneventful, except for complete palsy of the ipsilateral hypoglossal nerve. The patient was treated also by chemotherapy, radiotherapy and brachytherapy.

CONCLUSION

The final pathological examination including immunohistochemical picture, showed findings consistent with synovial sarcoma (monophasic spindle-cell type).

\section{P54}

\section{PONTINE BRIGHT LESIONS: MRI FINDINGS AND DIFFER- ENTIAL DIAGNOSIS}

$E S N R$

V.K. Katsaros ${ }^{1}$, P. Lampropoulou ${ }^{2}$, P. Spathi ${ }^{2}$, A. Nikolaou ${ }^{2}$, Z. Nikolakopoulou ${ }^{2}$, C. Drossos ${ }^{2}$;

${ }^{1}$ IKA Oncology Hospital, Holargos-Athens/GR, ${ }^{2}$ IKA Oncology Hospital, Athens/GR

\section{PURPOSE}

The aim of this study was to evaluate different MRI sequences, unenhanced and contrast en-hanced SE T1, TSE T2, GRE T2* weighted and FLAIR (Dark-Fluid)images for the diagnosis of neoplastic, vascular, inflammatory and miscellaneous pontine lesions.

\section{MATERIAL AND METHODS}

The last 6 years in our department 336 brain MR examinations with pontine lesions were performed by a $1.5 \mathrm{~T}$ MR unit (Magnetom, Vision). The routine brain MRI protocol used includes axial $\mathrm{T} 1$, proton density and $\mathrm{T} 2$ weighted and FLAIR (Dark-Fluid) and coronal, sagittal T2 weighted images. T2* weighted in axial plane sequence is obtained in cases of suspected hemorrhage and coronal FLAIR (Dark-Fluid) in specific cases, especially for imaging the brainstem. If necessary $\mathrm{T} 1$ weighted sequence in axial, coronal and/or sagittal plane after contrast medium administration (gadolinium-DTPA, $0.2 \mathrm{mmol} / \mathrm{kg}$ body weight) is performed. Correlation with clinical and laboratory findings followed.

RESULTS

A pontine volume increase or decrease was proved comparing the data of the normal and af-fected brain stem. The topography of lesions was clearly documented by MRI. Subacute hematomas were better outlined than by $\mathrm{CT}$, while acute infarctions, foci of demyelination and pontine encephalitis were proved only by MRI. Small calcifications and vessels of arte-riovenous malformations, however, caused the same MR signal patterns. Pathological hyperintensity in T2, T2* weighted and FLAIR (Dark Fluid) sequences and pathological enhance-ment in contrast-enhanced T1 weighted images was found in the following lesions: 1) contusion: 12 ) hematoma: $8 ; 3$ ) vascular malformations: $12 ; 4$ ) ischemic lesions: 197; 5) infec-tions: 4; 6) multiple sclerosis: 64 ; 7) central pontine myelinolysis: 2 ; 8) polyarteritis nodosa: 1 ;9) Wilson's disease: 2; 10) neoplastic: 43 ; 11) radiation: 2 .

CONCLUSION

MRI is of outmost importance in the diagnostic work-up of patients with clinically suspected pontine lesions. In correlation with clinical and laboratory findings they establish the correct diagnosis in the majority of these cases.

P55

\section{HIGH-RESOLUTION MRI OF HIPPOCAMPUS IN SEIZURES}

ESNR

V.K. Katsaros ${ }^{1}$, C. Mourtopoulos ${ }^{2}$, P. Spathi ${ }^{2}$, P. Lampropoulou ${ }^{2}$, M. Mitropoulou ${ }^{2}$, C. Drossos ${ }^{2}$;

${ }^{1}$ IKA Oncology Hospital, Holargos-Athens/GR, ${ }^{2}$ IKA Oncology Hospital, Athens/GR

\section{PURPOSE}

To evaluate the diagnostic accuracy of high-resolution MRI of the hippocampus in seizure patients, in order to provide optimally the clinician with all the information required.

MATERIAL AND METHODS

34 patients, aged 13-61 years, with history of seizures and negative CT, were examined by brain MRI with a 1,5 Ô unit (Magnetom, Vision). Standard protocol for a brain examination included transverse SE T1-W, tSE PD and T2-W, coronal tGSE T2-W and sagittal SE T1-W sequences. Additionally highresolution oblique coronal T2-W images (Slice Thickness $3 \mathrm{~mm}$, Matrix 512×512) and FLAIR sequences in the hippocampal region were obtained.

RESULTS

35 brain examinations were evaluated. 25 of them showed high signal intensity lesion, diminished hippocampal volume and structural distortion, suggestive of mesial tempo-ral sclerosis, especially in the high-resolution oblique coronal T2-W and FLAIR images. 1 patient (2 examinations) demonstrated a low-grade cystic astrocytoma and 2 patients a space-occupying lesion of the hippocampus. 6 patients had no evidence of pathologic findings. FLAIR images compared to the $\mathrm{T} 2 \mathrm{-W}$ proved to have a better spatial resolution and higher contrast in 7 patients $(20 \%)$. CONCLUSION

High-resolution MRI of the hippocampus is imperative in the diagnostic work-up of patients with seizures, providing the clinician with all information required. 


\section{P56}

\section{OSMOTIC MYELINOLYSIS OF THE BRAIN: MRI FINDINGS}

ESNR

V.K. Katsaros ${ }^{1}$, P. Lampropoulou ${ }^{2}$, M. Mitropoulou ${ }^{2}$, P. Spathi ${ }^{2}$, C. Samara $^{3}$, C. Drossos ${ }^{2}$;

${ }^{1}$ IKA Oncology Hospital, Holargos-Athens/GR, ${ }^{2}$ IKA Oncology Hospital, Athens/GR, ${ }^{3}$ Athens/GR

\section{PURPOSE}

Osmotic myelinolysis is the newer term which includes lesions of central pontine myelinolysis, as well as lesions of the same origin in higher levels of the brain.

\section{MATERIAL AND METHODS}

We describe the MRI findings of osmotic myelinolysis in 7 patientsand review the literature of the clinical conditions which cause osmotic myelinolysis.

\section{RESULTS}

The MRI can show on T1-W hypointense lesion $i$ the center of the pons. On T2-W and FLAIR sequences, abnormal hyperintense signal in the same region can be noted. Lesions with the same signal intensity can also be shown in higher levels of the brain, especially in the periventricular white matter, mimicking the picture of multiple sclerosis.

CONCLUSION

To establish the diagnosis of Osmotic Myelinolysis, the MRIfindings should be combined with the patients' history, neurological symptoms, laboratory findings especially hyponatriemia and outcome.

\section{P57}

INTRACRANIAL OTOGENIC COMPLICATIONS OF CHOLESTEATOMA

\section{ESNR}

V.K. Katsaros ${ }^{1}$, S. Lyra $^{2}$, P. Lampropoulou ${ }^{3}$, S. Triantos ${ }^{4}$, N. Batakis ${ }^{5}$, C. Drossos ${ }^{3}$;

${ }^{1}$ IKA Oncology Hospital, Holargos-Athens/GR, ${ }^{2}$ KORGIALENEIO-BENAKEIO "RED CROSS" HOSPITAL OF ATHENS, Athens/GR, ${ }^{3}$ IKA Oncology Hospital, Athens/GR, ${ }^{4}$ Red Cross Hospital Athens, Athens/GR, ${ }^{5}$ Hellenic Red Cross Hospital, Athens/GR

\section{PURPOSE}

Intracranial and extracranial otogenic complications are uncommon and potentially devastating, if not early diagnosed. Meningitis, intracranial abscesses, subdural empyema and venous thrombosis are the most common. We present a case of postoperative complications, following surgery for cholesteatoma. MATERIAL AND METHODS

A 25-years-old male patient, was admitted at the Clinic of Otorhinolaryngology, due to a cholesteatoma of the right ear.

RESULTS

Three days after the operation, he referred to the M.R.I. unit because of high fever and headache. The brain MRI scan revealed an intracranial abscess of the right cerebellar hemisphere. The MRvenography showed thrombosis of the right transverse and sigmoid sinus as well as of the ipsilateral internal jugular vein. CONCLUSION

The patient referred for abscess drainage, followed by intravenous antibiotic therapy.

P59

DIFFUSION WEIGHTED IMAGING IN ACUTE MIGRAINE ATTACKS WITH AND WITHOUT AURA

ESNR

A. Haktanir, B. Degirmenci, M. Yaman, G. Caliskan; Afyonkarahisar Kocatepe University, Afyonkarahisar/TR

\section{PURPOSE}

To search the ADC values and diffusion MRI changes of hyperintense lesions in white matter areas, basal ganglia, thalami, and occipital cortex in acute migraine attacks with and without aura.

\section{MATERIAL AND METHODS}

Twenty-one patients ( 2 men and 19 women) aged between 17-49 (mean 35,1 $\pm 8,3$ ) with migraine were included in the study. Eighteen age matched (range 22-48, mean 36.2 $\pm 9,3$ ) healthy controls were enrolled into the study. For MR imaging, a 1.5 Tesla scanner was used. Hyperintense lesions were evaluated in transverse T2W (3600/90 [TR/TE]) and FLAIR (7800/120/2000 $[\mathrm{TR} / \mathrm{TE} / \mathrm{TI}]$ ) images. Diffusion MR imaging was performed by using a three gradient protocol $(4100 / 110[\mathrm{TR} / \mathrm{TE}])$. Heavily diffusion weighted $(b=1000 \mathrm{~s} / \mathrm{mm} 2)$ images and automatically generated apparent diffusion coefficient (ADC) maps were studied. $\mathrm{ADC}$ values were calculated by electronic readings from ADC maps by variably sized circular region-of-interest evaluations and by pixel-lens evaluations. Measurement zones were designated to include the areas in which alterations had been detected in previous MRI studies with migraine. ROIs with $45 \mathrm{~mm}^{2}$ in periventricular and subcortical white matter zones, lentiform nuclei, and cerebellar hemispheres: and ROIs with $25 \mathrm{~mm}^{2}$ in smaller areas were established. Pixel-lens evaluation was used for ADC calculation of periaquductal gray matter. All subjects provided informed consent. Mann-Whitney U test was established for statistical analysis. 


\section{RESULTS}

Migraine with aura had been diagnosed in 11 and migraine without aura in 10 of the patients. Twelve millimetric hyperintense lesions within supratentorial areas, subcortical and deep white matters in T2W and FLAIR images were detected in 4 patients $(19 \%)$. All of these lesions were in migraine patients with aura. No DWI $\left(b=1000 \mathrm{~mm}^{2} / \mathrm{s}\right)$ or ADC map change was seen. One illdefined lesion adjacent to left frontal horn showed increased diffusion pattern. Only one case of control group (6\%) had a hyperintense lesion seen in subcortical white matter. There was no significant difference of $\mathrm{ADC}\left(\mathrm{mm}^{2} / \mathrm{s}\right)$ values between migraine and control groups.

CONCLUSION

Hyperintense lesions in T2W and FLAIR images were significantly more frequent in migraine patients especially with aura than control group. No diffusion alteration was detected in the acute period of migraine patients with and without aura.

\section{P60}

VENTRICULITIS IS A RARE CEREBRAL INFECTION THAT MAY RESULT FROM THE RUPTURE OF A BRAIN ABSCESS, THE EXTENSION OF MENINGITIS INTO VENTRICLES, OR A NEUROSURGICAL PROCEDURE OR DEVICE. PYOGENIC VENTRICULITIS IS IMPORTANT TO RECOGNIZE BECAUSE ITS SIGNS AND SYMPTOMS MAY BE SUBTLE, ITS COURSE CAN BE INDOLENT BUT LETHAL. IN THIS STUDY, WE PRESENT 10 PATIENTS WITH PYOGENIC VENTRICULITIS THAT WERE DIAGNOSED RETROSPECTIVELY AS A RESULT OF SIGNS OF MARKED RESTRICTED WATER DIFFUSION ON DIFFUSION-WEIGHTED MR IMAGING AND ASSESS THE SIGNIFICANCE OF AN APPARENT DIFFUSION COEFFICIENT (ADC) VALUE.

\section{$E S N R$}

Y. $\mathrm{Ihn}^{1}$, B. Kim ${ }^{2}$, K.S.J. $\mathrm{Ahn}^{3}$;

${ }^{1}$ St.Vincent's hospital, Suwon city/KR, ${ }^{2}$ St.Mary's hospital, Seoul city/KR, ${ }^{3}$ The Catholic University of Korea, Seoul/KR

\section{PURPOSE}

To describe the features of pyogenic ventriculitis on diffusion weighted MR imaging and assess the significance of an apparent diffusion coefficient(ADC) value for diagnosis of ventriculitis. MATERIAL AND METHODS

10 patients with ventriculitis were enrolled in this study. DiffusionWeighted MRI and ADC maps in the dependent intraventricular collection. Periventricular white matter and non dependent cerebrospinal fluid(CSF) were obtained. The images and ADC value data from the different lesions were compared.

\section{RESULTS}

The DW MRI showed marked hyperintensity in the purulent pus lesion and corresponding ADC maps revealed decreased ADC value compared with the non-dependent CSF and normal white matter.

CONCLUSION

The decreased ADC value and increased signal intensity of the dependent intraventricular fluid on the diffusion weighted image shows restricted water diffusion in the purulent fluid, which is indicative of a pyogenic ventriculitis diagnosis.

P61

MR ANATOMY AND PATHOLOGY OF VIRCHOW-ROBIN SPACES- PICTORIAL ESSAY

ESNR

C. Kesavadas ${ }^{1}$, R. Sheik ${ }^{2}$, B. Thomas ${ }^{2}$, A.K.K. Gupta ${ }^{2}$, T.R. Kapilamoorthy ${ }^{2}$, T. Krishnamoorthy ${ }^{2}$, N. Bodhey ${ }^{2}$;

${ }^{1}$ Sree Chitra Tirunal Institute for Medical Sciences \& Technology, Trivandrum/IN, ${ }^{2}$ SCTIMST, Trivandrum/IN

\section{PURPOSE}

Virchow-Robin (V-R ) spaces are cerebrospinal fluid spaces covered by pia that accompany arteries, arterioles, veins, and venules as they perforate the brain. The development of MR imaging permitted the detection of these small cerebrospinal fluidfilled perivascular spaces that are routinely visualized in regions of the anterior perforated substance, basal ganglia, cerebral convexity, and midbrain. The aim of our study is to understand the MR anatomy of $\mathrm{V}-\mathrm{R}$ spaces and to review the various pathological conditions that involve the V-R spaces.

MATERIAL AND METHODS

The MRI reports and films of the various pathological conditions with involvement of the V-R spaces were reviewed from our MRI database of the last five years.

RESULTS

The various conditions that enlarge these spaces include ischemic vascular dementia, autistic disorder, migraine, CADASIL, mucopolysaccharidoses, CNS cryptococcosis. Few conditions that caused enhancement of V-R spaces included vasculitis, ADEM, meningitis.

CONCLUSION

A knowledge of the normal appearing V-R spaces and the conditions that cause enlargement or enhancement of the these spaces helps in the differential diagnosis of various CNS pathologies. 
P62

EVALUATION OF RELIABILITY OF SINGLE VOXEL $1 \mathrm{H}$ MRS AND 2D TSI TO IDENTIFY RESIDUAL AND RELAPSED HIGH GRADE GLIOMA

ESNR

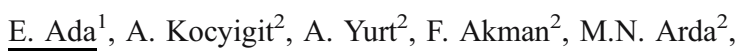
U. Acar ${ }^{2}$;

${ }^{1}$ Dokuz Eyl, Izmir/TR, ${ }^{2}$ Dokuz Eylul University Medical School, Izmir/TR

\section{PURPOSE}

To evaluate reliability for residual or relapsed high grade glial tumor and compare metabolite ratios on single voxel 1H MRS and 2D TSI for RT guiding.

\section{MATERIAL AND METHODS}

2D TSI images and single voxel (1VOI) spectra were obtained respectively by using point resolved spectroscopy sequence (PRESS) for localization and two phase encoding gradients for 19 patients after RT and 18 patients before RT. All were classified as tumor $(+)(n=24)$ and tumor $(-)(n=13)$ according to mainly MR spectroscopy and MRI findings on T2 weighted and contrast enhanced T1 weighted images. Cholin (Cho), Creatine $(\mathrm{Cr}), \mathrm{N}-$ Asetil Aspartate(NAA) maps were generated by spectroscopy soft ware of MR machine. Presence of tumor was recognized as brightness on Cholin map while low or no signal on NAA map. Single voxel spectra were localized on the bright area of cholin map. Multiple spectra obtained from metabolite maps by creating point were compared with $1 \mathrm{VOI}$ spectra. $\mathrm{Cho} / \mathrm{Cr}$, NAA/Cr ratios were compared for each technique and each category. Results were analyzed with Spearman's correlation test.

\section{RESULTS}

Strong and positive correlation was found between Cho/Cr's of 1 VOI and 2D TSI $(p<0,05)$. But there was no correlation between $\mathrm{NAA} / \mathrm{Cr}$ 's of each other. We found strong relation for detection of residual or relapsed tumor between two spectroscopy techniques $(\mathrm{p}<0,01)$ Mean values of $\mathrm{Cho} / \mathrm{Cr}$ and NAA/Cr on TSI and $1 \mathrm{VOI}$ were found as $2.63 \pm 1.22,1,84 \pm 0.77$, and $2.80 \pm 1.26,0.71 \pm 0.30$ respectively for tumor $(+)$ group while tumor $(-)$ group were $1.68 \pm 0.55,2.02 \pm 1.09$ and $1,156 \pm 0.76,0.98 \pm 0.34$.

CONCLUSION

TSI can be used for evaluation of residual or relapsed tumor identification due to its strong correlation with 1VOI on Cho to $\mathrm{Cr}$ ratio. Although mean value of NAA/ $\mathrm{Cr}$ is low on TSI and 1VOI for tumor $(+)$ group because of low mean value on 1VOI in tumor (-) group, it didn't demonstrate a good correlation between TSI and 1VOI.
P63

EVALUATION OF THE MANGANESE DISTRIBUTION IN PRIMATE AFTER WELDING FUME EXPOSURE

ESNR

H.S. Khang ${ }^{1}$, I.K. YU ${ }^{2}$;

${ }^{1}$ Seoul Health College, Sungnam/KR, ${ }^{2}$ Eulji university hospital, Daejeon/KR

\section{PURPOSE}

Welders working in a confined space, like in the shipbuilding industry, are at a risk of being exposed to high concentrations of welding fumes and other welding-fume exposure related diseases. Manganism resulting from welding-fume exposure remains a controversial issue in many country. Clinical and animal studies have raised the thpothesis that increased concentrations of manganese within the basal ganglia in patients. The increased signal intensity in the globus pallidus and subcortical frontal white matter in the T1-weighted image from welders further need to be identified for correspondence with the increase of manganese concentration. Therefore, to investigate the movement of manganese distribution after welding fume exposure, six cynomolgus monkeys were acclimated for a month and assigned to 3 dose groups : unexposed, low dose $\left(37 \mathrm{mg} / \mathrm{m}^{3}\right)$, and high dose $\left(63 \mathrm{mg} / \mathrm{m}^{3}\right)$ total suspended particulates. The primates were exposed to manual metal arc-stainless steel (MMA-SS) welding fume for $2 \mathrm{hrs}$ per day in an inhalation chamber system that is equipped with an automatic fume generator. Magnetic Resonance Imaging(MRI) study was performed before the initiation of exposure and thereafter every month.

\section{MATERIAL AND METHODS}

To investigate the manganese distribution in primate induced by welding-fume exposure, we desined the welding fume exposure system and generator. There are two exposure concentration. Low concentration is $31.36 \pm 2.75 \mathrm{mg} / \mathrm{m}^{3}$, and high concentration is $62.45 \pm 2.70 \mathrm{mg} / \mathrm{m}^{3}$. Exposure duration is $2 \mathrm{hrs}$ per day up to MRI signal and time points(TP) are $0,1,2,3,4,5,6,7$ months. Animals are 2 male cynomolgus monkey per dose. Welding condition is MMA-SS with robotic arm. The welding fumes in the chamber were sampled using a personal sampler(MSA 484107, Pittsburgh, PA) with a flow rate of 2 liters $/ \mathrm{min}$. An Anderson sampler(AN-200, Shibata, Tokyo, Japan) was used to measure the mass median aerodynamic diameters of the welding fumes. To measure the T1 relaxation time,TSE sequences echoes with different TR was used. MR scans were performed with a quadrature head coil on a 1.5 Tesla whole body system (Magnetom SONATA, Siemens Medical System, Erlangen, Germany). 


\section{RESULTS}

As building up Mn concentration in the blood, the decreases of T1 relaxation time in the basal ganglia were detected and maintained continuously, indicating inverse relationship between blood Mn concentration and $\mathrm{T} 1$ time.

\section{CONCLUSION}

The welding fume concentration and metal concentration in the exposure chamber shows even distribution at low and high dose chamber, repectively. There is a direct relationship between blood Mn concentration and high signal intensity in T1 weighted image at the basal ganglia area of brain.

\section{P64}

INVESTIGATION OF REGIONAL CEREBRAL BLOOD FLOW AND BLOOD VOLUME IN PATIENTS WITH HEAD INJURY AND ITS CONSEQUENCES USING CT-PERFUSION METHOD

ESNR

N. Zakharova ${ }^{1}$, A. Potapov ${ }^{2}$, I.N. Pronin ${ }^{3}$, L.M. Fadeeva ${ }^{2}$, D. Gunba ${ }^{1}$, V.N. Kornienko ${ }^{2}$;

${ }^{1}$ Burdenko neurosurgery institute, Moscow/RU, ${ }^{2}$ Burdenko Neurosurgery Institute, Moscow/RU, ${ }^{3}$ N.N. Burdenko Neurosurgery Institute, Moscow/RU

\section{PURPOSE}

To study the regional blood flow and blood volume rates in patients with head injury or its consequences.

\section{MATERIAL AND METHODS}

20 pts (age form 7 to $76 \mathrm{yrs}$ ) were examined using spiral CT tomography. Regional blood flow, blood volume rates and the mean transit time of the contrast media were analyzed in vascular beds of anterior, middle and posterior cerebral arteries of both hemispheres. The control research data (Wintermark M. et al. 2004) were used as normal reference values.

\section{RESULTS}

The study reveals that the regional cerebral flow rates are heterogeneous and the data from repeated research were the same. In three of the six comatose patients with underlying intracranial hypertension, rates of the regional blood flow and blood volume in the vascular beds of the anterior cerebral arteries were lower than the normal values (oligaemia). In another patient requiring haemodynamic support by vasopressors, cerebral blood flow and blood volume rates were dramatically higher than the normal values (hyperaemia), indicating the derangement of mechanisms of autoregulation. In four patients with severe consequences of the head trauma ( 3 - 4.5 month after injury) the sites of oligaemia were noted in middle and posterior cerebral arteries distribution. In three others with chronic subdural haematomas and minor neurological deficits no essential distinctions between the hemispheric blood flow rates were shown before and after surgical drainage.

\section{CONCLUSION}

CT-perfusion is the non-invasive method for simultaneous evaluation of the cerebral structure and haemodynamic disturbances. Therefore, additional data should be collected for more proper assessment of the results.

\section{P65}

ROLE OF 1H-MRS IN THE DISTINCTION OF NEOPLASTIC RECURRENCE VERSUS RADIATION EFFECTS

ESNR

R. Ricci ${ }^{1}$, A. Bacci ${ }^{1}$, V. Tugnoli ${ }^{2}$, H.A. Sheikh Maye ${ }^{1}$, S. Battaglia ${ }^{3}$, M. Maffei ${ }^{3}$, S. Agati ${ }^{4}$, M. Leonardi ${ }^{4}$; ${ }^{1}$ Ospedale Bellaria, Bologna/IT, ${ }^{2}$ Università degli Studi di Bologna, Bologna/IT, ${ }^{3}$ Bellaria, Bologna/IT, ${ }^{4}$ Ospedale di Bellaria, Bologna/IT

\section{PURPOSE}

Aim of the study is to evaluate the role of $1 \mathrm{H}-\mathrm{MRS}$ in discriminatig a neoplastic recurrence from a radio-induced lesion. MATERIAL AND METHODS

We examined with localized 1H-MRS 17 patients (12 male and 5 female, age 30-60) affected by cerebral tumors, 2 astrocytomas and 7 oligodendrogliomas low grade, 1 anaplastic oligodengroglioma, 3 anaplastic astrocytomas and 4 glioblastomas. All patients underwent surgical treatment or biopsy and radiotherapy. The exeresis of the tumor was total in 9 patients only. On the basis of the surgical treatment and the presence at MRI of enhancing tissue after gadolinium, we divided our cases into three groups. I group: patients with complete resection of the tumor without enhancing tissue (6 cases); II group: patients with complete resection of the tumor with enhancing tissue ( 3 cases); III group: patients with partial resection of the tumor or biopsy with enhancing tissue ( 8 cases). MRI controls were carried out in all patients and the follow-up included from 5 to 13 months. All $1 \mathrm{H}-$ MRS measurements were performed by a $3.0 \mathrm{~T}$ whole-body scanner (General Electric). Relative concentrations of N-acetylaspartate(NAA), Choline containing compounds(Cho), Creatine (Cr) and myo-Inositol(mI) were expressed by their ratios and compared with the values obtained in 16 healthy volunteers. RESULTS

MRI unchanged in the patients of the I group and showed a disease progression in those of the II and the III groups. In the I group, the NAA/Cr ratio were altered in 3 cases and the $\mathrm{Cho} / \mathrm{Cr}$ ratio was slightly above the control value (1.2) in 2 cases. Lactate and Lipids were present in 4 and in 2 patients, respectively. In the II group, NAA was not detectable in 2 cases. In all cases the Cho/ $\mathrm{Cr}$ ratio was above the control value (1.4-1.6), $\mathrm{mI}$ was not detected in a case and $\mathrm{mI} / \mathrm{Cr}$ was increased in the remaining 2 cases. Lactate and Lipids were present in 1 and in 2 patients, respectively. In the III group, NAA was not detectable in 2 cases, 
while the NAA/Cr ratio was reduced in 2 cases. The $\mathrm{Cho} / \mathrm{Cr}$ ratio was increased in all cases (1.4-1.8) but one. Lactate and Lipids were present in 4 and in 6 patients, respectively.

\section{CONCLUSION}

Among the main metabolites, the $\mathrm{Cho} / \mathrm{Cr}$ ratio was able to metabolically differentiate the presence of a neoplastic recurrence from a radio-induced lesion. Values higher than 1.4 were indicative of tumoral tissue, all the more so when associated to Lipids. Lactate did not discriminate the two kinds of lesions.

P66

DIAGNOSTIC EVALUATION OF PATIENT WITH WHITE MATTER CHANGES - COULD IT BE AN CLINICALLY ISOLATED SYNDROME SUGGESTIVE OF MULTIPLE SCLEROSIS? - A CASE REPORT

\section{$E S N R$}

K.S. Kacar ${ }^{1}$, A. Kacar ${ }^{2}$, S. Lavrnic ${ }^{3}$, S. Gavrilovic ${ }^{3}$, M. Jivancevic ${ }^{4}$, T. Stosic-Opincal ${ }^{3}$;

${ }^{1}$ Railway Health Care Institute "Belgrade", Belgrade/YU, ${ }^{2}$ Institute of neurology, CCS, Belgrade/YU, ${ }^{3}$ Clinical Center of Serbia, Belgrade/YU, ${ }^{4}$ Railway Health Care Institute, Belgrade/YU

\section{PURPOSE}

The mechanisms behind the demyelination that is characteric of multiple sclerosis (MS) are still poorly understand. The aim of this papper was to compare neurological findings and magnetic resonance imaging (MRI) and spectroscopy (MRS).

\section{MATERIAL AND METHODS}

We are presenting a 46-year old woman with right hemi paresis. MR imaging was performed by a 3T (Intera, Philips).

\section{RESULTS}

Until now, she has two attacks of transitory weakness and numbness half part of face and body (1984. and 2002). Blood and liquor tests were normal. VDRL was negative. Neuropsychological testing showed no specific cognitive impairment. Initial brain CT revealed cortical reduction with white matter lacunar ischemic lesions. MRI examination showed multiple asymmetrically focal lesions, dominant on left side, distributed in: subcortical and cortical fronto-occipital deep white-matter, both temporomedial lobe, corona radiate, basal ganglia, brain-stem, and right cerebellare hemisphere. Lesions were hyperintense on both T2weighed and FLAIR sequence, with no distinct borders and contrast enhancement, without perifocal edema. MR angiography was normal. Left occipital MR spectroscopy revealed reduced NAA, elevated Cho and myo-inositol, which is caracteristic as chronic demyelination. Other single voxel proton magnetic resonance spectroscopy has not detected any changes in cerebral metabolites ratios.

\section{CONCLUSION}

Considering the lesions localization, imaging characteristics and MR spectroscopy the diagnosis was demyelination disease - MS (benign or SP form). Differential diagnosis included: vasculitis, deficiency B12, acute disseminated encephalomyelitis (ADEM), SLE. MRI combined with MRS has proved its significance in the diagnostic evaluation of patients with minimal clinical presentation and unknown etiology.

P67

VENOUS SINUS THROMBOSIS - A CLINICAL STUDY AND SPECTRUM OF MRI AND MRV FINDINGS

\section{ESNR}

K.S. Kacar ${ }^{1}$, S. Lavrnic ${ }^{2}$, A. Kacar ${ }^{3}$, T. Stosic-Opincal ${ }^{2}$;

${ }^{1}$ Railway Health Care Institute "Belgrade", Belgrade/YU, ${ }^{2}$ Clinical Center of Serbia, Belgrade/YU, ${ }^{3}$ Institute of neurology, CCS, Belgrade/YU

\section{PURPOSE}

Cerebral venous sinus thrombosis is a rare disease with a heterogeniius clinical features and variety of simptoms. The aim of this study was to determine magnetic resonance venography (MRV) in conjuction with convenctional magnetics resonance imaging (MRI) for reliable diagnosis of venous sinus thrombosis. MATERIAL AND METHODS

10 patients underwent MRI (1,0 T-Siemens) in T1 and T2weighted axial, sagital and coronal sequences. We also aquired MRV images. At the time of examinations all patient have different symptoms: headache, focal deficit, epileptic seizures, impaired consciusness and papilloedema.

\section{RESULTS}

MRI was performed in all 10 patients and MRV was performed in 9 patients. The abnormalities of brain included multiple infarct unilaterally or bilaterally in 3 patients. Unilareral haemorrhagich infarct in 4 patients with thrombosis of the lateral and sigmoid sinuses. Multifocal haemorrhagic infarctions in both cerebral hemispheres in 2 cases. Falx cerebral meningeoma was found in 1 case.

CONCLUSION

Cerebral venous sinus thrombosis (CVST) often present with hemorrhagic infarction areas atypical for arterial vascular distribution. Magnetic resonance venography (MRV) in conjuction with convenctional MRI can accurately diagnose cerebral venous thrombosis because (CVST) may be difficult to diagnoses clinically of various nonspecific manifestation. 


\section{P68}

DIFFUSE CRANIAL NERVE AND CAUDA EQUINA LESIONS ASSOCIATED WITH BREAST CANCER

ESNR

K. Nomiyama, A. Uchino, Y. Yakushiji, M. Kosugi, Y. Takase,

S. Kudo;

Saga Medical School, Saga/JP

\section{PURPOSE}

Background and Purpose: There are several types of paraneoplastic syndrome including sensorimotor neuropathy. We report a case of presumed paraneoplastic sensorimotor neuropathy associated with breast cancer.

\section{MATERIAL AND METHODS}

A 56-year-old woman in whom double vision and gait disturbance had recently developed was transferred to our institution from a local private hospital. Neurologic examination revealed oculomotor nerve palsy and spinal nerve dysfunction.

\section{RESULTS}

Magnetic resonance (MR) imaging of the brain and spinal cord showed diffuse abnormal enhancement without definite enlargement of the cranial nerves or cauda equina, suggesting blood-nerve barrier disruption. There was no associated brain or spinal cord lesion. On the basis of the MR findings, chronic inflammatory demyelinating polyneuropathy was tentatively diagnosed. After neuroradiologic examinations, cancer with multiple bone metastases was found in the left breast. Thus, both paraneoplastic sensorimotor neuropathy and diffuse metastases to the nerves were added to the possible diagnosis. Because there was no definite enlargement of the nerves, diffuse metastases were unlikely. Therefore, the final diagnosis was paraneoplastic sensorimotor neuropathy. However, results of subsequent testing for several antineural antibodies were negative.

\section{CONCLUSION}

Conclusion: We should exam whole body, especially breast, to find a cancer when we observed diffuse abnormal enhancement without definite enlargement of the cranial nerves or cauda equina on MR images.

\section{P69}

EVALUATION OF MANGANESE DISTRIBUTION IN PRIMATE AFTER WELDING FUME EXPOSURE

\section{ESNR}

H.S. Khang ${ }^{1}$, B. Lee ${ }^{2}$, H.J. Kim ${ }^{3}$, I.K. YU ${ }^{4}$, S.O. Yang ${ }^{2}$, H. Yang ${ }^{1}$; ${ }^{1}$ Seoul Health College, Sungnam/KR, ${ }^{2}$ Eulji University Hospital, Daejeon/KR, ${ }^{3}$ Eulji University, Daejeon/KR, ${ }^{4}$ Eulji University Hospital, Daejeon/KR
PURPOSE

Welders working in a confined space, like in the shipbuilding industry, are at risk of being exposed to high concentrations of welding fumes and developing pneumoconiosis or other weldingfume exposure related diseases. Among such diseases, manganism resulting from welding-fume exposure remains a controversial issue, as the movement of manganese into specific brain regions has not been clearly established.In this study, to investigate manganese distribution after welding fume-exposure, six cynomolgus monkeys were acclimated for a month and assigned to 3 dose groups: unexposed, low dose and high dose total suspended particulates.

\section{MATERIAL AND METHODS}

Welding fume exposure system and generator were desined newly. In the exposure concentration, Low's $31 \mathrm{mg} / \mathrm{m}^{3}$ and High's $62 \mathrm{mg} / \mathrm{m}^{3}$. The primates were exposed to manual metal arcstainless steel (MMA-SS) welding fume for 2 hrs per day up to increase MRI signal in an inhalation chamber system that is equipped with an automatic fume generator.MRI studies were performed before the initiation of exposure and thereafter every month. Animals are 2 male cynomolgus monkeys per dose. Welding condition is MMA-SS (with robotic arm). Mn was measured in the Blood, lung, liver, brain. MRI scans were performed on a $1.5 \mathrm{~T}$ Whole body system.Turbo Spin Echo sequence was used which having different TR's and same TE.

RESULTS

Time-dependent increases of $\mathrm{Cr}$ were observed in the blood of the exposed primates exposed for 1 month and the blood $\mathrm{Mn}$ concentration showed a significant increase from 3 months of exposure and reached a plateau at 100 days of exposure, showing at least more than 60 days of exposure period were required to build up blood Mn concentration. As building up Mn concentration in the blood, the decreases of $\mathrm{T} 1$ time in the basal ganglia were detected and maintained continuously, indicating inverse relationship between blood $\mathrm{Mn}$ concentration and $\mathrm{T} 1$ time.

\section{CONCLUSION}

The welding fume concentration and metal concentration in the exposure chamber shows even distribution at low and high dose chamber. The MMD of welding fume particles in the exposure chamber is $0.5 \mathrm{im}$. The $\mathrm{Mn}$ concentration in the exposed group peaked after 90 days of welding fume exposure, indicating at least 60 more days of exposure period were required to build up blood $\mathrm{Mn}$ concentration. There is a direct relationship between blood Mn concentration and high signal intensity at the basal ganglia area of brain (inverse relationship between blood Mn concentration and T1 time). 
P70

SPORADIC SCHWANNOMA OF THE RADIAL NERVE WITHOUT NEUROFIBROMATOSIS

ESNR

V.K. Katsaros ${ }^{1}$, E. Kyrkou ${ }^{2}$, A. Katsarou ${ }^{3}$, V. Venizelos ${ }^{4}$; ${ }^{1}$ IKA Oncology Hospital, Holargos-Athens/GR, ${ }^{2}$ Oncology Hospital IKA, Athens/GR, ${ }^{3}$ Red Cross Hospital Athens, Athens/GR, ${ }^{4}$ IKA Oncology Hospital, Athens/GR

\section{PURPOSE}

To present a rare case of sporadic Schwannoma of the radial nerve discovered spontaneously.

MATERIAL AND METHODS

A 40-year-old, right hand dominant male presented to a general surgeon with a several-week history of an enlarging, firm, mobile mass in his right axilla. He was admitted to our institution, for a thorax -CT, and then MRI. A mass in the right axilla was discovered. The MRI sequences included T2-, proton density, STIR (fat suppression T2-W) images, T1-W images and T1-W fat saturation images, before and after i. v. Gd chelate administration. MR arteriography was also performed.

RESULTS

On CT a space-occupying lesion was demonstrated in the right axilla. The margins were normal and discrete and the density was similar to soft tissue mass. On MRI the signal intensity behaviour was inhomogeneous in all sequences. After i. v. Gd chelate administration the lesion showed inhomogeneous enhancement and was described more precisely. The MR-arteriography excluded the possibility of an axillary artery aneurysm or an AVM. Our differential diagnosis included Schwannoma and lymph-node enlargement. Postoperative course was uneventful, except for partial palsy of the ipsilateral radial nerve.

\section{CONCLUSION}

The final pathological examination showed findings consistent with Schwannoma of the radial nerve.

\section{P71}

\section{FIBROUS HISTIOCYTOMA OF THE LACRIMAL GLAND}

$E S N R$

$\underline{\text { V.K. Katsaros }^{1}}{ }^{\text {, P. Lampropoulou }}{ }^{2}$, M. Mitropoulou ${ }^{2}$,

A. Nikolaou ${ }^{2}$, C. Drossos ${ }^{2}$;

${ }^{1}$ IKA Oncology Hospital, Holargos-Athens/GR, ${ }^{2}$ IKA Oncology Hospital, Athens/GR

\section{PURPOSE}

Fibrous histiocytoma is a slow-growing tumor that most commonly occurs in the superficial and deep soft tissue, with an occasional occurrence in the orbit. However, fibrous histiocytoma of the lacrimal gland is very rare.

MATERIAL AND METHODS

A 44-year-old female with a palpable mass in the right lacrimal gland and epiphora was admitted to our institution. CT and MRI including T2-, proton density, STIR (fat suppression T2-W) images, T1-W images and T1-W fat saturation images, before and after i. v. Gd chelate administration, were performed.

RESULTS

A large space-occupying lesion was demonstrated, in the right orbit, presumably arising from the lacrimal gland. The margins were normal and discrete, and the signal intensity behaviour was inhomogeneous in all sequences. After i. v. Gd chelate administration the lesion showed intense enhancement and was described more precisely. CT revealed the presence of calcifications. FNA biopsy was performed, but the pathology results were inconclusive. The patient underwent a surgical excision of the mass.

CONCLUSION

The final pathological examination showed findings consistent with fibrous histiocytoma of the lacrimal gland.

P72

HEMORRHAGIC SCHWANNOMA OF THE IAC

ESNR

$\underline{\text { V.K. Katsaros }}$

IKA Oncology Hospital, Holargos-Athens/GR

\section{PURPOSE}

To present a rare case of hemorrhagic Schwannoma of the IAC, discovered spontaneously.

\section{MATERIAL AND METHODS}

A 56-year-old male was admitted to our institution, for an IAC MRI, reporting an acute onset of vertigo and tinnitus ten days ago. The MRI included T2-, proton density, STIR (fat suppression T2W) images, CISS 3D, T1-W images and T1-W fat saturation images, before and after i. v. Gd chelate administration, as well as diffusion weighted images.

RESULTS

MRI revealed a tumor in the right cerebellopontine angle. The margins were normal and discrete, and the signal intensity behaviour was inhomogeneous in all sequences, with hemorrhagic components. After i. v. Gd chelate administration the lesion showed enhancement and was described more precisely. Diffusion weighted images excluded the possibility of epidermoid cyst or abscess. CONCLUSION

The diagnosis, based on the combination of clinical and MRI findings, was consistent with intratumoral hemorrhage of an acoustic Schwannoma. 
P73

THE INFLUENCE OF IMAGING CONDITIONS ON THE RELAXIVITY AND ENHANCEMENT EFFECT OF MR CONTRAST AGENTS

\section{ESNR}

M. Essig ${ }^{1}$, F.L. Giesel ${ }^{2}$, V.M. Runge ${ }^{3}$, I.D. Wilkinson ${ }^{4}$; ${ }^{1}$ German Cancer Research Centre, Heidelberg/DE, ${ }^{2}$ German Cancer Research Center, Heidelberg/DE, ${ }^{3}$ Scott \& White Clinic, Temple/US, ${ }^{4}$ University of Sheffield, Sheffield/GB

\section{PURPOSE}

Multiple factors determine both longitudinal and transverse relaxation rates ( $\mathrm{R} 1 \& \mathrm{R} 2)$ associated with the presence of exogenous contrast media. As the choice of available MR contrast agents and the range of possible MRI field strength increases, knowledge of the interaction of MR contrast agents with imaging variables becomes critical. Herein, we review the variables that affect MR contrast agent relaxivity, and thus the enhancement effect in vivo.

\section{MATERIAL AND METHODS}

Several recently published studies on the relaxivity and enhancement mechanism of gadolinium-based contrast agents were reviewed. Three contrast agents were studied: a non-protein interacting $0.5 \mathrm{M}$ agent (Gd-DTPA), a non protein interacting $1 \mathrm{M}$ agent (Gd-DO3A-butrol), and a $0.5 \mathrm{M}$ agent that interacts weakly and transiently with serum albumin (Gd-BOPTA). Studies were conducted to determine the relaxivity and accurate relaxation rates of these agents in human plasma and to compare their relaxation times at various field strengths.

RESULTS

Overall, the relaxivity of a given gadolinium agent depends on the conditions under which relaxivity is assessed. Proton relaxation times shorten (and thus enhancement increases) with higher field strengths. Higher field strengths resulted in lower values of R1, $\mathrm{R} 2$, and $\mathrm{r} 1$ for all contrast agents tested and of $\mathrm{r} 2$ for Gd-DTPA and Gd-DO3A-butrol. For Gd-DTPA and Gd-BOPTA the R1 decreased by $10 \%$ and $20 \%$ respectively at $3 \mathrm{~T}$ compared to $1.5 \mathrm{~T}$. While the relaxivity of gadolinium agents tends to be comparable when measured in water, some agents (such as Gd-BOPTA) show increased relaxivity (i.e., shorter transverse and longitudinal relaxation times) in the presence of serum proteins. Theoretical calculations showed that Gd-BOPTA provides the highest signal increase at any given TR and benefits most from the use of short TE and flip ankle measurements.

\section{CONCLUSION}

The use of an agent with increased relaxivity can compensate the reduced signal intensity enhancement and signal loss that are characteristic of sequences with short TE imaging both in structural MRI and MR angiography. The advantage of a higher relaxivity agent over conventional gadolinium agents is evident at all magnetic field strengths. A better understanding of the factors influencing the contrast enhancement provided by gadolinium-based agents under various imaging conditions will enable neuroradiologists to maximize contrast enhancement, and thus diagnostic efficacy, while minimizing dose and cost related to the imaging study.

P74

DIFFUSION-WEIGHTED MR IMAGING OF VIRAL ENCEPHALITIS

ESNR

Y. KİROGLU ${ }^{1}$, C. Calli ${ }^{2}$, N. Yünten ${ }^{2}$, O. Kitis ${ }^{2}$, N. Karabulut ${ }^{3}$; ${ }^{1}$ Pamukkale University, Medical school, Denizli/TR, ${ }^{2}$ Medical school of Ege university, izmir/TR, ${ }^{3}$ Pamukkale University Hospital, DENIZLI/TR

\section{PURPOSE}

This study was performed to evaluate the role of diffusionweighted (DW) MR imaging in the diagnosis of viral encephalitis and its relationship with the stage of the illness.

MATERIAL AND METHODS

18 patients suspected of having encephalitis underwent MR imaging examination that included DWI. The final diagnosis was established on the basis of signs, symtoms, electroencephalographic findings (EEG), cerebrospinal fluid (CSF) analysis and serologic tests. The abnormal imaging areas seen on MR examination and DWI were divided into three groups according to clarity of the lesions: Group I, DWI is superior to conventional MR imaging. (Group Ia, the number and extent of the affected sites were greater at DWI; Group Ib, the number of the affected sites were equal but extent of them were superior at DWI. Group Ic, no abnormal signal on conventional imaging while they were seen on DWI. Group II, the number and extent of the affected sites were equal on DWI and the conventional MR imaging. Group III, the number and extent of the affected sites on conventional MR imaging were superior to DWI.

RESULTS

In 11 out of 18 patients DWI was superior to the conventional imaging (Group I). Three patients were in group Ia, DWI detected greater number of encephalitic lesions and depicted the borders of the lesions more broadly. Six patients were in group Ib, DWI and conventional MR imaging detected equal number of the encephalitic sites but extent of the lesion areas in DWI were larger. In Two patients were in group Ic, the abnormal signals were seen only on DWI. Four of the 18 patients were in group II, the number and extent of the lesions were relatively equal at each technique. Three patients represented group III, the number and the extent of the lesions on conventional imagings was absolutely superior to the DWI. Patients in group I had a significantly lower ADC compared with group II (P value $<0.01)$. 


\section{CONCLUSION}

DW-MR imaging is superior to other diagnostic MR imaging sequences in the detection of early encephalitic lesions and also helpful in the determination of the disease stage.

P75

METABOLIC FINDINGS OF THE PERILESIONAL CEREBRAL EDEMA STUDIED BY $3 \mathrm{~T}$ 1H-MRS

\section{$E S N R$}

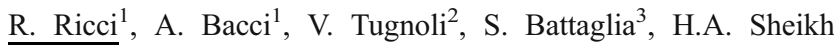
Maye $^{1}$, M. Maffei ${ }^{3}$, S. Agati ${ }^{4}$, M. Leonardi';

${ }^{1}$ Ospedale Bellaria, Bologna/IT, ${ }^{2}$ Università degli Studi di Bologna, Bologna/IT, ${ }^{3}$ Bellaria, Bologna/IT, ${ }^{4}$ Ospedale di Bellaria, Bologna/IT

\section{PURPOSE}

Aim of this study is to evaluate by $1 \mathrm{H}-\mathrm{MRS}$ the metabolic aspects of cerebral tissue involved by edema surrounding different kinds of tumors and a cavernous hemangioma.

\section{MATERIAL AND METHODS}

We examined with localized in vivo 1H-MRS 21 patients (12 male and 9 female, age 35-84) affected by cerebral lesions. 13 patients were operated and the histological diagnosis were: 7 glioblastomas, 1 metastases, 4 meningiomas and 1 cavernous hemangioma. 8 patients were not surgically treated because of the site or the number of lesions. The supposed diagnosis in that cases were high grade glioma in 3 patients (MR findings) and metastasis in 5 (presence of a primitive tumor). All 1H-MRS measurements were performed by a $3.0 \mathrm{~T}$ whole-body scanner (General Electric Medical Systems, Milwaukee, Wisconsin), using the standard 8 channels phased array head coil. Spectra were obtained by a point-resolved spin echo sequence (PRESS) for localization, with TR $2000 \mathrm{~ms}$ and TE $35 \mathrm{~ms}$, and a three-pulse chemical-shift selective saturation sequence (CHESS) to provide water suppression. All spectra were analysed using the SAGE program (GE Medical Systems). Relative concentrations of $\mathrm{N}$-acetyl-aspartate (NAA), Choline containing compounds (Cho), Creatine (Cr) and myo-Inositol (mI) were expressed by NAA/Cr, NAA/Cho, Cho/Cr e $\mathrm{mI} / \mathrm{Cr}$ ratios and compared with the values obtained in 16 healthy volunteers in the left frontal area (NAA/Cr $1.8+/-0.3$; NAA/Cho $2+/-0.4$; Cho/Cr $0.9+/-0.2 ; \mathrm{mI} / \mathrm{Cr} 0.6+/-0.2$ ).

\section{RESULTS}

All the spectra showed metabolic patterns different from unaffected brain tissue. In 19 cases we detected very high amount of Glutamate plus Glutamine (Glx) and Glucose. Lactate were detected in 13 cases and Lipids in 8. Interestingly the resonances pertaining to Aminoacids Valine, Leucine e Isoleucine were prominent in 12 cases. NAA/Cr ratio was decreased in 5 cases, 3 glial tumors, 1 meningioma and the cavernous hemangioma, while it was increased in a metastasis where was also strongly increased the $\mathrm{Cho} / \mathrm{Cr}$ ratio.

CONCLUSION

The signal alteration, characteristic of the edematous cerebral tissue, is generally correlated to an increased amount of water. However our results suggest that the signal alteration could be also associated to an important metabolic alteration involving not only neuronal function but also energetic and proteic metabolism.

P76

QUANTIFICATION OF LACTATE IN BRAIN DISEASE USING PROTON MR SPECTROSCOPY

ESNR

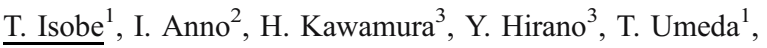
A. Matsumura ${ }^{3}$;

${ }^{1}$ Kitasato University, Sagamihara/JP, ${ }^{2}$ Graduate School of Comprehensive Human Sciences, Tsukuba/JP, ${ }^{3}$ University of Tsukuba, Tsukuba/JP

\section{PURPOSE}

Lactate is an important metabolite in clinical cases that can indicate the status of metabolic impairment. We applied a clinically relevant simple method for lactate quantification using proton MR spectroscopy (MRS).

MATERIAL AND METHODS

We used a lactate phantom with known concentrations. As a clinical example, we evaluated a patient with mitochondrial myopathy, encephalopathy, lactic acidosis and stroke-like episodes (MELAS). Proton MRS was performed using a clinical 1.5 T super-conducting MR system. Data were acquired by point resolved spectroscopy (PRESS). A coupling constant of $\mathrm{J}=7.35 \mathrm{~Hz}(2 / \mathrm{J}=272 \mathrm{~ms})$ and two long in-phase TEs of $272 \mathrm{~ms}$ and $544 \mathrm{~ms}$ were used to calculate the T2 relaxation time. The tissue water signal was used as an internal standard to quantify lactate.

RESULTS

The correlation coefficient $\mathrm{R}$, between the calculated lactate concentrations and the known concentration of lactate was 0.99 with a constant factor of $0.32(=1 / 3.14)$. In patients with MELAS, the lactate concentration measured by MRS was $6.2 \mathrm{mmol} / \mathrm{kg}$ wet weight, which is similar to the value obtained in previous studies.

CONCLUSION

In the present study, we have established a reliable method for lactate quantification in a phantom study and have shown the successful analysis of a sample in a clinical case of MELAS. 


\section{P77}

SYRINGOMYELIA ASSOCIATED WITH THE HINDBRAIN WITHOUT ARNOLD-CHIARI MALFORMATION IN COMBINATION WITH SCOLIOSIS OF SPINAL THORACOCERVICAL JUNCTION

ESNR

$\underline{\text { V.K. Katsaros }}^{1}$, A. Mitropoulos ${ }^{2}$, P. Lampropoulou ${ }^{3}$, M. Mitropoulou ${ }^{3}$, N. Georgakoulias ${ }^{2}$, C. Drossos ${ }^{3}$; ${ }^{1}$ IKA Oncology Hospital, Holargos-Athens/GR, ${ }^{2}$ Athens General Hospital, Athens/GR, ${ }^{3}$ IKA Oncology Hospital, Athens/GR

\section{PURPOSE}

The majority of cases with syringomyelia associated with the hindbrain (73\%) are due to Arnold-Chiari malformation. Cases of syringomyelia associated with the hindbrain, without ArnoldChiari malformation, are very rarely reported in the literature.

\section{MATERIAL AND METHODS}

A case of a 33-years-old male patient with history of anidrosia of the right part of the face and body, weakness of the left upper limb and mild spasticity of the left lower limb will be presented. MRI and surgical findings will be reported.

\section{RESULTS}

The neuroimaging control showed syringomyelia in the level between $\mathrm{C} 1$ and Th3 vertebral bodies. Severe scoliosis in the thoracocervical junction of the spine was also present, without Arnold-Chiari malformation. The surgical findings included presence of a diaphragm in the region of the Magendie foramen and gliotic cerebellar tonsils, which were resected. The clinical picture after surgery improved promptly with diaphoresis of the affected body part and improvement of the weakness of the left upper limb. Two months later, while the patient showed constant clinical improvement, the follow-up cervical and thoracic spine MRI demonstrated clear reduction of the syringomyelic cavity. The scoliosis of the spine was constant.

\section{CONCLUSION}

The relevant literature will be reviewed and the pathophysiology, the imaging findings, the surgical approach and the resulting improvement of the patient will be discussed.

P78

CLINICAL IMPLICATIONS OF A VERY RARE ANOMALY OF BOTH VERTEBRAL ARTERIES

\section{ESNR}

T. Seipel ${ }^{1}$, T. Jimenez ${ }^{1}$, A. Arat $^{2}$, R. Fischer ${ }^{1}$, C. Whigham ${ }^{1}$; ${ }^{1}$ Baylor College of Medicine, Houston/US, ${ }^{2}$ Houston/US
PURPOSE

We present a patient with anomalous origins of both vertebral arteries, as additional supra-aortic trunks. To our knowledge, this is the second patient in the literature with this anomalous predispositon. Unlike the previous report, the anomaly had significant impact on the management of our patient.

MATERIAL AND METHODS

A 54-year old male presented to the emergency center following a motor vehicle accident. A contrast-enhanced CT angiography (CTA) of the chest, abdomen, and pelvis were performed and revealed a large traumatic pseudoaneurysm of the proximal descending thoracic aorta. A bovine arch and anomalous origins of the vertebral arteries were noted. A subsequent digital subtraction angiography of the thoracic aorta and cerebral blood vessels was performed to better characterize the anomalous vessels' relationship to the aortic injury as well as to identify completeness of the circle of Willis in anticipation of endovascular repair.

RESULTS

On arteriogram, the left vertebral artery originated from the aorta, distal to the left subclavian artery and proximal to the origin of the right vertebral artery. It followed a retroaortic/retroesophageal course and entered the foramen transversarium at C6 level. Moreover, right vertebral artery originated postero-superiorly at the level of the large pseudoanuerysm which involved at least $2 / 3$ of the circumference of the proximal descending aorta. Small (less than 1-mm) posterior communicating arteries were identified. Note was also made of a fenestration of the proximal basilar artery. Based on the proximity of the origins of the vertebral arteries to the aortic dissecting aneurysm, the decision to proceed with endovascular stent-graft was aborted. The graft would cover the origins of both vertebral arteries, possibly resulting in major posterior circulation stroke. Instead the patient was managed with conservatively with an option for surgical intervention later.

CONCLUSION

This is not only a rare vertebral artery variant together with a relatively infrequent injury, but also an example of the superior ability of CTA in depicting cervical vascular anatomy. In this case, the diagnosis may have been easily missed without a CTA and resulted in potential morbidity or fatality.

P79

UNUSUAL MENINGEAL MASSES: MR AND PATHOLOGIC CORRELATION AND REVIEW OF THE LITERATURE

ESNR

$\underline{\text { I.K. YU }}^{1}$, B. $\mathrm{Lee}^{2}$, H.J. Kim ${ }^{3}$, C.J. SONG ${ }^{4}$; ${ }^{1}$ Eulji University Hospital, Daejeon/KR, ${ }^{2}$ Eulji University Hospital, Daejeon/KR, ${ }^{3}$ Eulji University, Daejeon/KR, ${ }^{4} \mathrm{CHUNGNAM}$ NATIONAL UNIVERSITY HOSPITAL, DAEJEON/KR 


\section{PURPOSE}

To understand the MR features of unusual meningeal masses by demonstrating MR and pathological features of intraparenchymal mass-looking meningeal masses and meningioma-looking unusual meningeal lesions and reviewing the literature.

\section{MATERIAL AND METHODS}

We will present the clinical, MR and pathological features of intraparenchymal mass-looking meningeal masses including angiomatous, atypical, chordoid, clear cell, rhabdoid, anaplastic meningiomas, hemangiopericytoma and other meningioma-looking unusual meningeal lesions inculding dural lymphoma, en-plaque type meningioma, idiopathic hypertrophic pachymeningitis and meningeal melanosis.

\section{RESULTS}

Unusual meningeal masses such as angiomatous, atypical, chordoid, clear cell, anaplastic, rhabdoid meningiomas and hemangiopericytomas are often misdiagnosed as being malignant intra-axial masses, while other types of unusual meningeal masses such as dural lymphoma, en-plaque type meningioma, idiopathic hypertrophic pachymeningitis and meningeal melanosis as being benign meningiomas or even subdural or subarachnoid hematoma because of their various mimicking features.

\section{CONCLUSION}

Unusual meningeal masses are often misdiagnosed as being malignant intraaxial masses or simple meningioma or even extracerebral hematoma because of their various mimicking features. To understand the clinical, MR and pathological features of them facilitate the accurate diagnosis and the appropriate treatment.

\section{P80}

\section{IMAGING OF NONTRAUMATIC SCALP MASSES}

\section{$E S N R$}

Y. Kim, K. Kim;

Uijongbu St. Mary’s Hospital, Uijongbu/KP

\section{PURPOSE}

A wide variety of disease processes involve the extracalvarial soft tissues. These lesions are usually apparent on physical examination. The purpose of our exhibit is to illustrate a pictorial review of the CT and MRI findings of different types of lesions presenting as palpable scalp mass.

\section{MATERIAL AND METHODS}

We evaluated MR and CT images of many disease entities involving the extracalvarial soft tissue. Each one of the cases was pathologically or angiographically proven.

\section{RESULTS}

We categorized various disease entities involving the extracalvarial soft tissue into 1) congenital \& developmental, 2) vascular, 3) inflammatory, 4) neoplastic, and 5) miscellaneous lesions.

\section{CONCLUSION}

This exhibit illustrates variable disease entities involving the scalp.

\section{P81}

PYOGENIC VENTRICULITIS : CT AND MR IMAGING FINDINGS

ESNR

$\underline{\text { L.R. Lopes-Melo }}^{1}$, A. Ederies ${ }^{2}$, A. Saddiqui ${ }^{3}$, R. Sousa ${ }^{4}$, J. Ruivo ${ }^{5}$, P. Sequeira ${ }^{5}$, J. Campos ${ }^{5}$;

${ }^{1}$ Lisboa/PT, ${ }^{2}$ National Hospital of Neurology and Neurosurgery, London/GB, ${ }^{3}$ National Hospital for Neurology and Neurosurgery, London/GB, ${ }^{4}$ Hospital de Santa Maria, Lisboa/PT, ${ }^{5}$ Hospital Santa Maria, Lisboa/PT

\section{PURPOSE}

Pyogenic ventriculitis with purulent ventricular debris is an uncommon manifestation of complicated purulent meningitis. Clinically indolent, it may be source of persistent infection, therapeutic failure and even fatal outcome. Seldom have its imaging features on $\mathrm{CT}$ and MR been described in adults.

MATERIAL AND METHODS

A series of 3 adult male patients with complicated pyogenic meningitis were studied by CT and MR Imaging. Each study was evaluated for complications of meningitis such as ventriculomegaly, ventricular debris, choroid plexitis, ependymal enhancement, periventricular changes, parenchymal involvement and pial/dural enhancement.

RESULTS

The CT studies showed obstructive ventriculomegaly and parenchymal involvement in all three cases, with one case of cerebral abscess and two with tumour-like cerebritis. Only in one patient did CT show ventricular debris. MRI however demonstrated evident intraventricular debris in all three patients which was best seen on the Fluid-attenuated Inversion Recovery (FLAIR) and Proton-Density (PD) sequences. Besides parenchymal involvement and ventriculomegaly other findings, which were evident in all patients on MRI, were signs of choroid plexitis, ependymal and pial/dural enhancement.

\section{CONCLUSION}

MR Imaging is a very useful non-invasive imaging tool to characterize pyogenic ventriculitis, which may complicate bacterial meningitis. With $\mathrm{T} 2 *$ and FLAIR sequences it is also possible to differentiate ventricular fluid signal intensity and thereby differentiate blood from purulent debris. Multiplanar MR Imaging allows prompt and accurate diagnosis of ventriculitis, which has significant implications on the management and the clinical outcome. 
P82

\section{CEREBRAL HYDATID CYST: MR AND MRS PATTERN}

ESNR

\author{
N. ARIFA-ACHOUR ${ }^{1}$, K. DHAHBI ${ }^{1}$, F. EL OUNI $^{1}$, \\ H. JEMNI-GHARBI ${ }^{1}$, H. KRIFA ${ }^{1}$, K. TLILI-GRAIESS ${ }^{2}$; \\ ${ }^{1}$ Faculte Medecine Sousse, Sousse/TN, ${ }^{2}$ Faculte Medecine Sousse, \\ El Kantaoui Sousse/TN
}

\section{PURPOSE}

Proton MRSpectroscopy (MRS) has been found to be useful in differentiating various intra cranial cystic lesions. The purpose of the present study is to describe the MR and MRS pattern of 5 intra cranial hydatid cystic (HC) and demonstrate the typical MR and MRS features of this entity.

\section{MATERIAL AND METHODS}

5 patients aged from 2 to 18 years were evaluated with MR imaging including non enhanced and enhanced T1, T2, Fluid attenuated inversion recovery (FLAIR) and diffusion sequences. 2 cases included MRS evaluation with single voxel press technique at echotime $35 \mathrm{~ms}$ ( 1 case) and multivoxel 2 Dimensional Chemical Shift Imaging at echo time $144 \mathrm{~ms}$ (1 case).

\section{RESULTS}

Round shaped and well defined cystic area with thin hypo intense rim on T2 weighted images and a CSF like signal on all sequences including diffusion was demonstrated in all cases. The $\mathrm{HC}$ was unique in 4 cases, intra aqueducal in 1 and thalamic in 1 . A surrounding oedema and wall enhancement were noted in 1 case resulting from cyst rupture.In the 2 cases, MRS demonstrated intra cystic lactate, large resonance of pyruvate and alanine.

\section{CONCLUSION}

MR and MRS pattern appears typical of $\mathrm{HC}$ and different from that seen in other cystic lesions of the central nervous system. MRS offers another tool of characterisation of intra cranial HC.

\section{P83}

\section{ACUTE DISSEMINATED ENCEPHALOMYELITIS ASSOCI-} ATED WITH ACUTE BACTERIAL MENINGITIS

\section{ESNR}

M.Q. Ribeiro, P. Beleza, J. Rocha, F. Almeida;

Hospital Sao Marcos, Braga/PT

\section{PURPOSE}

Introduction: Acute disseminated encephalomyelitis is a monophasic desmielinieting disease of central nervous system that usually arises after a respiratory infection or vaccination. Parainfectious ADEM associated with meningitis is a rare entity and it is crucial that it be considered to make an early diagnosis and give appropriate treatment.

\section{MATERIAL AND METHODS}

Case Report: A 19-year-old boy was admitted to our emergency department having suffered occipital headache and fever for the previous 12 hours together with respiratory infection over the last week. He was under corticotherapy because had had a glomeropaty - minimal change disease - diagnosed 9 months before. In the examination, he had stiffness of the neck, but otherwise was unremarkable. Cerebral computer tomography (CT) was normal. CSF examination was compatible with bacterial meningitis (1120 cel/mm3 - 78\% Neutrofils - $1.44 \mathrm{~g} / \mathrm{L}$ proteins, $41 \mathrm{mg} / \mathrm{dL}$ glucose $-39 \%$ glycaemia) with capsular antigens for Haemophilus influenzae B. He began antibiotherapy but suffered clinical deterioration after 24 hours with prostration and bilateral irritative pyramidal syndrome that evolved into coma on the following day. Cerebral CT was repeated and showed multiple none-enhanced hypodensities spread in both cerebral hemispheres located in profound and subcortical white matter and right basal ganglia. Cerebral magnetic resonance (MR) was carried out and revealed multiple nodular lesions with high-signal in long TR ponderations in the white matter, profound grey matter bilaterally, and brain stem. There was no blood-brain-barrier rupture or diffusion restriction. He began corticotherapy (metilpredinisolone) and recovered consciousness progressively and improved neurological deficits. Cerebral MR was repeated after 16 days showing great improvement with only residual lesions. He was discharged with a diagnosis of para-infectious ADEM.

RESULTS

see conclusions

CONCLUSION

Conclusion: To our knowledge, this is the first case described of para-infectious ADEM caused by Haemophilus influenzae type B. It is imperative to be aware of this entity to be able to carry out an early diagnosis and prompt treatment. We must stress the vital importance of MR in complicated bacterial meningitis with deterioration of consciousness and focal deficits to make a differential diagnosis with vasculitis or cerebritis.

P84

INTRAMEDULLARY TERATOMA ASSOCIATED WITH A LIPOMA ALONG SPINAL CORD

ESNR

M.Q. Ribeiro, J. Fernandes, J. Rocha, J. Cerqueira; Hospital Sao Marcos, Braga/PT

\section{PURPOSE}

Intramedullary teratoma is a rare congenital tumor that contains tissues originated from three germinal layers and is associated with dysraphic congenital malformations.This combination suggests 
disarrangement of embryological development occurring simultaneously. The authors report a case of intramedullary teratoma at the level of the conus, associated with a lipoma.

\section{MATERIAL AND METHODS}

A 30 year-old woman presented with an acute violent headache. She was discharged after a normal cerebral CT. Subsequently, she began complaining of progressive weakness and numbness in her left leg for eight months, after which she sought medical attention. The neurological examination revealed monoparesis of the left lower limb, with hiperreflexia and Babinski. Spinal MRI revealed a large intramedulary lesion at the level of conus medularis from D10-L1, with solid and cystic components, and heterogeneous gadolinium enhancement. In addition, MRI was also remarkable for a second intramedulary lesion with same signal of fat in all ponderations, extending from conus to dorsal-and partially cervical-spinal cord.Cerebral MRI showed several fat droplets scattered along CSF cisterns. The patient underwent surgical resection of the tumor. The fragments obtained intraoperatively, consisted of different types of tissue including adipose, dense connective tissue, neuronal, calcifications, mucous-secreting glands and hairy structures. A diagnosis of mature teratoma with elements of three germinal layers was established. Postoperatively the patient exhibited improvement in motor deficit, but developed voiding difficulties and sella hyposthesia. During the eight year follow-up, the tumor has not recurred and the patient remains stable from the neurological point of view.

\section{RESULTS}

conclusion

\section{CONCLUSION}

This is a unique case of intramedulary teratoma associated with intramedulary lipoma. We discuss the pathogenesis of teratoma to justify the presence of intramedulay lipoma that spreads along spinal cord. This could be due to a fault occurring early in embryonic development,during the migration of Hensen's node that is responsible for neuronal induction. That could explain the presence of three germinal layer tissue- teratoma -and the rostral spread of the lipoma. This case is also peculiar for its clinical presentation: violent headache caused by chemical meningitis secondary to rupture of tumor into the subarachnoid space,is commonly described in dermoid tumors, but has not been previously reported in teratoma, despite sharing the same mechanism.

\section{P85}

\section{OLIGODENDROGLIOMA PRESENTED AS A PONTINE EXOPHITIC TUMOR}

\section{ESNR}

M.Q. Ribeiro, J. Fernandes, C. Alegria, J. Rocha;

Hospital Sao Marcos, Braga/PT

\section{PURPOSE}

The authors report a case of a pontine exophitic tumour with the histological diagnosis of anaplastic oligodendroglioma that presents as a cerebelopontine angle mass.

MATERIAL AND METHODS

A 40 year-old man sought medical attention with right facial palsy. He was discharged with a diagnosis of idiopathic facial palsy and began rehabilitation therapy but without results. After 3 months, he presented to our emergency department complaining of headaches and progressive gait difficulties. The neurological examination revealed gait ataxia, hearing disturbance in the right ear, ipsilateral hemifacial palsy and hypoesthesia in three trigeminal divisions. He had a history of asthma, otherwise, his medical record was unremarkable. A CT was performed revealing a huge mass in the left cerebelopontine angle with pontine oedema which was interpreted as a schwannoma. As the patient had an atopic disease, contrast could not be given. Cerebral MR showed the lesion to be homogeneous, with a high-signal in T2 and iso-signal in T1 with faint gadolinium enhancement. The lesion spread rostraly until ASCA and caudally to the medulla with encasement of the low cranial nerves; invaded the inner auditory canal and the gasser ganglion. The demarcation between the lesion and the parenquima was not clear with extensive oedema in the pons and middle cerebellar peduncle. It had mass effect pushing the pons contralateraly causing enlargement of the homo-lateral brainstem cisterns. It remained unclear whether it was an extra-axial lesion or a pontine exophytic tumour. During surgery it was discovered that it was in fact an intra-axial tumour and impossible to resect. A biopsy was performed revealing an anaplastic oligodendoglioma. The patient was referred for radio- and chemo- therapy.

RESULTS

see conclusions

CONCLUSION

The authors describe this rare case of a oligodendoglioma presented as an exophytic pontine tumour mimicking a vestibular schwannoma. We present this as a rarity but also to remind the neuroradiologist that these lesions must be included in the differential diagnosis of cerebelopontine angle tumours, along with schwannoma which are by far the most frequent type.

P86

OBJECTIVE IMAGE QUALITY OF SINGLE DETECTOR AXIAL CT AND MULTIDETECTOR HELICAL CT REGARDING GRAY TO WHITE MATTER DIFFERENTIATION AND BEAM HARDENING ARTIFACTS

ESNR

S. Klein ${ }^{1}$, K. Heering ${ }^{1}$, A.J. Aschoff ${ }^{2}$, B.L. Schmitz ${ }^{1}$;

${ }^{1}$ University Hospitals Ulm, Ulm/DE, ${ }^{2}$ University Hospital Ulm, $\mathrm{Ulm} / \mathrm{DE}$ 


\section{PURPOSE}

The increasing availability of multidetector CT scanners on which helical acquisition is preferred because of technical reasons has led to questions on how image quality is affected in cranial CT especially regarding gray to white matter contrast. The purpose of the present study was to compare objective criteria of image quality of brain CT's acquired on a single detector CT in axial mode and multidetector CT in helical mode.

\section{MATERIAL AND METHODS}

Objective image criteria of brain $\mathrm{CT}$ scans from routine clinical imaging were measured for 64 age and sex matched patients acquired on a 40 detector-row CT (Brilliance 40, Philips, Cleveland, $\mathrm{OH}$ ) in helical mode and single detector CT (Somatom Plus 4, Siemens, Erlangen, Germany) in axial mode. Criteria included contrast to noise ratio (CNR) of gray and white matter, signal to noise ratio (SNR) at specified supra- and infratentorial locations and beam hardening artifacts of the posterior fossa. Helical CT was acquired with $40 \times 0.625 \mathrm{~mm}$ collimation reconstructed at $5 \mathrm{~mm}$ slice thickness at $285 \mathrm{mAs}, 120 \mathrm{kV}$. Axial CT was acquired with $4 \mathrm{~mm}$ slice thickness for the posterior fossa and $8 \mathrm{~mm}$ slice thickness for the cerebrum with $257 \mathrm{mAs}$ and $140 \mathrm{kV}$. RESULTS

CNR between gray and white matter was significantly higher on multidetector helical CT acquisition (mean 2.11, SD 0.42 vs. 1.72, SD $0.81 ; \mathrm{p}<0.05)$. Beam hardening artifacts in the posterior fossa artifacts expressed as standard deviations in homogenous areas were significantly less pronounced with helical acquisition (pons [HU]: mean 5.43, SD 0.91 vs. 7.86, SD 2.65, $<<0.01$; temporal pole[HU]: mean 4.35 , SD 0.47 vs 6.05 , SD 0.92 , p<0.01). SNR was higher for helical $\mathrm{CT}$ at the temporal pole (7.53, SD $1.21 \mathrm{vs.}$ 5.48, SD 0.94; $\mathrm{p}<0.01)$ and pons (5.62, SD 1.34 vs 3.87, SD 1.59, $\mathrm{p}<0.01)$ and lower for the centrum semiovale $(8.32$, SD 1.18 vs. 12.85, SD 2.02, $\mathrm{p}<0.01)$ and thalamus (9.26, SD 1.25 vs 12.83 , $\mathrm{SD} 1.40, \mathrm{p}<0.01)$ without correcting for differences in slice thickness.

\section{CONCLUSION}

Even without accounting for additional benefits of multiplanar reconstruction capabilities, objective image quality of routine helical CT acquisition on a 40 detector row $\mathrm{CT}$ is superior to single slice axial CT with significantly higher contrast to noise ratios reflecting better gray to white matter differentiation and significantly less posterior fossa beam hardening artifacts.

\section{P87}

\section{THE PETROSQUAMOSAL SINUS IN HUMANS}

\section{ESNR}

D. San Millán Ruíz ${ }^{1}$, P. Gailloud ${ }^{2}$, H. Yilmaz ${ }^{3}$, J. Rathgeb ${ }^{1}$, F. Perren ${ }^{1}$, D. Rüfenacht ${ }^{3}$, J.H. Fasel ${ }^{3}$;

${ }^{1}$ Geneva University Hospital, Geneva/CH, ${ }^{2}$ Johns Hopkins Hospital, Baltimore/US, ${ }^{3} \mathrm{HUG}$, Geneva/CH

\section{PURPOSE}

To provide a comprehensive review of the petrosquamosal sinus (PSS) in humans based on the literature and on our own observations from corrosion cast studies of the cranial venous system, and from radiological observations in patients.

\section{MATERIAL AND METHODS}

Corrosion casts of the cranial and cerebral venous system were prepared from 13 non-fixed human specimens. High-resolution CT were obtained from the corrosion casts and virtual dissections were performed on a Vitrea workstation. Two radiologically documented clinical cases illustrating the variable anatomical presentation of the PSS, were drawn from routine diagnostic activity.

\section{RESULTS}

A PSS was present in 5 out of the 26 corrosion cast sides. Connections with of the transverse sinus were constant. Connections with the emissary veins of the foramen ovale were found in 2 out of 5 cases. In one case, the anterior portion of the PSS was laterally connected extracranially with a deep temporal vein through a postglenoid foramen (PGF). The morphological aspect of the PSS was compatible with a diploic vessel in 3 cases, and with a meningeal vessel in 2 . The diameter of the PSS observed in the corrosion casts did not exceed $3 \mathrm{~mm}$.Case 1: a $2 \mathrm{~mm}$ diameter bony canal in the left temporal bone compatible with a PSS was documented with high resolution bone CT in a 29 year-old patient with an occipital fracture. Case 2: MRI/A, CT/CTA and DSA were performed on a 7 year old girl suffering from severe postural headaches disclosing an extreme venous anomaly of the posterior fossa. On the left side, the sigmoid sinus and internal jugular vein (IJV) were absent, and drainage of the transverse sinus occurred through a large PSS. The PSS provided a connection with the deep temporal veins through a large PGF. On the right, the IJV was also absent, and the sigmoid sinus drained into a large posterior condylar vein. DSA disclosed signs of venous hypertension.

\section{CONCLUSION}

The PSS is not a rare finding in humans, though only parts of its embryological constituents usually persist into adult life. Rarely, the PSS may become a major outflow pathway of the transverse sinus when the sigmoid sinus is hyppoplastic or absent. On such occasions, the external jugular vein system becomes the major encephalic outflow pathway in the affected side, a drainage pattern which is observed in most mammals. Modern imaging techniques may demonstrate a PSS, which may be of clinical importance when planning surgical procedures or when the PSS is involved in pathological conditions. 
P88

PARKINSON AND ATYPICAL PARKINSON SYNDROMES: A PICTORIAL REVIEW AND NEW IMAGING TRENDS

ESNR

M.A. Miranda $^{1}$, C. Micallef ${ }^{2}$, T. Yousry ${ }^{3}$;

${ }^{1}$ The National Hospital for Neurology and Neurosurgery, London/

GB, ${ }^{2}$ London/GB, ${ }^{3}$ Institute of Neurology / UCL, London/GB

\section{PURPOSE}

To create awareness and illustrate to the radiologist and neuroradiologist the more recent studies and efforts in imaging to create a diagnostic profile for Parkinson and Parkinsonian syndromes. MATERIAL AND METHODS

The value of routine MRI in the diagnosis and differentiation of Parkinson (PD) and Atypical Parkinson Syndromes (APS) including Multiple System Atrophy (MSA), Progressive Supranuclear Palsy (PSP) and Cortico Basal Degeneration (CBD) is examined. A review of the literature over the last 15 years has been performed and the main imaging findings detailed with correspondent illustrations. In addition to the classical anatomical criteria several new imaging criteria are described. A summarized imaging protocol for the evaluation of Parkinsonism is suggested.

RESULTS

The new proposed Imaging Techniques and structural changes in APS are: • Single voxel proton magnetic resonance spectroscopy - Changes in T2 and T2* signal associated with the increased iron deposition in the SNc $\bullet$ DWI imaging and measurement of ADC of the putamen, globus pallidus and substantia nigra $\bullet$ Magnetization Transfer Ratios (MTR) of the globus pallidus, putamen in MSA and substantia nigra - A novel technique based on calculating the ratio between two different inversion recovery sequences, a white matter suppressed IR on the substantia nigra and a gray matter suppressed sequence $\bullet$ Cortical hypodensity in T2 images at the level of the motor cortex $\bullet$ Fluid registration volumetric maps to establish ratios of annual atrophy in the brainstem, cerebellar and cerebral cortex $\bullet$ The evaluation of the Hummingbird, King Penguin and Morning Glory silhouettes • Linear and volumetric measurements of the midbrain.

CONCLUSION

The clinical differentiation between the APS (MSA, PSP, and CBD) and them from Parkinson's disease (PD) remains a challenge. The availability of new surgical and pharmacological therapies that may be effective only in patients with PD has highlighted the need for precise diagnosis. At the present time, the most sensitive imaging techniques for the detection of PD are PET and SPECT, although these techniques are expensive and not widely available. Magnetic resonance imaging (MRI) is not usually considered helpful for establishing the diagnosis of Parkinson's disease, but it is much more important to support the clinical diagnosis in atypical parkinsonian disorders. It is also widely available, with a reasonable cost and has demonstrated its ability to support the clinical diagnosis in Atypical Parkinson Disorders.

P90

\section{PATTERNS OF VOLUME LOSS IN DEMENTIA}

ESNR

C. Micallef ${ }^{1}$, M.A. Miranda ${ }^{2}$, J. Stevens ${ }^{2}$;

${ }^{1}$ London/GB, ${ }^{2}$ The National Hospital for Neurology and Neurosurgery, London/GB

\section{PURPOSE}

Brain imaging in dementia is still mainly used to exclude symptomatic causes and intercurrent disease. The purpose of this pictorial review is to demonstrate how different patterns of atrophy and detection of accelerated rates of change early in the disease can have definite positive predictive value and can distinguish different types of dementias.

MATERIAL AND METHODS

We have access to a large pool of patients with various types of demential mainly familial in whom a molecular diagnosis has been established. Most have had optimized serial MRI, in many cases beginning preclinical stages. Change is detected by fluid registration of serial high resolution volumetric acquisition developed locally [Ref].

RESULTS

Alzeihmer's Disease: in early stages change is seen asymmetrically throughout each hippocampus and parahippocampal gyrus, later extending to adjacent gyri then precuneus, then generalised by which time change has ceased in medial temporal structures. The cerebellum remains unchanged.In the posterior variant, change and atrophy apeear earliest in the occipitoparietal lobes, affecting the temporal lobe only late in the disease. Frontotemporal dementia: the most characteristic pattern of atrophy is asymmetrical within either temporal lobe, involving particularly medial temporal structures, the fusiform gyrus, with a striking anteroposterior severity gradient. In early stages change is detected in these structures including the amygdala and ceases in these regions as atrophy becomes more generalized. In primary progressive aphasia: cortical change has been demonstrated in Broca's area, spreading centrifugally and contralaterally as disease progresses. Progressive supranuclear palsy: atrophy affects the tegmentum of the midbrain and superior cerebellar peduncles, in early stages change is seen only in these regions. Multiple system atrophy: [associated with demtia] change is strikingly localised in the pons. Prion disease: it is often signal change in the basal ganglia, thalami, and cerebral cortex rather than atrophy that contribute to an early diagnosis. Most familial cases progress slowly clinically and have shown little change so far, except in two mutation types where early volume loss has been confined to the cerebellum. 


\section{CONCLUSION}

MRI at a single time point can have positive predictive value for al diseases, but often only when disability is greatly advanced. Fluid registration is of great value in detecting early [even preclinical] change, which is disease specific, but is of less value when disease is advanced.

\section{P91}

THE IMPORTANCE OF BEHAVIOURAL MEASURES IN INTERPRETING FUNCTIONAL DATA: EVIDENCE FROM A WORKING MEMORY STUDY

\section{ESNR}

S.M. Jaeggi ${ }^{1}$, M. Buschkuehl ${ }^{1}$, A. Etienne ${ }^{1}$, C. Ozdoba ${ }^{2}$, W.J. Perrig ${ }^{1}$, A.C. Nirkko ${ }^{3}$;

${ }^{1}$ University of Bern, Bern/CH, ${ }^{2}$ Institute for Diagnostic and Interventional Neuroradiology, Bern/CH, ${ }^{3}$ Inselspital, Bern/CH

\section{PURPOSE}

Cognitive decline with advancing age is reflected in age-related neuronal changes in the brain as observed on structural but also on functional level. However, the significance of those changes along with behavioural changes is not well understood. While poorer performance in older adults is sometimes correlated with reduction in activity in some brain areas compared to young adults, there are other findings where the elderly express higher activities in some task-related areas. These higher activations have been interpreted in functional compensation processes in order to fulfil the required task demands.

\section{MATERIAL AND METHODS}

Since the larger part of such studies is conducted with older adults, we performed a study with middle-aged, i.e. 50-60 year-old adults. We investigated load-dependent processing in young and middle-aged adults by using a parametric working memory task, i.e. the n-back task. The task was used as dual task as we wanted to reach and exceed capacity limits in each participant. To assess the correlating neural activity, we used whole brain and high resolution fMRI with a blood oxygenation level dependent (BOLD) echo-planar imaging $(\mathrm{EPI})$ sequence (matrix $128 \times 128 \times 48$ slices $\times$ 108 measurements, resulting in $1.5 \times 1.5 \times 3 \mathrm{~mm} \times \mathrm{TR} 7500 \mathrm{~ms}$; TE $60 \mathrm{~ms}$ ) on a 1.5-T whole-body MRI scanner (Magnetom Vision, Siemens Medical Systems, Erlangen, Germany).

RESULTS

Preliminary results with 7 middle-aged participants suggest that the above-mentioned compensation view holds true: Compared to a young healthy sample (reported in detail somewhere else), the middle-aged sample showed lower accuracy and a higher BOLDresponse, thus, reflecting developmental changes. Interestingly, taking performance groups into account, behavioural and fMRI data in the middle-aged sample were comparable to those of lowperforming young participants.

\section{CONCLUSION}

It can be suggested that the higher activity pattern reflects compensatory processes on neuronal level. However, these activation patterns are not easily explained as a function of agerelated processes, since the behaviour of the middle-aged sample did not differ from the young low-performing group. Therefore, the fMRI-data are rather interpreted in terms of an unspecific attentional and effort-related recruitment of resources, which seems either not relevant or even detrimental to performance; independent of age, but dependent on performance. In sum, this study underlines the importance of behavioural measures in interpreting functional data.

P92

COMPARATIVE FINDINGS OF DYNAMIC CONTRAST-ENHANCED MR IMAGING OF PITUITARY MICROADENOMAS AT 1.5T AND 3.0T

ESNR

T. Stosic-Opincal, S. Lavrnic, M. Gavrilov, S. Gavrilovic, V. Peric; Clinical Center of Serbia, Belgrade/YU

\section{PURPOSE}

Dynamic gadolinium-enhanced MR imaging improves detection of pituitary microadenomas and provides increased image contrast beyond that of conventional contrast-enhanced imaging. The aim of this study was to compare dynamic MR imaging of microadenomas at $1.5 \mathrm{~T}$ and $3.0 \mathrm{~T}$ field strengths using identical acquisition conditions.

\section{MATERIAL AND METHODS}

Fourteen patients (mean age 27.6 years) with moderate hyperprolactinemia and clinically suspected microadenomas made up the study group. None of the patients were taking any medications or had any systemic illness known to be associated with increased levels of pituitary hormones. The patients were imaged at $1.5 \mathrm{~T}$ and 3.0 T MR systems. The imaging technique was the same in all 14 patients: a standard T1-weighted spin echo (SE) sequence was followed by intravenous administration of a $0.1 \mathrm{mmol} / \mathrm{kg}$ of gadolinium-DTPA; Immediately after contrast administration, a dynamic contrast study was performed using a standard T1weighted 2D gradient-echo (GE); after completion of dynamic study, a standard T1W postcontrast imaging was performed. Three coronal slices best covering the pituitary were selected and the GE sequence was repeated every 12 seconds. From these data, a time vs. signal intensity curve was constructed.

\section{RESULTS}

On $1.5 \mathrm{~T}$ the dynamic sequence was better than the standard enhanced sequence for depicting microadenomas in 6 patients. Lesions were identified only with the dynamic study in 2 patients. Lesions were seen equally well on the standard and dynamic sequences in 5 cases. On $3 \mathrm{~T}$ the dynamic sequence was better in 7 
patients. Lesions were identified only on the dynamic study in 2 patients and were seen equally well in 5 cases.

\section{CONCLUSION}

High-field 3.0 T dynamic contrast-enhanced MR imaging demonstrates similar sensitivity in the detection of pituitary microadenomas compared with $1.5 \mathrm{~T}$.

\section{Spinal interventions}

P93

\section{RADIOLOGICAL SPECTRUM OF LESIONS INVOLVING THE HIPPOCAMPUS}

$E S N R$

A. Rovira ${ }^{1}$, A. Rovira ${ }^{2}$, N. Bargallo ${ }^{3}$, E. Grivé ${ }^{4}$,

J. Alvarez Linera-Prado 5

${ }^{1}$ Hospital Vall d, Barcelona/ES, ${ }^{2}$ Sabadell/ES, ${ }^{3}$ Hospital Clinic, Barcelona/ES, ${ }^{4}$ Hospital Vall d'Hebron, Barcelona/ES, ${ }^{5}$ Hospital Ruber Internacional, Madrid/ES

\section{PURPOSE}

To review the MR imaging findings of several lesions that predominantly affect the hippocampus.

MATERIAL AND METHODS

In this scientific exhibit we will present representative cases of various lesions involving the hippocampus.

\section{RESULTS}

The hippocampus, which forms a part of the limbic system, has a crucial role in cognition and memory, particularly in the formation of long-term memory. In vivo visualization of the hippocampus became possible with the advent of MR imaging, which has allowed the identification of a variety of lesions that mainly affect this formation. Many of the MR imaging examinations performed to identify structural abnormalities of the hippocampus are obtained in patients with temporal lobe epilepsy (medial temporal lobe sclerosis) and several forms of primary neurodegenerative dementia, particularly those of the Alzheimer type (hippocampus atrophy). However hippocampal changes can occur in a broad spectrum of disorders beyond dementia and epilepsy, including ischemic lesions (infarction within the posterior cerebral artery territory), primary brain tumours, inflammatory and infectious diseases (viral and paraneoplastic encephalitis, demyelinating lesions), vascular malformations (cavernoma, arterio-venous malformation), and focal cortical dysplasia, as well as several neuropsychiatric disorders (schizophrenia, post-traumatic depression). The hippocampus may also be selectively affected in patients with neurofibromatosis type I, and in the acute phase of transient global amnesia and status epilepticus.

\section{CONCLUSION}

The hippocampus can be affected by a variety of processes that may present with similar clinical findings. MR imaging establishes the proper differential diagnosis with relatively high specificity when a suitable imaging protocol is used.

\section{Pediatric neuroradiology}

\section{P94}

DESMOPLASTIC INFANTILE GANGLIOGLIOMA - A CASE REPORT

ESNR

M.C. Gallo ${ }^{1}$, C. Capellini ${ }^{2}$, R. Moricca ${ }^{3}$, A. Taccone ${ }^{3}$;

${ }^{1}$ S. Andrea Hospital Radiology Department, La Spezia/IT, ${ }^{2} \mathrm{La}$ Spezia/IT, ${ }^{3}$ S.Andrea Hospital, La Spezia/IT

\section{PURPOSE}

Desmoplastic infantile ganglioglioma, also known as a DIG tumor, is a form of ganglioglioma occurring in young patients, typically less than 2 years of age. The majority of patients with this tumor present around 5-6 months of age. There is no gender predilection. DIG tumors are typically large, supratentorial, heterogeneously-appearing mass lesions with both solid and cystic components, located predominantly in the temporal lobes.

MATERIAL AND METHODS

A 5-month-old female child presented with enlargement of head, repeated generalized tonic-clonic seizures and loss of acquired milestones of one-month duration. At the time of admission, the child was irritable. The head circumference was $51 \mathrm{~cm}$. And the anterior fontanelle was wide and tense. There was no neurological deficit. Computerized Tomographic scan (CT scan) of brain showed a large cystic tumor in the right frontotemporoparietal regions, with a moderate-sized, isodense and intensely enhancing surface mass. A right frontotemporoparietal craniotomy was performed. The subarachnoid cyst contained xanthochromic fluid. The solid tumor was approximated to the dura. It was firm and relatively avascular and measured about $6 \mathrm{~cm} \times 5 \mathrm{~cm} \times 3 \mathrm{~cm}$. The tumor was excised completely. The postoperative course was uneventful. Histopathology showed the tumor with marked desmoplastic component with neoplastic astrocytes and a few scattered neuronal ele ments. Immunohistochemistry showed strong reaction with Glial Fibrillary Acidic Protein (GFAP) with areas showing posi tive reaction for Synaptophysin and Chromogranin.

RESULTS

The predominant histopathologic feature is striking desmoplasia, characterized by a dense stroma incorporating glial, neuronal, and fibroblastic elements. This tumor may fill in the subarachnoid space and can extend along perivascular spaces. The DIG tumor is identified with intensely positive GFAP immunohistochemistry as well as positive trichrome stain due to the abundant collagen. Although the bulk of the DIG is superficial and seemingly well demarcated, some lesions include densely cellular focally infiltrative regions resembling a primitive neuroectodermal tumor. Nevertheless, 
the overall prognosis is favorable, and most patients have prolonged survivals after surgical excision of the DIG tumor.

\section{CONCLUSION}

Desmoplastic infantile ganglioglioma is a rare tumor of infancy, which has excellent prognosis after total excision. No adjuvant therapy is required.

P97

NEONATAL CRANIAL ULTRASOUND AS A PREDICTOR OF
LONGTERM NEURODEVELOPMENTAL OUTCOME IN A
PRETERM OR LOW BIRTH WEIGHT INFANTS- A REVIEW
OF LITERATURE

ESNR

S. Narayanaswamy

Derriford hospital, Plymouth/GB

\section{PURPOSE}

Cranial ultrasound scan is a safe and an effective method for assessing neonatal brain abnormalities. Although there has been an improvement in the survival of preterm and low birth weight infants, disability remains a major concern in this group. The present study reviews the current available literature to assess the usefulness of cranial ultrasound scan appearances in predicting neurodevelopmental outcome.

\section{MATERIAL AND METHODS}

A MEDLINE literature search was carried out using key words 'Cranial ultrasound', 'preterm infant', 'neurodevelopmental delay', and 'low birth weight'. Search was limited to all English articles from 1980 to 2005 .

\section{RESULTS}

Preterm or low birth weight infants are highly susceptible to an insult from ischemic, haemorrhagic and infective factors. Abnormal outcome is associated with both haemorrhagic and ischemic lesion but the severity of the disability depends to an extent on the cranial ultrasound appearance in the neonate. Several studies have been published in the literature looking at the neonatal cranial ultrasound appearances and the neurodevelopmental outcome at a later stage. Most of these studies differed with respect to the timing and method of assessing neurodevelopmental outcome. Infants with a normal and an uncomplicated IVH on cranial ultrasound scan had a lesser chance of minor neurodevelopmental disability $(8-14 \%)$ and this group carried a better prognosis. Infants with ventricular dilatation, hydrocephalus, cerebral atrophy and periventricular leucomalacia at the time of discharge carried a poor prognosis and the neurodevelomental outcome was adversely affected by these perinatal ischemic white matter injury. Cranial ultrsound is good at diagnosing haemorrhage and ventricular dilatation but MRI is more sensitive than ultrasound in detecting white matter changes. Spectrum of cranial ultrasound abnormilites in preterm and low birth weight infants will also be discussed.

\section{CONCLUSION}

Several factors determine the neurodevelopmental outcome of preterm or low birth weight infants but cranial ultrasound scan is highly specific and plays a major role in predicting neurodevelopmental disability. Good understanding and a careful evaluation for the presence of ultrasound abnoramlities along with a regular follow up is crucial in predicting disability in preterm and low birth weight infants.

P98

\section{WIDENING SPECTRUM OF CLINICALLY MILD ENCEPHA- LITIS/ENCEPHALOPATHY WITH A REVERSIBLE SPLEN- IAL LESION [MERS]}

\section{ESNR}

J. Takanashi ${ }^{1}$, H. Tada ${ }^{2}$, A.J. Barkovich ${ }^{3}$, H. Oba ${ }^{4}$, M. Maeda ${ }^{5}$; ${ }^{1}$ Kameda Medical Center, Kamogawa/JP, ${ }^{2}$ Chiba University, Graduate School of Medicine, Chiba/JP, ${ }^{3}$ UCSF, San Francisco/ US, ${ }^{4}$ Teikyo University, Tokyo/JP, ${ }^{5}$ Mie University School of Medicine, Tsu/JP

\section{PURPOSE}

In our practices, we have identified 25 patients with clinical diagnoses of encephalitis/encephalopathy with a reversible lesion in the splenium of the corpus callosum (SCC). The purpose of this study is to clarify the clinical and radiologic characteristics of these patients.

\section{MATERIAL AND METHODS}

Possible encephalitis/encephalopathy patients with a reversible SCC lesion on MRI were collected retrospectively. Their clinical, laboratory, and radiologic data were reviewed.

\section{RESULTS}

We identified 25 encephalitis/encephalopathy patients with a reversible SCC lesion. Homogenously reduced diffusion of SCC was seen in 19 patients who underwent diffusion-weighted imaging. There was no enhancement in 10 patients so examined. The SCC lesion had completely disappeared in all 25 patients at follow-up MRI exams between 3 days and 2 months after the initial MRI (within a week in 18 patients). 18 patients with an isolated SCC lesion had relatively mild clinical courses, and clinically recovered completely within a month (10 patients within a week) after the onset of neurological symptoms. 7 patients had other lesions in addition to a SCC lesion. Among them, 4 patients had reversible lesions with transiently reduced diffusion in the symmetrical peripheral fronto-parietal white matter and SCC; their clinical signs and symptoms were mild, and recovery was complete. Other 3 patients had a reversible SCC lesion and irreversible lesions in cerebellar hemispheres, basal ganglia, or frontal lobe; who also had neurologic sequelae. 


\section{CONCLUSION}

These observations suggest a less severe course and outcome for patients with reversible lesions isolated to SCC or to SCC and peripheral fronto-parietal white matter. We propose that this may represent a new clinicoradiological syndrome with an excellent prognosis (clinically mild encephalitis/encephalopathy with a reversible splenial lesion [MERS]); and that MRI is a key study in establishing the diagnosis.

\section{P99}

\section{PARASAGITTAL LESIONS AND ULEGYRIA IN HYPOXIC- ISCHEMIC ENCEPHALOPATHY: MRI FINDINGS}

\section{$E S N R$}

\section{$\underline{\text { I. NIKAS }}^{1}$, V. DERMENTZOGLOU ${ }^{2}$,} M. THEOFANOPOULOU ${ }^{1}$, C. HADJIGEORGI ${ }^{1}$, M. ZARIFI ${ }^{1}$; 1“Agia Sophia” Children's Hospital, ATHENS/GR, ${ }^{2}$ ATHENS/GR

\section{PURPOSE}

Perinatal hypoxic-ischemic brain injury is a major cause of neurologic morbidity and mortality in the neonatal period and of chronic disability later in childhood, presenting with cerebral palsy, seizures and mental retardation. The gestational age determines the neuropathology of the hypoxic-ischemic brain injury. One of the patterns of hypoxic-ischemic encephalopathy, typically affecting full-term infants, consists of parasagittal lesions and ulegyria. Aim of this study is to describe the MRI features of this pattern which affects the cortex and the white matter in a mainly parasagittal distribution, thus resulting in ulegyria; in this type of brain injury the damage usually involves the deeper sulcal portion while sparing the apex.

\section{MATERIAL AND METHODS}

Brain MR imaging examinations were performed on a 1,0 T scanner in 14 patients (aged between 6 months and 14 years) with clinical history of perinatal hypoxia/anoxia presenting with mental retardation, seizures and cerebral palsy.

RESULTS

In all patients, severe tissue loss in the depths of the sulci of the affected gyri, with relative sparing of their apex, the so called "mushroom gyri" pattern, was demonstrated, findings characteristic of ulegyria. The distribution of cortical damage was variable, occurring mostly in the parasagittal watershed areas between the major cerebral arteries, commonly in the pre-central and posterior regions. 13 patients had bilateral involvement, completely symmetrical in 4 cases and totally assymetrical in 4 other. 5 patients had lesions symmetrical in distribution but not in severity. In one patient unilateral involvement of all lobes of the left hemisphere and severe atrophy, was demonstrated. White matter loss and gliosis underneath the shrunken cortex was a constant finding in all cases; Marked ventricular enlargement was found in 2 cases, 4 patients had porencephalic cysts and in 6 thinning of the corpus callosum was present. Deep gray matter involvement with basal ganglia injury was observed in 2 and microcephaly in 6 cases.

CONCLUSION

MRI allows a specific diagnosis of parasagittal lesions and ulegyria resulting from perinatal cerebral hypoxia-ischemia, also identifiying their distribution and extension. It is also a valuable tool in their differential diagnosis from polymicrogyria, focal cortical dysplasia and periventricular leukomalacia.

\section{P100}

POSTERIOR REVERSIBLE ENCEPHALOPATHY SYNDROME (PRES) IN CHILDHOOD: MRI FINDINGS

ESNR

\section{NIKAS ${ }^{1}$, M. THEOFANOPOULOU ${ }^{1}$, V. DERMENTZOGLOU ${ }^{2}$, C. HADJIGEORGI ${ }^{1}$, M. ZARIFI ${ }^{1}$; \\ 1،Agia Sophia" Children's Hospital, ATHENS/GR, ${ }^{2}$ ATHENS/GR}

\section{PURPOSE}

Posterior Reversible Encephalopathy Syndrome (PRES) is an entity whose pathophysiological mechanisms are not fully understood. It presents with acute headaches, decreased alertness, visual loss and seizures. It is thought to be the end result from several pathologies such as hypertensive encephalopathy and Cyclosporin A (CsA) neurotoxicity. In this study we document the presence of PRES in the pediatric population and describe its MRI findings.

\section{MATERIAL AND METHODS}

We carried a retrospective review of the cases of 5 children aged between 5-14 years, examined in our department during a 5-year period (1999 - 2004), with clinical symptoms and MRI findings suggestive of PRES.

RESULTS

Four children suffered of acute lymphoblastic leukemia. Three of them had undergone allogeneic bone marrow transplantation and were treated with CsA. One child was under induction chemotherapy with L-asparaginase. The last patient, with known renal disease, had hypertensive encephalopathy. MRI showed abnormal signal intensity, increased in $\mathrm{T} 2 \mathrm{-W}$ and FLAIR images, in the parietal and occipital cortex and subcortical white matter, with unilateral or bilateral involvement. In one case the rare demonstration of cerebellum involvement was encountered. In all cases regression of both clinical and imaging manifestations was noted after a 2-8 week period.

CONCLUSION

PRES is an entity, also present in the pediatric population, especially in children treated for neoplastic disease, following 
immunosuppressant therapy, such as CsA and L-asparaginase. It is also the result of hypertensive encephalopathy in patients with known renal disease. MR is the imaging modality of choice for the documentation of PRES, its differential diagnosis and the monitoring of the patient's follow-up.

\section{P101}

BIOTINIDASE DEFICIENCY: INITIAL AND POST BIOTIN TREATMENT MR IMAGING PATTERN INCLUDING DIFFUSION AND MR SPECTROSCOPY.

\section{ESNR}

N. ARIFA-ACHOUR ${ }^{1}$, N. MAMA ${ }^{1}$, S. HASSAYOUN ${ }^{1}$, H. JEMNI-GHARBI ${ }^{1}$, A. HARBI ${ }^{1}$, K. TLILI-GRAIESS ${ }^{2}$;

${ }^{1}$ Faculte Medecine Sousse, Sousse/TN, ${ }^{2}$ Faculte Medecine Sousse, El Kantaoui Sousse/TN

\section{PURPOSE}

The purpose of this report is to describe the initial and post biotin treatment MR Imaging pattern including diffusion and MR Spectroscopy (MRS) in a case of. biotinidase deficiency.

MATERIAL AND METHODS

A 16 month old girl presented with a 5 month history of progressive developmental regression and neurological deterioration with complete alopecia. She underwent a sudden severe decompensation during her initial neurological investigations. Her cerebral imaging included Computed Tomography (CT) and Magnetic Resonance Imaging (MRI) including MRS evaluation with a multivoxel 2 Dimensional Chemical Shift Imaging at echo time $144 \mathrm{~ms}$.

\section{RESULTS}

CT scan and MRI showed moderate brain atrophy and low attenuation with signal abnormalities in the fronto-temporal white matter, corpus callosum, basal ganglia and brain stem. A restricted diffusion was noted in sub cortical white matter, genu of the corpus callosun and thalami suggesting an acute episode with cytotoxic and/or intra myelinic sheat oedema. MRS demonstrated lactate in these areas along with low N-Acetyl Aspartate and increased Choline.A clinico-radiological diagnosis of late onset multiple carboxylase deficiency due to biotinidase deficiency was made. The child improved markedly with biotin treatment.MRI follow-up 5 months later demonstrated normal brain size, large resolution of signal abnormalities on all sequences excepting for the genu of the corps callosun, normal age related pattern of myelinisation and normalisation of the MRS profile.

\section{CONCLUSION}

Biotinidase deficiency is a rare cause of late onset progressive encephalopathy. This curable entity should be considered in the differentiel diagnosis of abnormal grey and white matters on cerebral imaging.

\section{$\mathbf{P 1 0 2}$}

TUBEROUS SCLEROSIS: CONTRIBUTION OF MR SEQUENCES IN THE DETECTION OF BRAIN LESIONS.

ESNR

N. MAMA ${ }^{1}$, N. ARIFA-ACHOUR ${ }^{1}$, W. GAMAOUN ${ }^{2}$, K. MRAD-DALI ${ }^{1}$, S. ABROUG ${ }^{1}$, M. YACOUB ${ }^{1}$, H. KRIFA $^{1}$, K. TLILI-GRAIESS ${ }^{3}$;

${ }^{1}$ Faculte Medecine Sousse, Sousse/TN, ${ }^{2}$ Sahloul Medical Hospital, Sousse/TN, ${ }^{3}$ Faculte Medecine Sousse, El Kantaoui Sousse/TN

\section{PURPOSE}

MR is the imaging method of choice to demonstrate structural brain lesions in tuberous sclerosis (TS). Our objective in the study is to compare MR sequences and determine which is the most useful for the demonstration of each type of lesions.

MATERIAL AND METHODS

We reviewed MR scans of 9 TS patients aged from 10 months to 21 years for the presence of cortical and sub cortical tubers, white matter lesions (radical bands) subependymal nodules and sub ependymal giant cell astrocytomas (GCA) on the following sequences: non enhanced and enhanced T1 weighted spin echo (T1 SE) images, non enhanced Magnetisation Transfert T1 weighted images (MT-T1WI). Fluid attenuated inversion recovery (FLAIR), T2 weighted Spin Echo (T2 SE) and T2 weighted gradient echo (T2 EG).

RESULTS

Cortical and sub cortical tubers were found in all patients in larger numbers (from 1 to 40 with mean 25) and more conspicuously in Flair and on MT-T1WI comparing to the T2 findings. The Flair and non enhanced MT-T1 sequence appeared superior to other sequences in detecting white matter lesions. The enhanced T1SE images delineated clearly the limits of the GCA ( 2 cases with 1 bilateral) and the T2EG demonstrated the calcified subependymal nodules with good correlation to computed tomography. The cystlike component of some tubers was better delineated on T1SE and Flair images with the particular enlargement of the corresponding gyri.

CONCLUSION

FLAIR, MT-T1WI and the enhanced T1SE appear the most appropriate MRI sequences for the diagnosis of the most frequent brain lesions in T.S. 


\section{Spinal imaging}

\section{P103}

VERTEBRAL NEOPLASTIC INFILTRATION: DIFFUSION
WEIGHTED MR IMAGING SIGNAL INTENSITY CHANGES
AND ASSESSMENT OF APPARENT DIFFUSION COEFFICIENT

ESNR

T. Gerukis ${ }^{1}$, E. Vafeiadis ${ }^{2}$, A. Fotiadou ${ }^{2}$, K. Koutroumanidis ${ }^{2}$,

V. Kalpakidis ${ }^{2}$, P. Palladas ${ }^{2}$;

${ }^{1}$ G.R.H.G.Papanikolaou, Thessaloniki/GR, ${ }^{2}$ G. Papanikolaou Hospital, Thessaloniki/GR

\section{PURPOSE}

The purpose of this study was to investigate Diffusion Weighted Imaging signal intensity changes of vertebral bone marrow, in tumor infiltration and to assess the utility of the apparent diffusion coefficient.

\section{MATERIAL AND METHODS}

59 patients with clinical suspicion of malignant vertebral infiltration were prospectively investigated. Of these 38 had a known primary tumor and 21 suffered from multiple myeloma. We performed T1 TSE sequence before and after contrast material administration, T2 TSE, STIR and Diffusion Weighted Imaging (DWI) with Apparent Diffusion Coefficient (ADC) maps calculation to all patients. The DWI signal intensity and the region of interest measurements of affected and normal vertebrae were analyzed. Follow up and biopsy were used as the gold standard. RESULTS

In29 of the 38 patients with a known primary tumor, DWI and ADC maps were consistent with metastases. In patients with multiple myeloma, DWI and quantitative analysis were able to differentiate between active disease and response to therapy. In patients with vertebral tumor infiltration the affected vertebrae appeared hyperintense on DWI, reflecting restricted diffusion and the mean ADC value was $(0.82+-0.20) \times 10^{-3} \mathrm{~mm}^{2} \times \mathrm{s}^{-1}$. The mean ADC value of non affected vertebral bodies was (1.94+ $-0.35) \times 10^{-3} \mathrm{~mm}^{2} \times \mathrm{s}^{-1}$.

CONCLUSION

DWI was proven to be a powerful tool for evaluating vertebral neoplastic infiltration. The ADC of benign processes was significantly higher than that of vertebral tumor infiltration, which supports the hypothesis that water mobility in tumors is hindered. Our findings confirm that DWI and ADC in combination with conventional MR imaging are able to distinguish normal vertebrae from vertebral tumor infiltration.

\section{P104}

\section{VERTEBRAL CHEMICAL SHIFT IMAGING}

ESNR

T. Gerukis ${ }^{1}$, S. Koptopoulos ${ }^{2}$, M. Pilavaki ${ }^{2}$, K. Anastasiadou ${ }^{1}$, V. Kalpakidis ${ }^{2}$, P. Palladas ${ }^{2}$;

${ }^{1}$ G.R.H.G.Papanikolaou, Thessaloniki/GR, ${ }^{2}$ G. Papanikolaou Hospital, Thessaloniki/GR

\section{PURPOSE}

To assess prospectively a range of values for signal intensity change in normal and pathologic vertebral marrow, by using chemical shift magnetic resonance (MR) imaging, in an effort to establish whether there is significant change mainly, in differentiating benign from malignant marrow abnormalities.

MATERIAL AND METHODS

We used 1.5-T chemical shift MR imaging to study a total of 438 normal vertabrae in 46 patients (27 women, 19 men; mean age, 59.6 years; age range, 22-83 years) (control group) and 58 lesions in 23 patients (13 women, 10 men; mean age 61.1 years; age range, 33-84 years) (study group) with focal vertebral marrow abnormalities. We calculated the proportional change (drop) in signal intensity on out-of-phase compared with in-phase images. We used $1 \times 1 \mathrm{~cm}$ regions of interest (ROIs) in the control group and ROIs as large as possible for lesions in the study group. The percentage of signal intensity change was compared with that of normal levels and focal marrow lesions. The paired T-test was used for statistical analysis.

RESULTS

We noted a significant decrease in signal intensity for all normal vertabrae (mean, $71.0 \%$ ), but only a slight decrease for hemangiomas (mean, 6.6\%). On the other hand, abnormalities such as metastasis, multiple myeloma and even Modic II (the most common type of endplate degeneration) lesions, presented mostly with a minimal increase in signal intensity (mean values, 4.5, 2.6, and 5.2 respectively). Statistical analysis showed that the difference in signal intensity changes was significant $(\mathrm{P}<.01$ after adjusting for multiplicity) between normal vertabrae and hemangiomas, Modic II degenerative and malignant lesions (pairwise comparisons). However there was no significant change $(\mathrm{P}>.01)$ in signal intensity between malignancies and hemangiomas.

CONCLUSION

Vertebral bone marrow displays variable behavior at chemical shift MR imaging. Our results suggest that this technique can be used for distinguishing between normal appearance and malignancy, but not between focal benign and malignant lesions, in which case, it must be used only as an adjunct to the other available conventional MR sequences (T1, T2, STIR and T1-FS with intravenous contrast administration). 


\section{P105}

MULTI-LEVEL LUMBAR DISCOGENIC DISEASE: THE ROLE OF THREE DIMENSIONAL MR MYELOGRAPHY IMAGING

ESNR

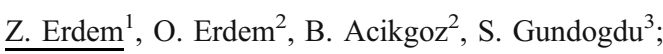
${ }^{1}$ Zonguldak Karaelmas University Hospital, Zonguldak/TR, ${ }^{2}$ Zonguldak Karaelmas University, Faculty of Medicine, Zonguldak/ TR, ${ }^{3}$ Zonguldak Karaelmas University, Zonguldak/TR

\section{PURPOSE}

To evaluate the role of the three dimensional (3D) MR myelography (MRM) in the diagnosis of the multi-level lumbar discogenic disease compared with conventional MR imaging.

\section{MATERIAL AND METHODS}

Fifty consecutive patients with multi-level disc disease diagnosed on conventional MR imaging were enrolled for the study. Conventional MR imaging and coronal 3D MRM were performed on a $1.5 \mathrm{~T}$ MR system. Five lumbar disc space levels were evaluated for each patient. At each disc space level, the presence and the location of disc herniation and nerve root compression were evaluated. Note was also made if MRM had additional contribution to the determination of most significant level in the cases of multi-level disc disease and lumbar spinal stenosis.

\section{RESULTS}

A total of 250 disc levels were evaluated. Disc herniation was found in 165 disc space levels on conventional MR imaging and in 152 disc space levels on 3D-MRM imaging. Regarding disc herniation, the sensitivity, specificity, accuracy, negative and positive predictive value of 3D-MRM was 92\%, 100\%, 94\%, $84 \%$, and $100 \%$, respectively. Nerve root compression was seen in 120 levels on conventional MR images, as opposed to 132 on 3D-MRM. Regarding nerve root compression, the sensitivity, specificity, accuracy, negative and positive predictive value of 3DMRM was $100 \%, 96 \%, 97 \%, 100 \%$, and $90 \%$, respectively. Lumbar spinal stenosis was found in 21 patients. In all patients with multi-level disc disease and lumbar spinal stenosis, 3D-MRM had additional contribution.

CONCLUSION

Three dimensional MRM can be easily added to routine lumbar MR imaging. It provides additional information in patients with multi-level disc disease of the lumbar spine and lumbar spinal stenosis by allowing a rapid and easy appreciation of the level most likely to account for the pathology. The presence of falsenegative and false-positive examinations necessitates caution in interpreting 3D-MRM images.
P107

PERI-MEDULLARY AVM AND DURAL AVF OF THE SPINAL CORD MIMICKING INTRAMEDULLARY SPINAL CORD TUMOR

ESNR

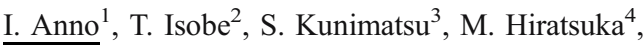

A. Matsumura ${ }^{4}$, M. Minami ${ }^{1}$;

${ }^{1}$ Graduate School of Comprehensive Human Sciences, Tsukuba/ JP, ${ }^{2}$ Kitasato University, Sagamihara/JP, ${ }^{3}$ University of Tsukuba, tsukuba/JP, ${ }^{4}$ University of Tsukuba, Tsukuba/JP

\section{PURPOSE}

Two cases of spinal dural AVF(arteriovenous fistula) and perimedullary AVM(arteriovenous malformation) of the spinal cord will be presented. Venous congestion of the spinal cord causes the spinal cord swelling and enhancement and thus easily misinterpreted as a spinal cord tumor, myelitis or fulminant multiple sclerosis. It is sometimes difficult to make diagnosis, even if DSA was carefully performed. The purpose of this paper will be presented the key point for the correct diagnosis by MRI, CT and DSA

\section{MATERIAL AND METHODS}

Case one is seventithree years old male who presented urinary and rectal incontinence and weakness of bilateral legs for several months. MRI examination revealed the swelling of the lower spinal cord and Gd enhancement of the spinal cord. The lesion was interpreted as a ependymoma at the first MRI examination. However, the axial Gd enhanced T1WI showed the asymmetrical enhancement with somewhat dilatation of the peri-medullary vessels. And there was no evidence of the dilatation of the central canal. The first DSA for all intercostal arteries and lumbar arteries was normal, without evidence of abnormal vascularity. Repeat MRI again revealed the dilated peri-medullary vessels on fat suppressed T1WI and then repeat DSA was performed under general anesthesia. Second DSA showed arteriovenous fistula at the level of cauda equina fed by Adamkiewicz artery originating from Th8 intercostal artery at more than 30 seconds from injection of contrast. Case two showed spinal cord swelling and enhancement. MRI diagnosis was interpreted as glioma. DSA revealed the dural AVF of the marginal sinus.

RESULTS

Two cases of spinal cord lesion due to dural AVF and perimedullary AVM was presented, Spinal cord swelling and enhancement tend to be diagnosed as spinal cord intramedullary tumor. We should be aware of the fact that venous congestion of the spinal cord also reveals spinal cord swelling and enhancement. 
Careful MRI interpretation is needed including fat suppressed Gd enhanced T1WI and Gd-enhanced phase contrast MRI.

\section{CONCLUSION}

Careful MRI interpretation is needed including fat suppressed Gd enhanced T1WI and Gd-enhanced phase contrast MRI. DSA under general anesthesia is also essential for venous congestion, because the visualization of the fistula and draining vein is extremely slow. It is important to chase more than 30 seconds by DSA with respiratory restriction under general anesthesia.

\section{P108}

\section{MR IMAGING OF SPONTANEOUS INTRACRANIAL HYPOTENSION}

\section{ESNR}

L. Incesu, K. Aslan, H.B. Diren, O. Yıldırım, . Yazmuradov, L. Güngör;

Ondokuz Mayis University, Samsun/TR

\section{PURPOSE}

Spontaneous intracranial hypotension $(\mathrm{SIH})$ is a syndrome of low cerebrospinal fluid (CSF) pressure characterized by postural headache occuring in patients without any history of dural puncture, surgery, or penetrating trauma.The correlation of clinical and magnetic resonance (MR) imaging findings of two patients with SIH were evaluated.

\section{MATERIAL AND METHODS}

Contrast-enhanced cranial MR imaging, MR myelography and MR angiography examinations were obtained, and lumbar puncture were performed on two patients who suffered from headache. RESULTS

Two woman presented with severe positional headache, aggravated by sitting or standing, and alleviated by lying down. Neurological examination demonstrated no deficit. Openning CSF pressure was low and extensive studies of the CSF disclosed no other abnormalities. Intracranial MR imaging revealed diffuse dural enhancement, dilatation of cranial sinuses, descent of brain, and spinal epidural fluid collection. On C1-2 level, the probable site of CSF leakage was identified by MR myelography images. $\mathrm{SIH}$ was diagnosed and the patients were treated by conservative therapy and improved with rest. After treatment, MR examinations demonstrated no abnormalities.

\section{CONCLUSION}

Routine cranial contrast-enhanced MR imaging has an important role in the diagnosis of SIH, however, MR myelography should be added to MR examination of patients with postural headache, because the CSF leakage site could be detected.
P109

SIGNIFICANCE OF THE EXTRADURAL INFLAMMATION ASSOCIATED WITH ANNULAR TEARS IN DIAGNOSIS OF THE BACK PAIN AND RADICULOPATHY

ESNR

W.M. Byun $^{1}$, H.W. Jang ${ }^{2}$, S. Lee ${ }^{3}$;

${ }^{1}$ College of Medicine, Yeungnam University Hospital, Daegu/KR,

${ }^{2}$ College of Medicine, Yeungnam University, Daegu/KR, ${ }^{3}$ Soonchunhyang University Hopspital, Gumi/KR

\section{PURPOSE}

Because inflammation associated with annular tears presumably results in irritation of the adjacent nerve root, patients with annular tears without evidence of mechanical nerve root compression at the lumbar spine may experience low back pain with radiculopathy. The aim of this study is to investigate clinical significance of epidural inflammation adjacent to annular tears in diagnosis of the symp-tomatic annular tears of patients with low back pain and radiculopathy.

\section{MATERIAL AND METHODS}

The study population consisted of 12 patients with low back pain and pain referred to leg(s) who underwent lumbar spine MR imaging. In patients with low back pain and radiculopathy, patients with disc herniation on MR imagings or with previous spinal surgery excluded at our study. Contrast enhanced axial T1-weighted images with fat suppression including $\mathrm{T} 1$-and Turbo-T2- weighted images were obtained in all cases. Levels and types of the annular tears were evaluated. MR imaging findings and locations of periannular inflammation adjacent to annular tears were assessed. Imaging findings of the periannular inflammation associated with the annular tears was compared with clinical symptoms for levels and sides.

RESULTS

Periannular inflammation associated with the annular tears revealed as a thick linear enhancement ( 2.5 to $7 \mathrm{~mm}$ thickness) along margins of annular tears on contrast enhanced axial T1weighted images with fat suppression. Types of annular tears included this study were concentric in all cases. All annular tears showed strong enhancement on contrast enhanced T1-weighted images. Locations of periannular inflammation adjacent to annular tears were intervertebral foramen (8/12) between the disc and facet joints and paravertebral space (4/12). There were excellent agreement $(75 \%)$ between locations of the periannular enhancement associated with annular tears and clinical findings for levels and sides.

\section{CONCLUSION}

This study concluded that periannular enhancement associated with annular tears on contrast MR imaging could be considered as a responsible for causing low back pain and radiculopathy secondary to extradural inflammation at the site of annular tears. 
We believe that periannular inflammation adjacent to annular tear may be relevant in the diagnosis of symptomatic annular tear such as discogenic low back pain with radiculopathy.

\section{P110}

SPINAL ARTERIO-VENOUS FISTULA: REGRESSION OF SYMPTOMS AND SIGNS BEFORE THE ENDOVASCULAR INTERVENTION

ESNR

M. El-Koussy $^{1}$, A. Humm ${ }^{2}$, C. Brekenfeld ${ }^{3}$, G. Schroth ${ }^{3}$; ${ }^{1}$ University Hospital Bern (Inselspital), Bern/CH, ${ }^{2}$ Inselspital Bern, Bern/CH, ${ }^{3}$ Inselspital, Bern/CH

\section{PURPOSE}

Spinal dural arterio-venous fistulas (sAVF) are known to cause myelopathy and consequent neurological deficits, including paraparesis and sphincter disturbances. Numerous reports described at least partial reversibility of myelopathy in sAVF cases after operative or endovascular interventions. The authors describe a case with spontaneous recovery of symptoms and signs before performing the endovascular treatment.

\section{MATERIAL AND METHODS}

This report describes a 72-year-old patient with a spinal arteriovenous fistula with progressive, but fluctuating sensory-motor symptomatology, which was followed by acute severe paraparesis and urinary retention.

RESULTS

MRI documented dorsolumbar myelopathy. Twelve hours after admission, there was significant regression of symptoms and signs, although no specific treatment was given. Digital subtraction angiography (DSA) demonstrated that the feeder was the right segmental lumbar L3 artery, which drained into an intradural arterialised vein. The latter did not extend over multiple segments, as it is the case in most sAVFs, but shortly exited the spinal canal to drain into the right radicular L3 vein, which had multiple significant stenoses. It was decided to embolize the sAVF to prevent future insults to the spinal cord. This was achieved effectively with two Fibered-Coils. The post-interventional MRI documented regression of myelopathy. Follow-up DSA and MRI 6 months later revealed regression of the sAVF and normal MRI signal of the dorsolumbar segments of the spinal cord respectively.

\section{CONCLUSION}

Based on the angiographic findings of high-grade stenosis of the ipsilateral draining vein we assume, that the acute aggravation of the symptoms, leading to paraplegia and emergency hospitalisation was due to occlusion of this local venous drainage of the fistula with subsequent increase of pressure in the intradural venous system. Decrease of the subarachnoidal pressure by lumbar puncture and drainage of cerebrospinal fluid may be a possible reason for spontaneous reopening of the local vein, analogous to the mechanism of a pressure sensitive valve. The short intraspinal course of the draining vein might have played a key role in the drainage of the SAVF and facilitated reversal of its occlusion and regression of symptoms and signs. To our knowledge, this is a unique case with regression of symptoms in SAVF, which occurred before intervention.

P111

CERVICAL SPINAL CORD DIMENSIONS BASED ON POSTMYELOGRAM CT SCAN

ESNR

$\underline{\text { E. KAPSALAKI }}^{1}$, L. NIKOLAKAKOS $^{2}$, K. Fountas ${ }^{3}$, J.S. Robinson ${ }^{3}$;

${ }^{1}$ UNIVERSITY HOSPITAL OF LARISSA, LARISSA/GR, ${ }^{2} \mathrm{MCCG}, \mathrm{MACON} / \mathrm{US},{ }^{3}$ THE MEDICAL CENTER OF CENTRAL GEORGIA, Macon/US

\section{PURPOSE}

Accurate knowledge of the cervical spinal cord dimensions in the determination of cervical stenosis is of paramount importance. The existent data are mainly originated from autopsy studies, which could be confounded by fixation artifact and post-mortem edema. In our current study, we present our systematic attempt to define a normal range of cervical spinal cord dimensions based solely on an imaging modality.

\section{MATERIAL AND METHODS}

In a prospective study, 200 patients (127 males and 90 females, age range 20-74 years, mean age: 48.6) undergoing myelogram and post-myelogram $\mathrm{CT}$ scan of the cervical spine were studied. Mid-sagittal antero-posterior and mid-transverse diameters were measured at each intervertebral disc level and the cross-sectional surface of spinal cord was calculated at each level $($ AP $\times$ TRAX $\left.\prod / 4\right)$.

\section{RESULTS}

The mean AP and TR diameters and CSS for each level were: C23: $7.8 \pm 0.9 \mathrm{~mm} 12.0 \pm 0.7 \mathrm{~mm} 74.0 \pm 10 \mathrm{~mm} 2 \mathrm{C} 3-4: 7.4 \pm 0.8 \mathrm{~mm}$ $12.7 \pm 0.7 \mathrm{~mm} 73.8 \pm 9 \mathrm{~mm} 2 \mathrm{C} 4-5: 7.2 \pm 0.8 \mathrm{~mm} 13.7 \pm 0.8 \mathrm{~mm}$ $78.1 \pm 9 \mathrm{~mm} 2$ C5-6: $7.0 \pm 0.8 \mathrm{~mm} \quad 13.5 \pm 0.8 \mathrm{~mm} 74.8 \pm 9 \mathrm{~mm} 2$

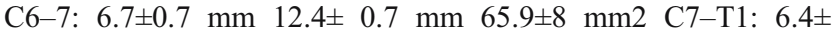
$0.6 \mathrm{~mm} 11.2 \pm 0.7 \mathrm{~mm} 56.6 \pm 7 \mathrm{~mm} 2$ The differences in cervical spinal cord dimensions between male and female patients did not reach level of statistical significance $(\mathrm{p}=0.343$, repeated measurement analysis of the covariance). Similarly, no correlation was found between spinal cord dimensions and patient's age. However, our findings shared statistically significant difference $(p=0.001)$ between our dimensions and autopsy based available dimensions. CONCLUSION

Cervical spinal cord dimensions measured by post-myelogram CT scan demonstrated that spinal cord is significantly smaller than 
previously considered. Patient's gender or age was not correlated to the size of the cervical spinal cord in our study.

\section{Tissue characterization}

\section{P113}

\section{EVALUATION OF MULTIPLE SCLEROSIS LESIONS WITH DIFFUSION-WEIGHTED IMAGING}

ESNR

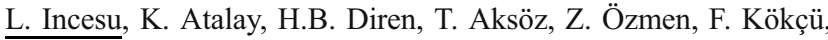
M. Terzi;

Ondokuz Mayis University, Samsun/TR

\section{PURPOSE}

The aim of this study is to investigate the role of diffusionweighted imaging (DWI) in the evaluation of histopathologic changes and early detection of tissue damage of the multiple sclerosis(MS).

\section{MATERIAL AND METHODS}

Sixty patients diagnosed with MS were performed routine contrast-enhanced brain magnetic resonance imaging (MRI), and $b=0, b=500, b=1000$ DWI and apparent diffusion coefficient (ADC) maps were obtained. MRI signal characteristics, contrastenhancement, and diffusion changes of lesions were evaluated. RESULTS

Six hundred and fifty six demyelinated MS lesions were detected with MRI examination. In contrast-enhanced T1-weighted magnetization transfer spin-echo images, enhancement were seen in 60 of all lesions which were suggested acute MS lesions. The remaining unenhanced 596 lesions were evaluated with inactive and chronic MS plaques. The sensitivity rates in detection of diffusion changes in MS plaques were $98 \%$ for $b=500$ and $40 \%$ for $b=1000$ DWI. DWI $(b=500)$ hyperintense, ADC maps hypointense diffusion restriction were observed only in homogenously contrast-enhanced 10 MS plaques $(1.5 \%)$ which were represented with hyperacute inflammation. Almost of all neurological symptoms of these patients were relieved with a high dose of metylprednisolone treatment. There was no significant difference between acute and chronic MS plaques in the sense of $\mathrm{ADC}$ values $((\mathrm{p}>0.05)$, whereas a significant statistical difference was detected between T1-hypointense and T1-isointense MS plaques $(\mathrm{p}<0.05)$. CONCLUSION

Patient's neurological disorders will improve and they should continue to live normally without sequela, if the MS plaques are detected at the period of hyperacute inflammation, inflammatory changes has just occurred without loss of myelinated axonal fibre. DWI is a method which can detect MS plaques at this period and it should be added to the MR imaging protocol.

\section{P114}

RELATIVE CEREBRAL BLOOD VOLUME AND APPARENT DIFFUSION COEFFICIENT OF INTRACRANIAL TUMORS AND PERITUMORAL EDEMA

ESNR

P. Palladas ${ }^{1}$, T. Gerukis ${ }^{2}$, K. Koutroumanidis ${ }^{1}$, S. Koptopoulos ${ }^{1}$, A. Petridis ${ }^{3}$, V. Kalpakidis ${ }^{1}$;

${ }^{1}$ G. Papanikolaou Hospital, Thessaloniki/GR, ${ }^{2}$ G.R.H.G.Papanikolaou, Thessaloniki/GR, ${ }^{3}$ General Hospital, Thessaloniki/GR

\section{PURPOSE}

To determine whether perfusion-weighted and diffusion-weighted MR imaging can be used to differentiate intracranial tumors based on the differences in vascularity and water molecular mobility.

MATERIAL AND METHODS

Twenty-one patients with a solitary brain tumor underwent conventional, diffusion-weighted and contrast-enhanced perfusion-weighted MR imaging before surgical resection or stereotactic biopsy. 11 patients presented with gliomas, 7 with metastases and 3 with intracerebral localization of haematological malignancies (2 non-Hodgkin lymphomas and 1 Acute Lymphogenic Leukaemia). All of them underwent both perfusion-weighted and diffusion-weighted MR imaging. The conventional MR imaging protocol included non-enhanced transverse T2-weighted and fluid attenuated inversion recovery (FLAIR) and contrast-enhanced T1weighted sequences. The relative Cerebral Blood Volume (rCBV) and Apparent Diffusion Coefficient (ADC) maps of the lesions were compared with the FLAIR and CE-T1W images at the same level, to determine the boundaries of the lesions (enhancing portion of the tumor) and the extend of the peritumoral edema (hyperintense on T2-weighted images, but not enhancing on postcontrast T1-weighted images). Calculations were made of the same areas in the rCBV maps and ADC maps of the following: a) normal white matter of the contralateral hemisphere, b) enhancing tumor area with the maximal perfusion (determined from the color maps), c) immediate peritumoral area (within $1 \mathrm{~cm}$ from the outer enhancing tumor margin) and d) distal peritumoral area. The paired Student $\mathrm{t}$ test was used to determine if there was a statistically significant difference in $\mathrm{rCBV}$ and $\mathrm{ADC}$ between lymphoma, gliomas and metastases.

RESULTS

The measured rCBVs in the peritumoral region of gliomas and metastases were 8.97_4.18 (mean _ SD) and 1.93_1.15, respectively - difference which is attributed to the presence of peritumoral neoplastic cell infiltration. This difference was statistically significant. There was no statistically significant difference between ADCs (of tumor or peritumoral edema) to distinguish metastases (1.14_0.12 and 1.42_0.22 respectively) from gliomas (1.13_0.29 and $1.50 \_028$ respectively). Intracranial 
lymphomas showed a significant low rCBV (0.94_0.41) compared to other brain tumors.

\section{CONCLUSION}

Perfusion Weighted MR Imaging allows distinction between primary and secondary intracranial tumors as well as differentiation from intracranial lymphomas. Diffusion Weighted MR Imaging was not proved useful in determining the presence of peritumoral neoplastic cell infiltration.

\section{P115}

CLINICAL APPLICATIONS OF SUSCEPTIBILITY WEIGHTED IMAGING (SWI) OF THE BRAIN- A PICTORIAL ESSAY

\section{ESNR}

$\underline{\text { B. Thomas }}^{1}$, C. Kesavadas ${ }^{2}$, A.K.K. Gupta ${ }^{1}$, T.R. Kapilamoorthy ${ }^{1}$, T. Krishnamoorthy ${ }^{1}$;

${ }^{1}$ SCTIMST, Trivandrum/IN, ${ }^{2}$ Sree Chitra Tirunal Institute for Medical Sciences \& Technology, Trivandrum/IN

\section{PURPOSE}

Susceptibility-weighted imaging (SWI) is a new MR imaging technique of the brain used to increase the conspicuity of the veins and other sources of susceptibility effects. The aim of this study was to demonstrate the utility of SWI in diverse clinical situations, including the demonstration of normal and abnormal venous anatomy of the brain, intracranial hemorrhage, calcifications, architecture of vascular malformations, brain tumors, neurodegenerative diseases and sequele of infarcts and post-traumatic brain damage.

\section{MATERIAL AND METHODS}

Sixteen patients were studied using Spin Echo (SE) T1, Turbo Spin Echo (TSE) T2, routine 2D Gradient Echo (GRE) and SWI sequences [using magnitude and phase images of a highresolution, fully velocity compensated (with gradient moment nulling in all three orthogonal directions), three-dimensional gradient echo sequence]. The examination performed at $1.5 \mathrm{~T}$ and the images are acquired with a phased array head coil. Post processing is applied to increase the conspicuity of the veins and other sources of susceptibility effects and projected using a minimal intensity projection (minIP). In addition phase images were also used to demonstrate susceptibility due to calcium and iron in the brain regions under evaluation.

RESULTS

The pathologies demonstrated include developmental venous anomalies, cavernous angiomas, hemorrhage and calcification in tumors (both intra and extra axial), normal venous displacements in mass lesions, and hemorrhage in arterial and venous infarcts. The susceptibility effects and hence the conspicuity of the lesions were best demonstrated by SWI compared to conventional sequences including GRE. In addition the minIP and phase images could demonstrate intracranial iron deposition and calcification in degenerative disorders of the brain. In brain trauma, particularly diffuse axonal injury, the use of SWI dramatically changed the diagnostic confidence level. Contrast enhanced SWI can differentiate between susceptibility due to flowing blood and mineral deposition or hemorrhage.

\section{CONCLUSION}

SWI seems to be a useful adjunct to routine MR sequences in demonstrating susceptibility effects due to various causes. However further evaluation is required to prove its diagnostic utility and possible therapeutic implications. Acknowledgement: Authors wish to thank Siemens Medical Systems for providing with the SWI sequence and the post processing tools.

\section{P116}

\section{HISTOPATHOLOGICAL ANALYSIS OF CAROTID ARTERY AFTER CAROTID BALLOON DILATION IN WATANABE HERITABLE HYPERLIPIDEMIC RABBIT}

ESNR

T. Yokouchi ${ }^{1}$, S. Iwabuchi ${ }^{2}$, M. Ueda ${ }^{2}$, H. Samejima ${ }^{2}$;

${ }^{1}$ Yokohama general Hospital, Yokohama/JP, ${ }^{2}$ Toho University, Ohashi Hospital, Tokyo/JP

\section{PURPOSE}

Background: PTA (percutaneous transluminal angioplasty) utilizing stents or balloons for luminal dilatation of arteriosclerotic cerebral arteries or carotid arteries has recently been used in Neuroradiology. However, intimal restenosis after successful PTA is not uncommon, for reasons that are not clearly understood. In the present study, we conducted a histopathological analysis of sections of common carotid arteries to determine the mechanism responsible for intimal restenosis after PTA.

\section{MATERIAL AND METHODS}

The common carotid arteries of WHHL (Watanabe heritable hyperlipidemic) rabbits $(\mathrm{n}=26)$, which had arterioscleroses naturally, were sectioned after balloon dilation and examined by using histopathological analysis. The common carotid arteries were sectioned either 3 hours, 3 days, 3 weeks, 3 months, 4 months, 6 months, or 10 months after angioplasty by carotid ballooning. The area of intimal thickening, the luminal area, and the stenosis rate were measured. Each section of common carotid artery was examined microscopically. RESULTS

At 3 hours and 3 days after ballooning, the luminal area was enlarged because of a reduction in intimal thickening and stretching of the arteriosclerotic plaque-free wall segment. In addition, intimal-medial disruption and medial dissection were noted. At 3 weeks, we noted neointimal thickening composed of a proliferation of smooth muscle cells that were migrating from the media through the splitting of the internal elastic lamina. These cells were positive on PCNA staining. The process of luminal 
enlargement had stopped at 4 months; the reduction in arteriosclerotic intimal thickness had also stopped and neointimal thickening was apparent. At 6 months and 10 months after ballooning, fibrocellular hypertrophy was observed in the intima, however, stenosis rate did not increase compared to control.

CONCLUSION

Our findings showed that balloon dilation did not permanently reduce arteriosclerotic intimal thickening, and then induced neointimal thickening. However progressive restenosis appeared only between 3 weeks and 4 months after carotid balloon dilation. It suggested that developing proliferative cells in neointima were self-limited and led to keep stopping of the enlargement of stenosis rate.

\section{P117}

\section{MRI AND CT PERFUSION IN THE DIFFERENTIATION BETWEEN LOW AND HIGH GRADE GLIOMA}

ESNR

C. Ozdoba ${ }^{1}$, J. Slotboom ${ }^{1}$, R. Schär ${ }^{2}$, M. Reinert ${ }^{2}$, F. von Bredow ${ }^{2}$, L. Remonda ${ }^{1}$, G. Schroth ${ }^{3}$, R. Wiest ${ }^{1}$;

${ }^{1}$ Institute for Diagnostic and Interventional Neuroradiology, Bern/CH, ${ }^{2}$ Inselspital / Universität Bern, Bern/CH, ${ }^{3}$ Inselspital, $\mathrm{Bern} / \mathrm{CH}$

\section{PURPOSE}

To compare CT and MRI brain perfusion imaging for evaluating the microcirculation related to tumor grade in patients with glioma. MATERIAL AND METHODS

Seventeen patients (10 women, 7 men, mean age $55.2 \mathrm{yrs}$ ) with histologically proven glioma ( 8 grade IV, 4 grade III, 6 grade II) were evaluated with dynamic susceptibility MRI (DSC-MRI). 9 pts. had additional dynamic perfusion CT (DP-CT). Tumor regions were segmented and $\mathrm{rCBF}, \mathrm{rCBV}$ and MTT maps were computed for $\mathrm{CT}$ and MR with an in-house developed application using a single-voxel-deconvolution based algorithm. ROI-based analysis of the tumor regions and histogram analysis of the pixel intensity distribution of the segmented images at different time points were performed. Asymmetry indices (path. vs. normal) were calculated for MRI and CT perfusion values. A new algorithm, dynamic perfusion histogram analysis (DHA), which includes perfusion histogram parameters like peak position, width and shape of distribution and asymmetry, was used to distinguish perfusion patterns of low and high grade glioma.

\section{RESULTS}

There were no statistical differences of the AI in the MRI and CT group. AI for rCBV and $\mathrm{rCBF}$, peak intensity of DSC-MRI and the intensity shift from baseline to maximum contrast gave significant differences beween high grade and low grade gliomas $(\mathrm{p}<0.01$ and $p<0.04)$. The pixel intensity shift of the maximum contrast images was increased in high grade gliomas using DHA due to the more aggressive tumor vasculature. Pixel intensity distributions in DP-CT and the AI of the MTT values provided no additional information.

\section{CONCLUSION}

Calculation of semi-automatic ROI-based $\mathrm{AI}$ for $\mathrm{rCBV}$ and $\mathrm{rCBF}$ from DSC-MRI and DP-CT provide similar results in discriminating tumor vasculature of high grade and low grade glioma.

\section{P118}

DEEP GREY MATTER LESIONS ON MRI: CLINICAL AND IMAGING CORRELATES - NARROWING THE DIFFERENTIAL DIAGNOSIS

ESNR

P.O. Cowley ${ }^{1}$, A. Siddique ${ }^{2}$, N. Sibtain ${ }^{2}$;

${ }^{1}$ Royal Free Hospital, London/GB, ${ }^{2}$ King's College Hospital, London/GB

\section{PURPOSE}

To review and pictorially illustrate the wide variety of conditions that are associated with symmetric abnormalities of the deep grey matter nuclei on magnetic resonance imaging (MRI). To provide a diagnostic approach to interpretation based on a classification of both the clinical presentation and pattern of abnormality on MRI. MATERIAL AND METHODS

The deep grey matter nuclei are unique in the brain with respect to their vascular supply, neurotransmitter content, oxygen and metabolic requirements. These features make them selectively vulnerable to certain insults.

RESULTS

The clinical presentation of conditions affecting the deep grey matter nuclei can be broadly categorised into acute and chronic. The main causative disease processes include toxic, metabolic, hypoxic- ischaemic, vascular, infectious/inflammatory and neurodegenerative conditions. The MRI appearances vary according to the disease process, in terms of anatomical location of lesions, T1, T2 and diffusion characteristics, the timing of the imaging and ancillary findings in the remainder of the brain. There is considerable overlap of MRI findings between the various pathologies and in isolation MRI remains non-specific.

CONCLUSION

A systematic approach to the interpretation of symmetrical deep grey matter abnormalities based on clinical presentation as well as the pattern of image findings increases diagnostic confidence and specificity. 


\section{P119}

PERFUSION COMPUTED TOMOGRAPHY IN DIFFERENT DIAGNOSTICS OF BRAIN METASTASES AND HIGH GRADE GLIOMAS.

ESNR

M.B. Dolgushin ${ }^{1}$, I.N. Pronin ${ }^{2}$, L.M. Fadeeva ${ }^{3}$, V.N. Kornienko ${ }^{3}$; ${ }^{1}$ Burdenko Neurosurgery Institute, RAMS, Moscow/RU, ${ }^{2}$ N.N. Burdenko Neurosurgery Institute, Moscow/RU, ${ }^{3}$ Burdenko Neurosurgery Institute, Moscow/RU

\section{PURPOSE}

The purpose of this study was to investigate the potential role of Cerebral Blood Volume (CBV), Cerebral Blood Flow (CBF) and Mean Transit Time (MTT) maps in evaluation of the neuovascularity of brain Mts in solid part of tumor and in peritumoral regions. MATERIAL AND METHODS

Twenty five patients (13-man, 12- woman, aged 34-69 years, mean age $-51 \mathrm{yrs}$ ) with solitary and multifocal brain Mts from known primary site (3- Mts of melanoma, 6-lungs, 5-intestines, 3breast, 2- ovary, 4- kidney, 2- uterus) and a control group of 11 pts with high grade gliomas (glioblastoma multiforme, Gbm), underwent MRI (T1, Flair, DWI, T1+Gd), CT and perfusion CT(timeseries of 40-50 images for 4 slices, thickness $6 \mathrm{~mm}$, time resolution-1 s, during the first pass of a iodine contrast media bolus: Omnipaque 370, $40 \mathrm{ml}$ intravenously, rate- $4 \mathrm{ml} / \mathrm{s}$. In all cases the diagnosis was verified histologically. Dynamic CT data were processed off line (Advantage Windows 4.2, deconvolution algorithm-Perfusion I, GE). The CVB,CBF,MTT were calculated in region's of interest (ROI) areas, chosen within the enhancing tumor, in peritumoral and edema zones and in contra lateral white matter. The peritumoral region was defined to be within approximately $1 \mathrm{~cm}$ outside the outer enhancing tumor margin (ROI, 2-5 $\mathrm{mm}$ in diameter) were placed on the color maps. Kruskal-Wallis test was used to determine the statistical significance of measurements. $\mathrm{P}>0.05$ was considered to be statistically significant difference.

\section{RESULTS}

Our main findings reveal statistically significant differences in neovascularisation of solid parts of Mts: $\mathrm{CBV}(\operatorname{mean}+/-\mathrm{sd})$ : $\max$ and min values show mts of kidney and ovary $(21.01+/-6.21)$ and $(5.46+/-1.71) \mathrm{ml} / 100 \mathrm{~g}$, respectively, Mts of melanoma show a high devations of CBV (15.03+/-11.40). CBF: $\max$ and min values show Mts of melanoma and ovary $(113.90+/-24.25)$ and $(58.32+/-19.61) \mathrm{ml} / 100 \mathrm{~g} / \mathrm{min}$, respectively. MTT values were max in kidney's Mts (17.5+/-3.0) and min-in melanoma's (5.1+/2.1) sec. $\mathrm{CBV}, \mathrm{CBF}$, MTT values of Gbm were: $(5.83+/-1.41) \mathrm{ml} /$ $100 \mathrm{~g},(65.93+/-22.33) \mathrm{ml} / 100 \mathrm{~g} / \mathrm{min},(6.9+/-2.6) \mathrm{s}$, respectively. Mean CBV,CBF, MTT in peritumoral regions of Gbm were higher then in Mts, but only MTT values differ significantly; it didn't differ from CBV,CBF in edema ROI's both for Gbm, and Mts, but in Gbm mean MTT were found to be longer then in solid part of tumor's one (8.2 vs $6.9 \mathrm{~s}, \mathrm{p}<0.07)$.

CONCLUSION

CT perfusion is able to add an important physiological information and to demonstrate differences in the neovascularisation of brain tumors.

P120

THREE DIMENSIONAL ISOTROPIC FLAIR AT 3 : CLINICAL APPLICATION IN AN EMERGENCY SETTING AND COMPARISON WITH STANDARD MR SEQUENCES

ESNR

S. Sarria Estrada ${ }^{1}$, V. Rentsch Granges ${ }^{1}$, M. $\operatorname{Vargas}^{1}$, H. Yilmaz ${ }^{2}$, A. Alimenti ${ }^{1}$, J. Delavelle ${ }^{2}$, F. Lazeyras ${ }^{3}$, F. Assal ${ }^{1}$, D. Rüfenacht ${ }^{1}$, K. Lovblad;

${ }^{1} \mathrm{HUG}$, Geneva/CH, ${ }^{2}$ Hopital Universitaire de Gen, Gen/CH,

${ }^{3}$ University Hospitals of Geneva, Geneva, Switzerland/CH, ${ }^{4} \mathrm{Neu}-$ roradiology, Genève/CH

\section{PURPOSE}

In the acute phase of any neurological disease it is necessary to investigate and image the whole brain. FLAIR has been used extensively for detection of tissular pathology. A new isotropic 3 D FLAIR sequence provides whole-brain coverage in less than ten minuets. Our aim was to investigate its use in the setting of acute neurological symptoms.

\section{MATERIAL AND METHODS}

Twenty patients were referred for the onset of acute neurological symptoms after having been neurologically examined. Imaging was performed on a $3 \mathrm{~T}$ clinical magnet (Siemens Treo). In addition to conventional MR imaging coimprising axial wohole brain diffusion-weighted imaging as well as $\mathrm{T} 1$ and T2-weighted imaging, FLAIR imaging was performed. An isotropc 3-D FLAIR sequence was acquired in the sagittal projection with the following parameters: TR: $600 \mathrm{~ms}$;TE:353 ms,NEX:1.0; Flip: 180,TI: $2200 \mathrm{~ms}$; FoV: $223 \times 260 \mathrm{~mm}$ with a hickness of $1 \mathrm{~mm}$. The 3-D flair images were reconstructed in 2 additional planes (axial and coronal). Imaging time was 9 minutes. Coronal FLAIR iomages were also acquired (TR: $9500 \mathrm{~ms}$;TE: $110 \mathrm{~ms}$; NEX: 2; Flip: 150; TI: $2500 \mathrm{~ms}$; FoV: $176 \times 220 \mathrm{~mm}$; Thickness $4 \mathrm{~mm}$ ). The images were viewed on external workstations by blinded radiologists.

RESULTS

Overall there was an agreement of slighter less spatial resolution and more fuzziness of the 3-D FLAIR datasets by both neuroradiologists. Cerebral lesions were encountered in 16 of the 20 patients. 4 patients had examinations that were judged normal on both FLAIR sequences. The conventional MR sequences did not bring additional information. The diagnoses provided by both types of FLAIR sequences was the same, however the isotropic 
sequence provided a better definition of lesion location by providing isotropic multiplanar reconstructions.

\section{CONCLUSION}

Isotrope 3-D FLAIR imaging provides a relatively fast way of dispaying brain lesions that may occur acutely in a multi-planarway. It has the same diagnostic accuracy as conventional FLAIR and other MR sequencs and has the advantage of allowing better lesion localization for clinical purposes.

\section{P121}

MULTI-MODALITY MR IMAGING FOR IMPROVED PREOPERATIVE DIAGNOSTIC AND SELECTION OF BIOPSY SITES IN BRAIN TUMORS (WORK IN PROGRESS)

\section{ESNR}

C. Ozdoba $^{1}$, L. Mariani ${ }^{2}$, M. El-Koussy ${ }^{3}$, A.R. Fathi ${ }^{2}$, J. Slotboom ${ }^{1}$; ${ }^{1}$ Institute for Diagnostic and Interventional Neuroradiology, Bern/ $\mathrm{CH},{ }^{2}$ Inselspital / Universität Bern, Bern/CH, ${ }^{3}$ University Hospital Bern (Inselspital), Bern/CH

\section{PURPOSE}

To improve diagnostic accuracy and to select significant biopsy sites in brain tumors by simultaneous MR imaging, perfusion, diffusion and spectroscopy studies.

\section{MATERIAL AND METHODS}

In an ongoing study that began in early 2006, we perform conventional brain imaging including three-plane contrast-enhanced studies in combination with diffusion-weighted imaging, perfusion studies and both single-voxel and chemical shift spectroscopy. All patients undergo brain biopsy which is, for the moment, based on conventional imaging.From the perfusion data, $\mathrm{rCBF}, \mathrm{rCBV}$ and MTT maps are computed. ROI analysis of the biopsy regions and histogram analysis of the pixel intensity distribution of the segmented images at different time points are performed. Likewise, diffusion and ADC (apparent diffusion coefficient) maps and spectroscopy data are evaluated retrospectively for the exact locations where biopsy was performed. It is intended to correlate these data with histo-pathological data from the biopsy specimens.

RESULTS

At the time of writing (May 2006), only preliminary data from a limited number of patients are available; to date, 25 biopsies were taken in eight patients. Preliminary evaluation indicates that detailed perfusion analysis is a reliable indicator of vessel density and the degree of neo-vascularization and correlates well with previously published studies. (Additional data will be available for the presentation.)

\section{CONCLUSION}

The accuracy of MR imaging studies in brain tumors with regard to tumor type and grading can be improved by additional functional studies (perfusion and diffusion-weighted imaging) and spectroscopy. In future, it seems feasible to select biopsy sites based on these data rather than on imaging alone to achieve the best possible degree of significance for the biopsy specimens.

\section{Other}

\section{P122}

ANGIOGRAPHIC COMPUTED TOMOGRAPHY (ACT) AND DUAL VOLUME TECHNIQUE (DV-TECHNIQUE): FINDINGS AFTER INTRACRANIAL STENTING OF A ATHEROSCLEROTIC STENOSES

ESNR

B. Claus, G. Benndorf, C.M. Strother, C.Y. Lee R.P. Klucznik; The Methodist Hospital, Houston/US

\section{PURPOSE}

3D-DSA and digital radiography (DR) are currently insufficient in visualizing intracranial stents. we evaluated the role of angiographic computed tomography (ACT), combined with DualVolume (DV) Technique for imaging of stented atherosclerotic lessions.

\section{MATERIAL AND METHODS}

Four patients with previously placed intracranial drug eluted stents (Cypher, Corids) in the basilar artery (BA: 1) and the middle cerebral artery (M1 segment: 2) and one patient undergoing initial stent placement (Cyper, Cordis) for treatment of a right M1 stenosis, underwnet angiographic studies using conventional DSA and $3 \mathrm{D}$ DSA. In additonal, ACT's were performed using a flat detector system (Axiom Artis dBA, Siemens medical Solution, Erlange Germany) and the following parameters: $20 \mathrm{sec}$ rotation, $0.4^{\circ}$ increment, 538 projections, total angle $220^{\circ}$. For DV technique, a $10 \mathrm{sec}$ 3D-DSA was performed using the following protocol: separate reconstruction of subtracted filling run and nonsubtracted mask run. Image analysis was performed using a commercially available workstation (Leonardo, Siemens). RESULTS

Following ACT findings were found: change in caliber, asymmetric deployment and inward crimping of stent ends. DV-technique showed the location of the restenosis with regard to the stent itself: in two cases at the proximal end of the stents, in one case inside the stents lumen (true in-stent restenosis), not easily identifiable on DSA. In case 4, DV imaging allowed to precisely visualize branches, adjacent to the stents that were difficult to identify on DSA or DR images. Axial views revealed the cross sectional area of the stenosed vessel segment in relation to the stent lumen and its increase after balloon angioplasty (1 case).

CONCLUSION

ACT provides significantly more detail information on placed stents in patients undergoing treatment of atherosclerotic lesions than does DSA or DR. Our preliminary experience suggests that 
the additional use of the DV-technique may contribute valuable information to DSA and DR in the acute setting of stents placement as well as during follow-up studies. Both ACT and DV technique could gain significant importance for assessment of stents restenoses and their underlying causes. Improved software is expected and ongoing studies will further prove the value of either techique for clinical technique for clinical practice in intracrabnial stenting. 